\title{
DER STOFF DES SPIELMANNSGEDICHTES
}

\section{ORENDEL.}

Das (in dem zwōlften jahrhundert verfasste) spielmannsgedicht Orendel ist die (legendarische) verarbeitung eines ălteren stoffes (nach E. H. Meyer, Zs. fda. XIl, 387 ff. unter einflechtung historischer tatsachen des zwölften jahrhumderts 1)). Das ergibt sich aus folgenden erwägungen: 1. der name des helden ist in urkunden zu verfolgen: zeitlich bis in das achte jahrbundert zurluck, ethnisch bei Franken; Baiern und auf italischem boden. ${ }^{2}$ ) 2. Die persönlichkeit des Orendel erscheint als held $\mathrm{zweier}$ weiterer, im norden im 12/13. jahrhundert aufgezeichneter sagen, welche, bei verhaltnissmăssig ursprunglichem charakter, unter einander wie gegen das erwăhnte spielmannsgedicht hinsichtlich des inhaltes auffallend abweichen, in einem masse, das bis zur annahme ihrer unvereinbarkeit gefuhrt hat. 3. Der name des helden erscheint angelsachsisch bereits als appellativ, und 2war als ein appellativ von bedeutsamer fărbung.

Mit diesen verhaltnissen der uberlieferung ist der forschung dio aufgabo gestellt, zu untersuchen: 1. besteht zwischen den drei sagen, die sich des gleichen belden berthmen, ein innerer zusammenhang: so nămlich, dass sie verschiedene abarten des gleichen grundstoffes, oder aber verschiedene entwickelungsstufen desselben, oder endlich verselbständigte einzelne seiten der altesten sagenform darstellen? 2. Wenn ein grundstoff der drei bezeichneten sagen anzunehmen ist: ist derselbe ein alter mythus? 3. Wenn die zweite frage zu bejahen: welche

1) Eine andere ansicht begrtindet Berger in seiner nenen Orendelausgabe.

2) Müllenhoff, Deutsche altertumsk. I, 33.

Beitrige sux geschiohte der doutechen mpreche. XWI. 
stellung nimmt derselbe ein in der yesamtheit der germanischen mythenmasse? 4. Beztuglich: welche stellung innerbalb der indogermanischen mythik ${ }^{1}$ )?

Keine der vier fragen lässt sich unabbängig von der anderen lösen. Denn gesetzt, den drei sagenformen liege ein gemeinsamer mythus zu grunde, so ist das verbältnis jeder einzelnen zu der urgestalt erst nach der feststellung und erörterung dieser urgestalt zu ermöglichen. Die erkenntnis eines mythus als solchen und die deutung seines anschauungsgehaltes ist widerum bedingt von der untersuchung seines verhăltnisses zu der gesamten einschlägigen deutschen, und, uuter unständen, ausserdeutschen mythenmasse. Denn mehr und mehr bricht sich seit den epochemachenden arbeiten von Kuhn, Schwartz und Mannhardt die therzeugung bahn, dass die deutung eines mythus nicht dem nachempfindenden genie einzelneer dichternaturen oder dem spursinn ibrer nachtreter aufbehalten ist sondern sich als das werk sorgfăltig kritischer analogiensammlungen und vergleichungen darstellt, welche schliesslich

1) Unter dem namen mythik begreife ich den gesamten mythenbestand eines volkes (beztigl. einer volkergemeinschaft): im gegensatz zu dem begriff mythologie, das ist der wissenschaftlichen systematik dieses mythenbestandes. Diese scheidung erscheint heute um so angebrachter, als die wissenschaft nach missverstandenen klassischen mustern zu der voreiligen annahme (bezuglich construction) eines germanischen gotterhimmels geschritten ist, der sich nur nordisch (und auch da erweislicher massen als das letzte erzeugnis einer ganz andersartigen entwickelung), westgermanisch uberhaupt nicht feststellen lässt. Der von anderer seite vorgeschlagene name sagenkunde erscheint nicht anwendbar: 1. weil es sich beispielsweise in der indogermanischen mythik, wie andrenorts ausfuhrlicher dargetan werden soll, wahrscheinlich uberhaupt nicht um gebilde handelt, auf die der name sage in irgend einer der bisher üblichen bedeutungen angewendet werden kønnte, sondern um die primitiven ansätze der sage, die naiv personificierten naţuranschaungen; 2. weil unter dem, in einer zeit unklarster wissenschaftlicher anschanung eingefuhrten ausdruck sage beinah jeder mythologe etwas anderes versteht. Mancher wird sich noch entsinnen, mit welcher entrüstung Müllenhoff einen anfänger abkanzelte, der das wort sage in einer anderen als der von ihm geprägten, keineswegs unanfechtbaren bedeutung anwenden wollte. Bei jeder, besonders aber einer jungen wissenschaft handelt es sich vornemlich um eine feste, allen gemeinsame terminologie, und es ist zu empfehlen unabgentitzte ausdriicke strittigen benennungen vorzuziehn. 
za einem erleuchtenden punkte fuhren, der die gesamte, um ihn geschaarte therlieferungsmasse erhellt.

Die beantwortung der angefuhrten vier fragen bietet somit nicht sowol die disposition, vielmehr den endzweck der folgenden erörterungen.

\section{Die drei sagen.}

\section{Die dånische sage.}

Unter den nordischen tuberlieferungen der Orendelsage ist die, hinsichtlich der bandschriftlichen fixierung, altere die aufzeichnung in des Saxo Grammaticus Gesta Danorum III.) Horvendillus, der sohn des Gervendillus, war ein grosser seekönig, das ist ein Viking, ein pirata Damit orregte or den eiferstlchtigen hàss eines anderen Viking, des kōnigs Collerus. Als ihre heere za beiden seiten einer insel lagern, trefien sich die beiden fuhrer durch zufall, offenbar auf einer recognosciorung. ${ }^{2}$ ) Unter ritterlichen bedingungen wird ein zweikampf beredet und inmitten einer lieblichen frthlingslandschaft in dramatisch dargestellter weise zu onde'gefuhrt. Koller fallt. Darauf verfolgt Horvendillus noch seines feindes schwester Sela und tötet sie. Nachmals vermăhlt er sich mit einer königstochter Gerutha. Nacbmals wird or von seinem neidischen bruder Fengo erschlagen, von seinem sohn Amleth geræ̆cht.

Die Gesta Danorum sind eine reichlich fliessende, aber durch mancherlei uble zutaten getrubte sagenquelle. In dem gedåchtnis des dănischen. mönches mischte sich ein buntes durcheinander von sagen, das er mit möglichster vollotandigkeit und in durchaus willkurlicher, mit eigenen poetischen zutaten verbrămter darstellung und anordnung dem leser unterbreitete. So entstand ein historisierender roman, eine pseudo-

1) Bei Holder B. 85 .

2) Saxo berichtet: der liebliche anblick der nfer hxitto die beiden fuhrer versnlasst die insel $2 u$ betreten, der friblingsherrliche anblick des waldes sie verleitet denseiben zu durchstreifen. Der moderne natursinn des civilisierten geistlichen und der innere drang, selbsttïtig poetheche ausschmtickungen zu den originalen vorlagen zu figen, haben bier deutlich das ursprtingliche tibertilncht. 
chronik, zu einem guten teil auf grund: wahrscheinlich einer umfangreichen traditionellen sagenkenntnis, nachweislich einer ansehnlichen zabl verschiedenzeitiger und verschiedenartiger, vielfach unvereinbarer lieder, die ebenso locker wie willkurlich ineinandergearbeitet, vielfach missverstanden, vielfach rationalistisch ausgedeutet oder mit chronistenhafter phantasie in das historische weiter ausgefuhrt und mit moralisierenden betrachtungen durchsetzt sind. Fur ibre benutzung sind folgende gesichtspunkte massgebend: 1. die lieder, aus welchen Saxo schöpft, sind von sehr verschiedener zuverlässigkeit. Einige von ihnen sind unverkennbare spielmannslieder ${ }^{1}$ ), motivieren auf das nachlăssigste, mischen anderweitig entnommeve motive ein oder tragen vielleicht gar einem verderbten geschmack frivole rechnung; es wird sich noch gelegenheit finden, ein beispiel fur die letztere gattung anzufuhren. ${ }^{2}$ ) Andere erweisen das geprăge eines höheren stils. Einige sind durchaus modern empfunden und tragen ritterliche sitten in ein anders geartetes zeitalter. Mit einem worte: die lieder sind von ihren verschiedenartigen und verschiedenzeitigen verfassern individuell gestaltet und bereits mit accessorischen elementen ausstaffiert worden. 2. Diese modificierten lieder wurden von Saxo des weiteren verunstaltet, indem or sie a) schlechtweg missverstand ${ }^{3}$ ), b) einem inneren dichterischen drange folgend mit ausfuhrlichen dialogen bereicherte 4 ), c) mit den eigenen kindlichen motivierungen versah, d) $\mathrm{zu}$ einem ganzen zusammenarbeitete, wobei or taten und menschen ziemlich willkturlich untereinander gemengt zu haben scheint.

Auf grund dieser beobachtung ist der kampf des Horvendil mit Koller nach rtlckwarts von der historischen ankntupfung, nach vorwărts von der angeschweissten Amlethsage zu losen. und Halfdan.

9) Gelegentlich der besprechnng der Mitothinßage.

3) Vgl. die analyse der Hothersage; ferner die verschiebung des dichterischen kరnigstitels Gram (zu vgl. Uhland schriften VI, 11। a. 112); endlich die widerholte zweimalige erzählung der nämlichen sage, wenn ein pasr namen verändert sind: beispiele weiter unten.

-) Vgl. die langatmige anrede des Othinus an Bous a. \&. 0. 82 and die analyse der Hothersage. 
Seine eigenschaft als seekōnig ist bedeutungslos bei einem berichterstatter, der mit vorliebe seine helden zu Vikingen macht und selbst den Hother uber Balder einen seesieg erfechten lässt. Die zufällige begegnung auf der insel ist ein missverstăndnis das in der nordischen sagenwelt typischen Holmgangmotivs, die begegnung auf der recognoscierung staffage nach beliebten mustern, der ritterliche zweikampf mit.dem, was darum und daran bängt, eigentum des dichters der vorlage. Es bleibt: 1. Horvendillus ist der sohn des Gervendillus. 2. Horvendillus besiegt und tōtet den könig Collerus. 3. Wahrscheinlich: der kampf findet in einem frubling statt (daruber spăter). 4. Vielleicht: der weitere kampf mit Sela. 5. Vielleicht: die vermählung mit Gerutha, sofern diese nicht in die Amlethsage gehört. Von Uhlands versuch, eine beziehung zwischen ihr und der eddischen Groa herzustellen, wird spater die rede sein. Sollte die vermählung als dem originale zugehörig betrachtet werden, so würde die wahrscheinlichkeit dafur sprechen; dass der kampf um den besitz der braut statt gefunden habe: ein hăufiges Holmgangsmotiv in nordischen quellen; um so mehr, da die kriegerische eifersucht als motiv mit dem seekönigtum steht und fallt und leicht einem missverstăndnis Saxos entsprungen sein kann. Das ihm wörtlich oder inhaltlich gegenwärtige lied wüde alsdann nichts enthalten haben als den kampf zwischen Ḧorvendil, dem sohn Gervendils, und Koller auf einer insel im fruhling, mit einer schlussbemerkung, dass nachmals Horvendil und Gerutha sich vermăhlt hătten. Alles dies wird andrenorts weiter erörtert werden.

\section{Die norwegische sage.}

Das siebzehnte capitel der Skalda knupft an die băuerliche erzăhlung von dem kampfe Thors mit Hrungnir ${ }^{1}$ ) die norwegische uberlieferung der Orendelsage. Ein stuck von Hrungnis schleifstein ist in Thors stirne gedrungen und nicht zu entfernen. Thor wendet sich an die zauberkundige Groa, die frau Oervandils des kecken. Als ihre lieder den stein zu lockern beginnen, will Thor ihr den dienst mit froher botschaft danken und verkundet ihr, er habe, von norden her ther die

1) Der später erörtert werden wird. 
Eliwagar watend, auf seinem rlicken im korb ihren gatten Oervandil aus dem riesenheim hertbergetragen. Zum wahrzeichen fuhrt er an, dass ein zeh jenem aus dem korb gestanden und erfroren sei; den habe er an den himmel als einen stern geworfen, welcher Oervandils zeh heisse. Bei dieser nachricht ist Groa so erfreut, dass sie ihre lieder vergisst und der schleifstein stecken bleibt. Daran knüpft der erzăhler die mahnung, solche steine wegzuwerfen: dann ruhre sich der stein in Thors kopf. Diese ermahnung, die etwas dunkel ist, nimmt, wie es scheint, auf einen volksbrauch bezug, der aber jedenfalls nicht aus dem mythus herrthrt sondern nur von dem erzăhler mit ihm in beziehung gesetzt wurde.

Die kritik und charakteristik dieser erzählung und ihrer quelle wird spăter statt haben. Ueber das verhăltnis der namen Oervandil und Orendel hat Mullenhoff ${ }^{1}$ ) erschöpfend gehandelt. Die etymologie wird weiter unten zur sprache kommen.

\section{Das spielmannsgedicht.}

Das spielmannsgedicht Orendel ist eine complicierte erscheinung. Spăt uberliefert, gibt es der philologischen wie der sagengeschichtlichen kritik manches rătsel auf. Steht jene vor einem verderbten, mehrfach interpolierten text, so muss diese mit zahlreichen umbildungen rechnen, die der stoff erfahren, und mit zudichtungen, um die or bereichert wutde. Die zudichtungen sind im wesentlichen: 1 . vervielfaltigende widerholnngen des nåmlichen abenteuers; 2. einfubrung von anderweitig beliebt gewordenen situationen und motiven; 3. vielleicht: episodische einflechtung historischer beziehungen.2) Die zweite klasse von zusatzen ist durch analogiensammlung in vergleichung $\mathrm{zu}$ den anderen erhaltenen spielmannsdichtungen, die dritte durch historische kritik auszumerzen; mit der ersten gruppe muss man sehr vorsichtig umgehen; nicht allein, dass sich sohwer bestimmen lăsst, welche redaction original, und welche vervielfăltigung ist: es kann geschehen sein, dass in dem kopfe des spielmannes zwei verschiedene fassungen der nămlichen episode durcheinander geraten sind und, in ziemlich

1) A. \&. 0. 33; จgl. auch Eschmann, Zs. fda. XI, 169.

2) Vgl. E. H. Mejer a. 8. o. 
paralleler und hinlänglich widersinniger gestalt, neben einander ihre stătte gefunden haben. Die kritik des spielmannsgediohtes, soweit sie in diese sagenuntersuchung einschlägt, wird sich mit der wahrscheinlichkeit zu befassen haben, dass dem verfasser der vorliegenden tuberlieferung verschiedene behandlungen des Orendelstoffes, wenn nicht als lieder, so dem inhalte nach bekannt waren, die er fur die herstellung der letzten ungeheuerlichen gestalt verwante; ein genetisches verhältnis, das auch für die Kudrun sehr lebhaft in erwagung zu ziehen ist.

Die vorliegenden erörterungen werden sich mit der genetischen untersuchung des spielmannsgedichtes nur insoweit beschaftigen, als es für die lösung der anfänglich gestellten aufgaben von nutzen erscheint.

Der Trierer kōnigssohn Orendel ist heiratslustig. Das ist die ausschlag gebende situation, mit welcher der. Oswald, der Salman, der Rother beginnen, die in der Kudrun eine hervorragende stellung einnimmt und auch widerholt in das Nibelungenlied hineinspielt.1) Gewöhnlich tritt der könig unter seine grossen und befragt sie ther die schönen der erde; aber Orendel ist noch knabenhaft jung und hat einen regierenden vater, den könig Oeugel; an ihn wendet er sich mit seinen wtinschen. Die antwort lautet in der regel: ich weiss eine schone jungfrau, aber sie ist nicht zu gewinnen; und als begrundung wird gern angegeben: ihr vater gibt sie nicht her. Hier weicht unser gedicht bedeutsam ab. Der könig weiss eine jungfrau, sie ist königin des heiligen grabes, sie ist auch zu gewinnen: geh hin, wirb um sio und weihe dein leib und seel dem heiligen grab. Also eine brautfahrt nach beliebten mustern, aber individuell eine fahrt in das heilige land. Und so wird sie denn auch eingeleitet: kein ritter soll zur teilnahme gezwungen werden. Wer sich beteiligen will, der nehme - man erwartet, das heilige kreuz? nein, aber einen goldenen sporn. Die fahrt beginnt; es folgen zwei abenteuer. Die seefahrer geraten in das klebermeer und kommen durch ein wunder frei; sie werden von heiden angegriffen und siegen. Auf diese

1) Um die beliebtheit der brautfahrten in der spielmannspoesie zu beurteilen, vergleiche man die hänfigkeit dieses motives in der biðrekssaga. Auch bei Saxo findet sich einschlägiges. 
bedeutungslosen episoden folgt der grosse schritt der handlung: die ganze flotte versinkt im sturm, Orendel allein erreicht auf einer planke treibend das land.

Nackt und bloss findet ihn ein fischer, der ihm misstrauisch die aufnabme verweigert; auch als sich Orendel selbst als einen gescheiterten fischer bezeichnet, schwindet sein argwohn nicht; or will erst die probe auf seine kunst machen: Du willst ein fischer sein? wirf aus! ziehst du nicht gut, bist du verloren. Der himmel legt sich in das mittel: das zweite wunder geschieht: Orendel zieht eine gewaltige ladung.

Fischer Ise ist ein grosser herr; er hat eine burg mit sieben turmen, und achthundert fischer dienen ihm. Auf der burgzinne empfängt ihn sein weib im kreise ihrer jungfrauen: wol eine typisehe situation. Hier widerholt sich die gleiche scene: die frau traut dem ankömmling nicht. Aber Ise ist durch den fischfang gewonnen, und Orendel wird sein knecht.

Man darf die handlung nicht fest anfassen. Das naturliche wäre gewesen, dass Orendel seinen stand und reisezweck angegeben hătte; aber wo wăre dann das wunder geblieben! und zudem wird der wunderbare fischzug folgenreich far die ganze dichtung.

Der empfang durch die fischerkönigin ist nur eine breite epische ausmalung der situation. $\mathrm{Zu}$ dem greisen kőnig gehört die königin. Ihr misstrauen gegen den ankömmling ist begritindet: seit unvordenklicher zeit ist kein fremder in diese abgelegenheit gekommen: ein bemerkenswerter zug.

Diese und eine gleich folgende situation waren trotz ihrer nebensăchlichkeit zu erörtern, weil Mullenhoff auf sie weitgehende schlusse gegrtundet hat.

In dem leibe eines der von Orendel mit göttlicher hulfe gezogenen fische findet sich der graue rock Christi, der dem legendarischen uberarbeiter des alten stoffes (vielleicht nicht dem letzten uberarbeiter, wie sich ergeben wird) das wichtigste ist und nicht wider aus dem auge schwindet. Orendel erbittet ihn von seinem herrn; aber meister Ise tut nichts um gottes willen, und Orendel bat kein geld. So muss er denn nackt weiter arbeiten. Eine interpolation erzählt freilich, das fischerehepaar, in einer plötzlichen anwandelung von anstandsgefuhl, habe auf bitten der frau dem knechte bekleidung gekauft, da- 
mit er zu sankt Thom nicht nackt einhergehe ${ }^{1}$ ); aber gleich darauf erfăhrt man, dass der junge könig noch ungebesserte blösse erdulde, bis der himmel ihn mit geld ausstattet und der geizige Ise, dem das himmlische angebot nicht gentigt, durch ein wunder zur herausgabe des heiligtums gezwungen wird.

Damit ist das dritte stadium der handlung erreicht: Orendel hat seinen grauen rock ${ }^{2}$ ), nimmt urlaub und geht nach Jerusalem. Unterwegs begegnet ihm noch ein abenteuer: er wird von heiden eingekerkert, und die königin Maria muss ibren sohn fur ihren schutzling wider in bewegung setzen, wie vormals bei dem klebermeer. In Jerusalem kommt or just zu einem grossen turnei: die tempelherrn zeigen vor ihrer furstin ihre ritterlichen ktunste, und frau Bride, umgeben von ihren jungfrauen, schaut von der burgzinne zu. Es scheint aber, dass auch heidnische könige an demselben teil nehmen; beiden wie templer sind frau Bride untertan, wenn auch die templer die eigentlichen schutzer des grabes sind. Ja, es scheint, dass es mit dem turnier eine besondere bewandnis hat: frau Bride ist unvermăhlt, und die hohen taten, welche vor ihren augen

1) Aus der combination dieser liebestat mit der situation von Orendels empfang bei der fischerkonigin folgerte Mullenhoff, dass dem mythus, ähnlich der Iymiskviðs (s. § 2) ein zug eigentlimlich gewesen sei, dass der gescheiterte Orendel von Ise mit gefährlicher feindschaft, von seinem weibe mit schlitzender freundlichkeit aufgenommen worden sei; sehr mit nnrecht, einmal, weil die empfangssituation episodische mache, das mitleid der fischerkőnigin zu st. Thomä augenscheinliche interpolation ist; sodann weil, wenn eine der beiden darstellungen ursprilinglich sein soll, die erstere jedenfalls für die zuverlässigere gelten muss, der zu folge die fischerkönigin den Orendel nichts weniger als freundlich aufnimmt.

2) Der graue rock ist undurchdringlich (v. d. Hagen 729). Hieraus eine unverletzlichkeit Orendels zu folgern, wäre im höchsten grade gewagt. Der unverletzlichmachende rock tritt in der deutschen sage mehrfach auf, aber immer so physiognomielos, dass er aus dem glauben erwachsen zu sein scheint, dass durch beobachtung gewisser heiligender gebräuche ein unverletzliches gewebe herstellbar sei (vgl. Grimm, Mythologie 920). Das motiv der unverletzlichkeit hat iberhaupt mit der zeit immer mehr an glaubwürdiger ursprünglichkeit verloren; der Achillessage ist es nach Prellers nachweis (Gr. m. II, 436, a. 1) accessorisch, für die Sigfridsage zum mindesten anfechtbar, für die Baldersage ebenfalls durchaus nicht uiber allen zweifel erhaben (s. u.). 
vollbracht werden, sind ritterliche werbungen um ihre minne; werbungen, die nicht unerhört bleiben, da sie dem nachmaligen sieger (Orendel) bereit ist ihre hand zu reichen. Es ist dies eine situation, die ganz den höfischen anschauungen der zeit entsprach; man braucht nur an das waffenspiel vor Herzeloide zu denken.

Als Orendel in seinem grauen röcklein das ritterliche schauspiel vor den augen der umworbenen sich vollzieben sieht, jammert er bittcrlich, dass or in erzwungner untätigkeit zuzuschauen verurteilt ist. Hier hebt eine scene an, in welcher durch das läppische gewand eines kindischen tuberarbeibeiters ein liebenswturdiges talent schaut. Orendel findet $2 w e i$ brtder beim brettspiel, zwei heidnische künige, welche fur die junge herrin sehr warme gefuhle hegen. Der eine der milde bruder, der andere der hochfahrende. Der milde stattet den unscheinbaren graurock auf seine schmerzlichen bitten mit ross und waffen aus, der hoffärige, darbber erbittert, greift den jungling an und muss sein leben lassen. Hier ist wirklich eine tragische situation vorbanden, die der tiberarbeiter freilich verzettelt. $\mathrm{Zu}$ bemerken ist: 1 . Orendel verspricht dem heiden, falls er sein ross oder seine waffen verliert, als eigenmann ersatz zu leisten. 2. Das ross des heiden ist ein wildes tier, es hat ibm schon manchen knecht erschlagen; freundlich mahnt er Orendel zur vorsicht. Orendel aber springt ohne steigbtugel auf seinen rlucken; ein kunststlisk, das noch mehrfach, und von anderen, berichtet wird. Auf beide umstande baute Mullenhoff weitergehende schlusse.

In besitz von ross und waffen, stősst der junge held nieder, was ihm entgegentritt; aber wol lauter heiden, da er spăter frau Bride versichert, or habe ihr keinen christen erschlagen. Die schöne königin staunt den furchtbaren kămpen an und lăsst ibn zu sich entbieten. Keiner kennt seinen namen, allen heisst or nach seinem unscheinbaren ausseren der graurock. Bescheidenlich lehnt or die ladung ab; er sei nur ein geringer knecht. Die tempelherrn zturnen auf die königin ob dieser auszeichnung und berufen einen feindlichen riesen, dessen therwindung Orendels waffenglanz nur steigert.

Nach solchen taten geht ihm die königin entgegen und begrtisst ihn, Da wir eine legende vor uns haben, folglich 
eine gōttliche fugung, weiss naturlich frau Bride die ankunft ihres ihr vom himmel bestimmten gemahls voraus und vermutet ibn in dem fremden; aber Orendel verschweigt seinen namen. Wichtig ist bei dieser ersten zusammenkun ft die klage der Bride: du erschlägst mir meine mannen, die mir das heilige grab behuten sollen! und seine antwort: nein herrin, ich erschlug dir keinen christen; aber deine heidnischen knechte tun tibel an mir, ich schone sie nur um deinetwillen.1) Hier stellt sich das obenerwăhnte verbăltnis klar: christen sind die htter des grabes, aber auch heiden die mannen der Bride.

Ein zweiter heidnischer riese erscheint mit heeresmacht und drobt die zerstörung des heiligen grabs, wenn ihm der graue rock nicht ausgeliefert werde. Auch er wird bewăltigt, und nun geht frau Bride dem belden zum zweiten mal entgegen und redet ihn mit worten an, die, zum teil typisch, im gegensatz zu der begrttssung nach dem ersten riesenkampf åusserst ursprunglich und frei pon legendarischem klingen: seid willkommen, herr graurock! whsste ich euren namen, wtide ich euch gern anders nennen. Doch auch so sollt ihr mein gemahl und könig sein. Nachdem ein engel die vermăhlung verhindert, und nach beliebten mustern das schwert der beiden brautlager getrennt hat, ist ein dritter kampf zu bestehen gegen einen heiden, der aber diesmal seine berausforderung in höchst charakteristischer weise begrundet: er ist nicht aus rauflust erschienen den grauen rock zu uberwinden, sondern als freier der frau Bride: sie soll sein eigen werden, der graurock hăngen; und zwar am burggraben soll er hăngen, allen bemerkbar. Die anschliessenden scenen sind dementsprechend von durchaus individuellem geprăge. Die kōnigin hat den templern entboten, ibren eigenmann (d. i. Orendel) zu beschirmen. Aber die treulosen ritter baben ihn im stich gelassen, so dass nur das persōnliche eingreifen des heldenhaften weibes den jungen könig in der höchsten not errettet. Wie die tempelherrn die königin im kampfe sehn, eilen sie auf das schlachtfeld. Aber frau Bride, auf das höchste erbittert, steht im begriff sich wider ihre eigenen mannen zu wenden; es ist

1) Bei v. d. H. $1443 \mathrm{ff}$. 
zu erwarten, dass sie in dem originalen gedicht nicht ganz allein, wie es lediglich die wunderwut der legende forderte, ibren belden herausgeschlagen habe, den treubruchigen folglich mit wenigen getreuen gegentbersteht; ein blutiger kampf scheint unvermeidlich: do gibt sich Orendel zu erkennen, und die hoheit der situation schimmert noch durch die kindereien des uberarbeiters. Die tempelherrn beugen und unterwerfen sich, und Orendel besteigt den tron.

Und, sollte man erwarten, herrscht fortan gltcklich und in frieden? Da erscheint der fischer Ise und fordert seinen knecht zurtlck. Frau Bride kauft :Orendel los, und reich beschenkt zieht Ise, ron dannen. Aber kaum ist er fort, tritt Orendel vor die königin und kundet ihr an, dass er zu seinem herrn zuruckkehren mlusse. Um dies zu verhindern, wird Ise von neuem berufen. Er erscheint in grauem rock, sein ruder in der hand, riesisch, die brauen zwei spannen von einander entfernt. Frau Bride macht ihn zum herzog und huter des heiligen grabs.

Hier sind zum ersten mal augenfällig zwei versionen in einander geraten. Entweder Ise kommt Orendel zu holen und frau Bride kauft ihn los, oder. Orendel fuhlt sich verpflichtet zu Ise zurdckzukehren, und frau Bride lässt diesen holen, den gemahl zu lösen; herzogswürde und der rang des grabschutzers sind nur legendarische mittel diesen zweck zu erreichen. Spätere erörterungen werden wahrscheinlich machen, dass die $\mathrm{zweite}$ wendung, in welcher sich auch die charakteristische und altertumliche schilderung Ises befindet, die ursprtanglichere ist; nur ist natturlich von der art der entschädigung abzusehen.

Hier, wo der erste grosse abschnitt in der handlung ist, muss einen augenblick halt gemacht werden. König Orendel unternimmt nach beruhmten mustern eine brautfahrt uber das meer. Diese fahrt ist eine ostfahrt, legendarisch gleichzeitig eine wallfahrt zum heiligen grabe. Auf dieser ostfahrt scheitert er im sturm und treibt an ein land, wohin seit menschengedenken kein lebendes wesen gekommen ist; ein fischerkönig von riesischer gestalt nimmt ihn als knecht an; der knecht findet in einem fischleib einen heiligen rock, mit dem bekleidet er seine orientfahrt fortsetzt. Er kommt nach Jerusalem gerade $\mathrm{zu}$ einem turnier, in welchem die mannen und umwerber 
der jungen königin ibre kunste zeigen, vielleicht: um ihr herz zu gewinnen. Eine dramatische scene folgt: ein milder heide stattet ihn aus mit ross und waffen, aber er muss den hoffărtigen bruder seines woltăters erschlagen. Er ist der sieger im turnier, die königin wird auf ihn aufmerksam. Es folgt der erste, ganz physiognomielose kampf mit einem beidnischen riesen, noch eingeschoben vor der ersten begegnung mit der königin, wahrscheinlich nur eine interpolation, eine vervielfăltigung der folgenden. Die erste begegnung gehört der legende an: frau Bride ist durch himmlische offenbarung ther Orendels kommen unterrichtet; er aber gibt sich nicht za orkennen. Der zweite kampf ist abermals physiognomielos; aber wichtig ist die zweite begegnung mit Bride durch ihr bekenntnis, dass sie nicht wisse, wer der fremde held sei. Trotzdem begehrt sie ihn zum gemahl. Der dritte kampf ist ausschlaggebend: 1. der riese verlangt Bride zum weib und hasst den graurock als nebenbubler. 2. Es folgt eine ausserst wirksame und dramatisch durchgefuhrte handlung, deren inhalt ist, dass Orendel, durch den verrat von Brides mannen in die höchste not gebracht, durch Brides treue gerettet, sich in dem augenblick, wo die erbitterte Bride (mit wenigen getreuen) sich auf die ungetreuen sturzen will, zu erkennen gibt und, sofort als rechtmassiger herrscher anerkannt, den thron besteigt. Durch diese $\mathrm{zwei}$ eigentumlichkeiten ${ }^{1}$ ) gibt sich der dritte kampf als urbild der beiden ersten za erkennen; aus dem zweiten ist vielleicht das bekenntnis der Bride, dass sio den granrock nicht kenne, und ihr begehr nach seiner hand als ztlge des originals herauszubeben, die aber nicht von anfang an nebeneinander gestanden zu haben brauchen.

Sehen wir ab ron typischen spielmannseituationen und legendarischen ztigen, so bleibt als ergebnis: ein held scheitert auf einer ostfahrt, gelangt nach langerem knechtesdienst in unscheinbarem gewande, von niemand gekannt, zu einer umworbenen königin, besiegt deren ungestumen oder ungestume freier und besteigt als ihr gemahl den thron.

Hinzuzufugen ist, dass Orendel in die knechtschaft Ises zurtckzukehren sich verpflichtet fublt, aber durch seine ge-

1) Die zweite wird noch weiter unten gewlirdigt werden. 
mahlin losgekauft wird. Was an diesem zuge ursprttnglich sei, wird spåter erörtert werden.

Der legendarische tuberarbeiter fthrt die handlung weiter. Ihm ist der graue rock Christi die hauptsache, der nach Trier gelangen muss. Ein engel verktindet dem Orendel, dass seine vaterstadt in heidnischer bedrăngnis schwebe; in begleitung von frau Bride, seiner unbertbrten gemahlin, eilt or zum entsatz herbei. An dieser fortfuhrung sind zwei umstånde wesentlich wegen der folgerungen, die man daran gekntupt hat: 1. (2906 ff.) frau Bride thergibt die hut des heiligen grabes zweien herzögen, ehemaligen heiden, die sich dann haben taufen lassen. Vielleicht ist es ein interpolator, der hinzubemerkt: nachmals rerkauften sie das grab an die heiden um einen schatz. 2. Orendel and die seinen sollen herrlich ausgestattet werden. Ise macht sich auf nach einem strand, an dem er apfelgraue rosse hat laufen sehen; or jagt sie mit seiner furchtbaren ruderstange, aber es gelingt ihm nicht, sie ohne die htlfe ihrer eigentlichen herrn zu fangen. Das bild des riesigen, furchterlich einherschreitenden graurocks, der die apfelgrauen rosse am strande mit der ruderstange vor sich herjagt, hat Mullenhoff ${ }^{1}$ ) mit recht hervorgehoben als ein altes und ursprungliches; ther die schlússe freilich, die er daran kntipfte, lăsst sich streiten.

So ist denn der graue rook nach Trier gelangt, und hier durfte die legende schliessen. Sie scheint auch hier geschlossen zu haben in dem text, der dem verfasser des Strassbenger heldenbuchs2) zu ohren gekommen war: 'und kam wider gen Trier, und starb. auch zu Triër, und liegt auch zu Trier'. In der anf uns uberkommenen bearbeitung bat die legende einen fortsetzer gefunden, der sie vielleicht auch mehrfach interpoliert hat 3); dieser letzten hand war es lediglich um eine moglichst reichhaltige abenteuererzăhlung zu tun. Ein traum belohrt frau Bride, dass das heilige grab in.den handen der heiden ist. Die Trierer helden eilen nach Ackers, die reliquie zurtcklassend. Von Ackers zieht frau Bride dem heer in

1) A. \&. 0. 41.

2) S. v. d. Hagen: der graue rock V.

8) Bei der späton handschriftlichen uberlieferung ist ein philologischer beweis nicht zu fubren. 
pilgerkleidern voran ${ }^{1}$ ), um zu sehen, wie es in ihrem lande steht. Ein herzog Daniel und sein bruder konig Wolffhart nehmen sie gefangen und fuhren sie auf die burg. eines königs Minolt, welcher ihre minne begehrt und den graurock hăngen will.2) Bride erklärt sich bereit sein weib zu werden, wenn er sich taufen lasse. ${ }^{3}$ ) Darauf ubergibt er sie einem ritter, der sich anheischig macht, sie durch misshandlungen $\mathrm{zu}$ zwingen, dass sie mit ihrer minne minder karge.4)

Orendel, durch einen pilger von dem geschicke seines weibes benachrichtigt, macht sich mit heeresmacht auf, lagert aber seine leute in einen hinterhalt (nach beliebten mustern) und gelangt mit Ise in pilgertracht durch die hulfe eines treuen christlichen torwartes in die burg des königs Minolt. Es folgt eine ausserst dramatische scene. Der torwart, der die belden nicht kennt und sie als boten gebrauchen will, um könig Orendel das schicksal seines weibes wissen zu lassen, erbittet von Minolt ein freundliches geleit für seine schwestersőhne, als welche er die fremden belden ansgibt. Der könig, nach bekannten mustern durch trăume gewarnt, fordert ihn auf, so lieb ihm seine huld, die fremden vor ihn zu fuhren. Der konig: seid willkommen, ihr waller! wo habt ihr den graurock und meister Ise gelassen? sagt mir die wahrheit. Ise: herr, wir kennen sie nicht, nach denen ihr fragt! Minolt (mit einer heftigen verwanschung, die aber unverstandlich tberliefert ist): ihr seid es selbst, nach denen ich gefragt habe! was schafft ihr in meinem lande? lbr musst beide sterben. Er laset fran Bride bringen: wenn sie die pilger kennt, wird sie dieselben willkommen heissen. Hort, frau Bride, sagt. der könig, begrtsset diese leute, sio hat der graurock gesant!

2) Ein beliebtes motiv; nicht allein Salman als pilger ist heranzuziehen: eine ganze sippe von volksliedern, -Bagen und -märchen alten gepräges, des inhalts, dass eine gattin in pilgertracht auszieht, ihren in der ferne bei den.Ttirken gefangenen gemahl zu befreien (bis nach Siebenbtirgen zu verfolgen). kempf.

2) Zu vergleichen die nämliche formel in dem dritten riesen-

8) Eine offenbare entstellung.

4) Hier ist bekannter boden. Die gefangene jungfran, die nicht ihres vergewaltigers weib werden will, ist aus der thberlieferten gestalt der Kudrun und, ahnlich, ans dem Karl Mainet 159, 38 f. bekannt. 
Aber Bride nimmt sich zusammen: ich sah pie nie! und, da sie fuhlt, dass der könig seine feinde erkannt hat, setzt sie schnell hinzu: wenn ich nun dein weib werden wollte, wurdest du diese månner ziehen lassen? Minolt weicht aus: und wåre diese burg silber und gold, sie sollte dir untertan sein! Aber Bride steigert: und wenn ich nun dein weib warde, und der graurock wäre da, würdest du ihn am leben lassen? Da bricht der könig los: so wăre mir sein tod doch erspriesslicher! den muss er auch erleiden, das wisse gewiss! und dagegen das hochherzige weib: so behtite mich gott, dass ich von meinem ersten gemahl liesse! Wio der graurock sieht, dass er erkannt ist, springt er zu den waffen, reisst das schwert beraus und ruft: könig, hier geht eine enge pforte aus, die hab ich dir verstanden! und bilft dir nicht der teufel durch, du stirbst von meinen händen! Der könig flieht, Orendel, Ise, Bride, der pförtner stürmen nach, die heiden laufen hinzu - und alle werden gefangen.

Hier bricht in mitten eines kindischen sagengewirrs eine grossartige dichtung durch. Die gefangenen werden naturlich durch das zu hilfe eilende heor gerettet; ob hier eine umarbeitung nach spielmånnischen mustern vorliegt und Orendel ursprunglich sofort den kōnig erschlägt, ist kaum zu entsoheiden; sicher aber ist, dass dem fortsetzer der legende ein selbstandig bestehendes und bedeutendes gedicht auf Orendel vorlag, dessen inhalt war: Orendels weib wird von einem sturmischen freier in banden gehalten; der in pilgertracht unerkannt heimkehrende gatte erschlagt den buhler und befreit sein weib.

Und zwar lag diese sagenform dem fortsetzer in $2 w 0 i$ versionen vor. Das ergibt sich, indem es 1. ein widersinn ist, dass der kōnig Wolffhart die gefangene Bride einem anderen könig uberlăsst, der nux seinerseits ihre minne begehrt; 2. der pilger dem Orendel ausdrucklich berichtet (3327 ff.), dass kōnig Wolffhart seine gefangene auf eine burg gefuhrt habe, wo er sie zur ehe zwingen wolle; 3. sich an das erzăhlte abenteuer eine scheinbare widerholung des nămlichen motivs schliesst: als die heimkehrenden sieger nach Ackers kommen, nimmt Bride pilgerkleider und zieht nach Jerusalem. Beim opfern an heiliger ståtte wird sie von einem helden Durian erkannt 
und dem könig Wolffhart ausgeeliefert, welcher ihre minne verlangt. Nachdem sie ihm diesse verweigert hat, trinkt der könig einen schlaftrunk und wird von eben jenem Durian, den plötzlich die ehrlichkeit angekommen sein muss, erschlagen. Durian wappnet frau Bride, sie schlägt dem pförtner das haupt $\mathrm{ab}$, stellt sich vor die geöffuete pforte und lăsst Orendel vermelden, das grab sei gewonnen; er kommt dann sogleich (von Ackers?!), dringt ein, und innen erhebt sich ein grosses blutbad. Die reine form beider versionen von einander zu schălen, ist nicht möglich. Das motiv, dass Bride gewappnet vor die pforte tritt, kommt in weit ursprtinglicherer und dramatischerer form in der ersten, freilich im tbrigen nieht allzuklaren situation vor. König Minolt ist in einen turm geflohn, die verfolgenden christen sind, wie es scheint, mit ihm in demselben eingeschlossen. Als das beer Orendels von aussen die burg angreift, ubernimmt Bride, die pforte des turmes zu wahren und eine flucht Minolts zu verhuten, wăhrend die drei månner in den burghof ausfallen, Ise dem pförtner das haupt abschlägt, die pforte sprengt und die anhănger einlăsst.

Mullenhoff hat die wichtigkeit dieser episoden des letzten gedichtteiles hervorgehoben, aber ibré ursprtungliche selbstãndigkeit nicht erkannt, gemãss seiner annahme, dass das lied in seiner vorliegenden gestalt im wesentlichen die einzligige niederschrift des nåmlichen dichters sei, der, einen alten stoff in eine legende umwandelnd, einzelne alte, echte teile durch das godicht hin versprengte, welche die litterarische kritik nunmebr wider zusammen zu lesen habe. Za diesen verstreuten schătzen rechnet er auch die obige handlung, behandelt sie aber in einer durchaus willkurlichen weise, indem or als ihre quintessenz hinstellt, dass frau Bride auf ihrer pilgerfahrt von den treulosen hutern des grabes gefangen genommen, ja, der zweiten version zu folge gar dem ungetreuen statthalter von Jerusalem ubergeben worden sei. Diese darstellung vergewaltigt die ausdruckliche auffassung des gedichtes, nach welcher Jerusalem von zwei christlichen herzogen an die heiden ver. kauft worden sei, und der gemäss Bride auf der reise nach dem heiligen grab von den heiden, und zwar von dem kōnig Minolt oder aber dem könig Wolffhart aufgegriffen wurde. 
Mag man tbrigens tber diese versprengungstheorie Mullenboffs abweichender meinung sein: jedenfalls wird man anzuerkennen haben, dass seine erörterung der Orendelsage das bedeutsamste oder das einzig bedeutsame ist, was uber diesen stoff geschrieben wurde; und da seine auffassung des Oervandilmythus bei manchen wunderlichkeiten und willkturlichkeiten einen ăusserst fruchtbaren gedanken enthălt, ist sie năher in das auge zu fassen.

\section{Charakteristik und kritik der Müllenhoffschen theorie.}

Mullenhoffs Orendeluntersuchung ist eine gelegenheitsarbeit: gelegentlich einer isolierung des der Odyssee zu grunde liegenden alten nostos făllt ihm ein merkwuturdiger parallelismus zwischen den scbicksalen des Ithakers und des Trierer königssohns auf. Diese entdeckung verfolgt ihn auf schritt und tritt; ihr zu liebe bemisst er nach den sieben jahren ") des Kalypsoabenteuers den griechischen winter statt auf vier auf sieben monde; sie lăsst ihn bei dem treuen torwart vor Minolts burg an Eumaios, bei der ankunft Orendels zu dem templerturnier an die spiele der freier bei Odysseus ankunft denken. Die Odyssee ist ihm eine schiffersage, und, von dem parallelismus befangen, zwingt er auch den Orendelstoff zu einer schiffersage zu recht.

Odysseus ist auf einer grossen fahrt gescheitert; sieben jahre hat or auf einer entlegenen insel weilen mussen; in anderen abenteuern ist diese fesselung an ein fernes gestade in andere formen geprägt worden. Als er endlich in unkenntlicher bettlergestalt beimkehrt, findet er sein haus von freiern wimmelnd; or erlegt sie und tritt in seine alten rechte als ebeherr und landesfturst ein.

Der norwegisch-islåndische Oervandill ${ }^{2}$ ) weilte auch in der

1) Die siebenzahl, die uns anch in vielen dentschen versionen begegnen wird, ist in den seltensten fallen mythisch suszulegen; sio ist eine jener althierstischen zshlen, welche die stehende bemessung eines, durch andere umotände nicht begrenzten zeitraums abgeben. Eine deutung anf die sieben wintermonate ist nur in uberzeugungskräftigen fällen zulässig.

2) Die dïnische fassung der sage lässt Mullenhoff als fur seinen zweck untauglich bei seite. 
ferne, im riesenland jenseits der Ellivagar; tber diese hat ihn Thor zurtickgetragen, und-seine heimkehr steht bevor. Wie sie sich vollzieht, wird nicht erzhhlt; wie Oervandill zu den riesen gekommen ist, ebensowenig. Aber gesagt ist: er wird zu seinem weibe zuruckkehren. Die vorgeschichte und das nachspiel ergänzt Mullenhoff aus dem deutschen gedicht.

Umgekehrt will er auch mit der nordischen tberlieferung die deutsche ergänzen. Dass Orendel eine fahrt nach dem heiligen grab unternahm, ist eine concession an den zeitgeschmack, dass er eine brautfahrt unternabm, eine spielmannsschablone. Der spielmann berichtet: er ist erst gescheitert und dann könig und eheherr der fran Bride geworden. Der stoff soll gelautet baben, er war erst Bridens könig und eheherr und ist dann gescheitert. Die brautfahrt des gedichtes ist eine heimkehr in der sage; wie Odysseus findet or ein haus voll freiern, das er săubern muss. Mit diesem såuberungswerk ist die geschichte eigentlich zu ende.

Vergleicht man die nordische und die deutsche quelle, liest in letzterer die echten bestandteile zusammen und zieht das facit, so soll es lauten: konig Oervandill geht auf reisen. Er gerăt in das klebermeer, das nach erweislichen britischen anschauungen das geronneve meer des Pytheas nördlich von den Orkaden um den polarkreis ist, jenseits dessen das eismeer des Adam von Bremen beginnt. Jenseits dieses eismeers wohnt nach der Hymiskviða am ende des himmels der riese Hymir, der dămmerer, zwischen den eisbergen in weiten hallen wie ein furst, umgeben von vielköpfigem, ihm gehorsamem volke, der tăglich auf fischfang zu gehen schetnt, und dem zur seite eine schōne, allgoldene, weissbrauige frau freundlich sich gegen fremde găste bezeigt, wie es Thor und Tyr bei ihrer fahrt nach dem kessel erfahren. Von einer anderen fahrt Thors uber die Elivagar (das ist eben das eismeer) als dieser letzteren ist Mullenhoff nichts bekannt; or folgert also, dass Thor von der fahrt zu Hymir den Oervandil mitgebracht habe.

Und welche analogie in der situation! Hymir fangt fische, Ise desgleichen; den weiten hallen des ersteren, einem bilde geturuter eismassen, entspricht die siebenturmige burg des letzteren; der gegen fremde gutigen leuchtenden kebse des nordischen riesen die frau des fischers, welche dem nackten 
knecht spåter kleider kauft.1) Wenn Orendel aus dem klebermeer wider freikommt, ist das willkur des dichters; nach Mullenhoff bleibt er unerlöst. Ise, der riesische greis mit der ruderstange, offenbart sich durch seinen namen als eisriesen und durch seine achthundert untertanen als riesenkōnig, wie ja auch Hymir nach Mullenhoff ein riesenkönig ist. Mit einem worte: Oervandill und Orendel sind beide im eismeer gescheitert; und wenn den gescheiterten Oervandil Thor heimfuhrt, so erinnert das Mullenhoff wider an Hermes, der die beimkehr des Odysseus veranlasst.

So wol wird es allerdings Orendel nicht, auf eines gottes schultern heimzukehren; hier reicht also das licht der eddischen uberlieferung nicht hin, die rătsel der deutschen sage zu erhellen. Aber diese selbst bietet zwei momente, deren verknupfung ein Mullenhoff befriedigendes resultat ergibt. Orendel erhält, um an dem turnier vor Bride teil zu nehmen, von einem heiden ein wildes ross geliehen mit dem beding, falls or es im wettspiel verliert, mit seiner person einzustehn. Er verliert es nicht; aber der beide nennt ihn später in eiferstlchtigem zorn seinen knecht. Ferner: auf der fahrt nach Trier jagt Ise an einem strande eine hin- und widerlaufende apfelgraue rossheerde mit seiner ruderstange auf, um Orendel ein ross zu fangen. Nimmt man hinzu, dass Orendel ôfters ein fischerknecht genannt wird, und dass Ise erscheint seinen knecht zu holen und Orendel sich erbietet in seine knechtsch a ft zurluckzukehren, so ergibt sich: Ise hat, um Orendel die heimkehr zu ermöglichen, eines seiner grauen rosse am strande gefangen und ihn uber das meer gefuhrt, unter der bedingung, dass er wider als sein knecht heimkehre.2) Das turnei der templer bietet die situation von Orendels beimkehr,

1) Hierüber 8. 9 a.1.

2) Nach Mullpnhoff hätte sich diese situation gespalten, und die brnchstïcke schienen hier und dort anfantauchen, etwa wie schiffstrümmer auf den wellen eines meeres: hier ein könig, der dem Orendel ein ross leiht, wenn er sich zur knechtschaft verpflichtet; dort Ise, der dem Orendel ein ross fängt. Ist aber diese anschaung nicht sebr therzeugend, so ist es schlechthin unwahrscheinlich, dass der spielmann sieh eine so schöne, phantastische situation hätte entgehen lassen, wie: Orendel von Ise durch die luft auf einem wunderpferd gefuhrt! 
der kampf mit den riesen ist durchweg dichterische zutat, auseinanderzerrung der katastrophe; diese selbst ist erbalten in den beiden schwung vollen situationen der pilgerfahrt Bridens: Bride in den hănden treuloser vassallen, Bride die pforte wahrend und niemand ein- noch aluslassend, wăhrend Orendel darinnen das werk der rache vollbringt: naturlich wider wie Telemach und Odysseus; auch bier sitzt Mullenhoff sein parallelismus als der schelm im nacken.

Und die deutung? Oervandill ist ein compositum, dessen erstes element aur sich mit der bedeutung des fenchten nachweisen lässt; er hat einen vater Oeugel, dessen etymologie uber Ouwilo auf ouwa = wasserland, wasserlauf fuhrt. Folglich ist die bedeutung des ersteren namens: der auf dem wasser umfahrende; ein rechter Odysseus-name. Sein weib heisst eddisch Gróa, und gróa heisst grthen, wachsen; folglich ist sie ein chthonisches wesen. Da nun Bride Orendels frau ist, so ist sie ebenfalls ein chthonisches wesen.1) Vor der heimkehr des Oervandil hat Thor dessen erfrorene zehe an den himmel geworfen; folglich geht das orscheinen des sterns Oervandilstá der heimkehr des helden vorauf. Diese knupfung seines erscheinens an das erscheinen eines sternes ist ein neuer beweis fur die natur der sage als eines schiffermythus. Da nun der Orendel des spielmannsgedichtes aus der knechtschaft kommt und wider in die knechtschaft zurltckkehren muss, so ergibt sich: der sommerliche held ist an eine riesische, ihm entgegengesetzte macht gebunden und ihr verhaftet, weil die zeit seiner herrschaft, beschrănkt auf die sommermonde, der winternacht erliegt. Im sommer, wenn die see fahrbar ist, kann er auf dem meere schweifen; im winter versinken seine schiffe, und or verfâllt der macht des eisriesen, welcher alsdann das meer beherrscht und seire apfelgrauen rosse zahllos am strande laufen lässt. Unholde gesellen, die winterlichen sturme, nehmen indes besitz von des helden reich und weib, umbublen, misshandeln dieses vielleicht. Mit dem lenz aber

1) Folglich ist Penelope anch ein chthonisches wesen; obwol man anführen dürfte, dass der name 'gewandweberin' schlechtweg ein griechischer frauenname war, und dass die eigenschaft des webens fir chthonische gottheiten, durch nichts festgestellt, nur eine recht gewagte hypothese ist. 
kehrt er răchend zurück als rechtnăssiger gatte und gebieter: freilieh, um dereinst der macht des eisriesen, welcher ihm jetzt gewichen ist, wider zu verfallen.

Die Mullenhoffsche deutung ist ein zwittergebilde von schiffer- und jahreszeitenmythus. Der held muss eine sommerliche gottheit sein, denn der name seines weibes bedeutet das chthonische fruhlingsgrun; aber er ist der seefahrer $x \alpha \tau^{2} \dot{k} \xi \alpha \dot{\eta} \boldsymbol{\nu}$ 1. um des parallelismus, 2. un der etymologio willen. Die schiffer bilden sich ein ideal, das im sommer umfăhrt und im winter scheitert; gleichsam eine personification ihrer erfahrungen. Das meer ist im sommer wirtlich, im winter unwirtlich; folglich beherrscht es im sommer ein gott, im winter ein dämon. Wenn jedoch der sommergott im sommer das meer beherrscht, im winter im eis stecken bleibt wio auf einem stusswasserteich, und im winter der dämon das meer beherrscht, im sommer aber entweicht: so wurde das, abgesehen von der absurdităt der anschauung, einen mythus des inhalts ergeben: der winterriese erobert im winter das meer und nimmt den sommerlichen meeresgott gefangen; im sommer lăsst er ihn los, man weiss nicht, warum, mit der gewissheit, ihn wider im winter in die hănde zu bekommen. An einen derartigen mythus hat selbstverstăndlich Mullenhoff nie gedacht; er ist aber das unausweichliche ergebnis seiner erklärungsversuche. Das Ise im winter das meer beherrsche, ist eine durch seine eigenschaft als fischer und durch die jagd auf die grauen rosse nicht genugend gestutzte annahme; dass or im sommer entweiche, widerspricht ausdrucklich dem inhalt der sage. Dass Orendel ein seeheros gewesen sei, kann sich auf das scheitern seiner schiffe oder auf den scheiternden Odysseus unmöglich ausreichend stutzen. Es bleiben also nur zwei grunde fur Mullenhoffs deutung: 1. eine gewagte etymologie des namens Orendel, 2. die genealogische anknupfung an einen Oeugel.

Mullenhoffs etymologie des namens Orendel ist in der tat nur aus seinem vorurteil heraus verstandlich. Der name Aurvandil soll in seinem ersten bestandteil die wurzel aur in der bedeutung des feuchten enthalten. Wenn aber Mullenhoff selbst das angelsăchsische appellativ eárendel - leuchte heranzieht und eingesteht, dass ${ }^{\circ}$, mit jener ableitung schlechthin unvereinbar, nur mit skr. vas = glănzen zusammenzuordnen ist, so 
gibt es nur zwei möglichkeiten: entweder das wort aurvandil ist von je her mit der wurzel vass gebildet gewesen, oder das angelsăchsische appellativ ist ein ewiges rătsel,

Auch der name des vaters Oeugel kann den verlorenen posten nicht retten. 1. ist jede' genealogie in der göttersage (um die es sich ja hier bandeln soll), und meist wol auch in der heldensage, accessorisch: entweder ein compromiss concurrierender wesenheiten, bezuglich mamen, oder aus dem dichterischen bedurfnis entsprungen, einem individuum charakteristische eltern zu geben, bezuglich: eine ehe mit charakteristischen kindern zu segnen. Von vorn herein also ist der name eines vaters ein bedenkliches kriterium für die ursprungliche natur des sohnes. 2. ist es gar nicht wahrscheinlich, dass der name Oeugel in sehr alter zeit mit Aurvandil verkntupt wurde; denn der name ist eine bypochoristische koseform, und es wåre doch hōchst eigentumlich, wenn der name des uninteressanten vaters sich abgegriffen hătte und der name des viel besungenen sohnes unverăndert geblieben wåre. 3. Gesetzt den fall, dass Mullenhoffs etymologie des namens Oeugel zutreffend wăre (was ja durchaus sein kann, aber keineswegs sein muss), und dass ferner der name des vaters um seiner bedeutung willen dem namen des sohnes nachtrăglich beigesellt worden wäre, so wutrde das eben nur beweisen, dass man zu der zeit dieser genealogischen verknupfung unter Aurvandil den seefahrer verstand; und wirklich wăre eine verschiebung in dieser richtung nicht erstaunlich, da sich fur die verwendung eines aur ${ }^{1}$ ) entsprechend skr. vas deutsch nur noch sebr wenige und zweifelhafte beitrăge liefern lassen.2)

1) Andere germanische gebilde dieser wurzel in der bedeutung glänzen sind nacbzuweisen: vgl. Fick I, 218: skr. vasars frubling, altn. vár (= vasra); lit. auszta es tagt, germ. austa, austana, austra. ost, osten, ostern (vgl. $\alpha \hat{v} \rho\llcorner o v$, und skr. usas zu lat. aurora).

$\left.{ }^{2}\right)$ Der interessanteste ist der name der Oerboða: Fiølsvinnsm. 38 sitzt Mengløð, die sich mit ziemlicher sicherbeit als eine sonnenjungfrau erweisen lässt, auf einem berg, umgeben von den jungfrsuen: schutz, thursenschutz, volksschirmerin, die glänzende, die gute, die guitige, die schïne, die heilende, Uerbota. In diesem zusammenhang ist eine zusammensetzung aur $=$ feucht mit bori $=$ flut zu der bedentung: die fenchtfutende weit unwahrscbeinlicher als die zusammensetzung aur $=$ glanz und boбi $=$ darbieter zu 0erboða $=$ glanzspenderin. 
Also etymologisch ist die theorie der schiffersage nicht $\mathrm{zu}$ halten; um sie sagengeschichtlich durchzufuhren, ist Mullenhoff in ein recht bedenkliches verfahren geraten. Er hat sich eine sage construiert, deren anfang aus einem deutschen spielmannslied, deren mitte aus der Edda, deren ende - aus der Odyssee entnommen ward. Nach diesem' Prokrustesbett hat er dann die norwegische tuberlieferung gereckt und die deutsche beschnitten. Wenn er aus der eddischen sage entnimmt, dass der held in der deutschen nicht auf der brautfahrt sondern auf einer ruckkehr begriffen ist, so wird man ihm das um so eher zugestehen, als sich in dem spielmannsgedicht reste einer in dieser richtung entscheidenden tradition nachweisen lassen.1) Wenn er aber, nach analogie der deutschen uberlieferung, den eddischen Oervandil als in dem eismeer, d. i. den Elivagar, gescheitert betrachtet und umgekehrt den deutschen Orendel in dem, unter anderen abenteuern ganz episodisch nach beliebten mustern eingefuhrten klebermeer endgultig stecken bleiben lăsst, so zerstört er durch seine willkür beidemal die anschauung; denn einerseits wagte sich der nordlăndische schiffer uberhaupt schwerlich in das eismeer, und wenn er sich einmal hineinwagte, hatte er weniger das scheitern als das einfrieren zu befurchten; und andrerseits: wăre Orendel wirklich in dem klebermeer endgultig stecken geblieben, so wăre or eben nicht gescheitert, folglich nicht allein sondern mit allen gefährten dem fischer Ise in die hănde gefallen. Gerade wenn der name Ise den eisigen bedeutet, hat fur die vermutung die Edda, welche nichts ron einem schiffbruch weiss, sondern ihren helden jenseits der eisströme in das winterland versetzt, das ursprtinglichere, und das deutsche lied, das ihn auf einer see-

1) Heranzaziehen ist besonders die situation von s. 13: die mannen der Bride haben Orendel im kampf mit dem riesischen freier im stich gelassen; die erzürnte konnigin steht in begriff, (mit wenigen getreuen) die treubrilchigen anzugreifen; die situation ist bis zur katastrophe gespannt: da gibt sich Orendel zu erkennen, und sofort ist alles beglichen, er ist der herr, und die widerspenstigen mannen huldigen ihm. Diese als ursprünglich erkannte entwickelung muss man sich an der stelle, wo sie steht, notdirftig ans dem umstand erklären, dass der legendarische held, von gott gesant, unterwlirfig aufgenommen wird; streicht man die legende, so bleibt einzig die unkenntliche rückkehr des rechtmässigen herrschers. 
fahrt scheitern lässt, das versehobene. Jedenfalls aber sind der scheiternde Orendel und der jenseits der Elivagar befindliche Oervandill unmittelbar nicht vereinbare versionen.

Nicht glticklicher ist Mullenhouf mit dem unternehmen, den ausgang der norwegischen taberlieferung durch die deutsche za controlieren. Der Groa, die jauchzend die kunde von ihres gatten naher heimkunft vernimmt und dartuber ibre zauberlieder vergisst, einen oder gar eine schaar von freiern aufzuladen, heisst doch etwas gewaltsam mit der therlieferung umspringen.

Geradezu verbluffend wirkt das verfahren Mullonhoffs, die eddischen lieder untereinander in einer weise in beziehung $\mathrm{zu}$ setzen, welche die ansicht zu involvieren scheint, dass diese lieder sich untereinander zu einen ganzen ergănzen, wăhrend wir in der tat nicht 2 wei eddische gōtterlieder haben, welche einander inhaltlich nahe stehen wie bruchteile des nămlichen mythus. Såmtliche eddische mythendichtungen, ob in prosa oder in versen taberliefert, sind kunstlerisch individuelle schöpfungen, fur den mythologen quellen zweiter hand; sie repräsentieren nicht allein einen spăten standpunkt der mythenentwickelung, sie sind gedichte a uf mythen. Ihr material also ist bereits ein verschobenes, ein in der uberlieferung durch einander geratenes, auf dem wege des compromisses geschlichtetes; und weiter ist die behandlung dieses materials eine freie, individuelle, dem bildungskreis des săngers wie seiner hörer entsprechende. Mullenhoff selbst hat darauf hingewiesen ${ }^{1}$ ), dass die pulir des nordens fahrende vom bettler bis zum ehrenwerten grundbesitzer waren; sein freund Liliencron hat fur das Harbaroslied dargetan ${ }^{2}$ ), dass es vor einem vornehmen kreis gesungen wurde; andere lieder lassen sich als vor und für die båuerliche bevölkerung gesungen nachweisen. Unter solchen umständen findet man nicht leicht eine situation in den liedern, die man fest anfassen durfte; eben weil sie phantasie-, dichterische producte sind. Der ursprungliche mythus ist stets concrete naturanschauung; wenn der nachtrabe mit eiserner schwinge eine hurde zerschlăgt, wenn die maruts die wolken-

1) Deutsche altertumsk. V, 291.

2) 7.8. fda. $X, 181$ ff. 
kabe melken, das kann man sich vorstellen; aber wenn Harbarô den Thor nicht uber den sund lăsst und der arme mann, um in den himmel zu kommen, einen umweg uber die erde machen muss - so kann man sich drehen und wenden: mit dieser mythischen geographie kommt man nicht ins reine.

Natürlich waren den eddischen dichtern ganze massen von reinen naturerscheinungen bekannt; aber nicht minder viele, in denen sich diese primitive mythengestalt schon zu einer fabel, oder gar die fabel zu einem roman fortentwickelt hatte. Viele ihrer primitiven mythen waren auch als bestandteile von romanen fortgewandert; wăhrend die naturanschaung sich wandelte, blieben sie formelhaft, missverstanden, umgedeutet bestehen. Andere, die der dichter noch selbst verstand, verwante or willkturlich zur ausschmuckung seiner gedichte, oder vereinigte sie willkurlich. Mit einem worte: der eddische dichter gestaltete nicht einzelne mythen, sondern er wirtschaftete mit ererbtem mythischem capital. Wenn der mythologe ihn ausnutzen will, muss er jede einzelne anschaung aus dem gegebenen zusammenhang herausheben und durch sorgfăltige sammlung von analogieen, durch vergleichung der einzelnen gebilde die alte anschauung zu gewinnen suchen, nicht ein gedicht vornehmen und schritt vor schritt auslegen: 'Loki und 'Thor wollen sieden, der sturmriese Thiazi verhindert es $=$ der trockene, kalte nordwind macht das frublingsdampfen der erde unmöglich; Loki wird von Thiazi an der stange geschleift = die temperaturdifferenz zwischen dem eisigen bergwind und dem lauen frublingswind ist zu gross, als dass die berthrung ohne niederschlag vor sich gehen könnte' (Laistner, Nebelsagen 287). In ganz der nămlichen weise mulssen die situationen verglichen werden; und wo sich ihre mythische ursprunglichkeit nicht schlagend feststellen lăsst, soll man es sich dreimal uberlegen, ob hier nicht der dichter ein eigenes zugetan hat.

Unter solchen verhältnissen ist es nicht zu billigen, wenn sich Mullenhoff die frage vorlegt: Thor trăgt den Oervandil uber die Elivagar: wo kam er da wol her? unter den eddischen liedern spricht nur ein einziges davon, dass Thor tuber die Elivagar gefahren ist: die Hymiskviða; folglich wird er Oervandil von Hymir mitgebracht baben, folglich war Qervandil 
bei Hymir, folglich ist Hymir gleiclh Ise. Es ist schon an und furr sich sehr fraglich, ob Thor lbei seinen Ostfahrten nicht regelmåssig die Elivagar, die naeh Hymiskviða und dem, allerdings sehr späten, Hrafnagaldr imı Osten liegen, uberschritten hat. Es soll nun, bei den wicihtigen folgerungen, welche Mullenhoff auf seine verknlupfunw des skaldaberichtes mit Hymiskviða gründete, dieses gedicht einer năheren erörterung unterzogen werden, welche, zugleich mit der beleuchtung des eigentumlichen verhăltnisses beider tuberlieferungen in dem vorliegenden fall, den praktischen massstab fur die weitere ausnutzung dieser quellen unserer untersuchung, besonders fur dio ausnutzung des auf Oerrandil beztiglichen skaldaberichtes gewahren wird.

Str. 1. Die götter nahmen einst die erjagten tiere, zechlustig, ehe sie das gelage abhielten, beschauten weissagend das opferblut ${ }^{1}$ ) und die geworfenen stăbe und entdeckten bei Oegir die ermanglung des kessels. 2. Das benutzt Thor, ibn in not zu bringen; drobend tritt er vor den bergbewohner und verlangt von ihm, dass er den göttern alsbald ein gelage riste. 3. Der riese ersobriekt, ersinnt aber schnelle rache: ich will es gern tun; jedoch ihr seht: ich habe keinen kessel; den sollt ibr mir schaffen. 4. Nun geht not bei den göttern an den mann; aber Tyr weiss einen ausweg: östlich jenseits der Eligavar an des himmels ende wohnt sein vater, der weise Hymir: der besitzt einen geræumigen kessel. 6. Thor und Tyr machen sich auf die fahrt. 7. In Hymis behausung finden sie seine hunderthauptige mutter (die dann nicht wider in dem gedicht vorkommt) 8. und eine allgoldige, weissbrauige frau, Tys mutter, die kebse Hymis. 9. Sie versteckt die beiden gäste unter kesseln, denn

1) Die auffassung Lünings (Edda 188), dass die götter tiere erjagt hätten, um opferblut zum weissagen zu erhalten, ist eine tble auskunft, bedingt durch das (später zu beleuchtende) vorurteil, dass die götter vor dem gelage bei Oegir ständen, welches das folgende lied der sammlung schildert: eine mit dem wortlaut des gedichtes nur durch advokatorische winkelzlige zu vereinbarende annahme. Die gutter rüsten ihr eigenes mahl; und wenn sie zu dessen beginn aus opferblut weissagen, so' ist dies eine sehr naive, aber verständliche libertragung menşchlicher gebränche auf das himmlische gelage. 
Hymir ist manches mal den gästen gram. 10. Hymir kommt heim von der jagd wie ein wandelnder eisberg. 11. Seine kebse fordert ihn zu gastlicher gesinnung auf: der sohn ist gekommen, den wir erwarteten von langen wegen; mit ihm der grosse Thor. 12. Am ende der halle ducken sio hinter einer saule (unter kesseln) sich zu retten (so bange sind sie vor dir). Vor Hymis blick birst die săule; 13. kessel sturtzen herab und zersplittern; nur einer bleibt ganz. 14. Hymir ahnt nichts gutes bei Thors anblick. 15. Thor verzehrt zwei riesenochsen zum nachtmahl, zu Hymis missvergnugen: wir werden uns nun morgen selbst speise erjagen. 17. Der folgende tag ist angebrochen: sie wollen fischen gehn, Thor vermisst den köder; Hymir verweist ihn auf seine allschwarze riosische rinderheerde. 19. Erste stärkeprobe: Thor holt ein stierbaupt als kỏder, zu Hymis steigendem missvergntigen. 20. Thor will immer weiter ins meer fahren, aber Hymir weigert sich (die strophe fallt in ihrer ausgeprägten skaldischen vergleichsspielerei etwas aus dem tone des ganzen). 21. Zweite stärkeprobe: wettangeln: Hymir zieht zwei walfische; Thor befestigt vor dem fischzug die leine am steuer: 22. Er făngt mit dem stierhaupt die Mitgardsschlange, 23. zieht sie an den schiffsrand und trifft ihr haupt mit dem hammer, 24. worauf sie zurucksinkt. 25. Hymir ist ausserst verstimmt auf der beimkehr. 26-27. Dritte stärkeprobe: Thor trăgt das schiff mit allem inhalt in den kessel der bergwaldhalde. 28-32. Vierte stärkeprobe: die zerschmetterung des kelches an Hymis haupt (auf den hulfreichen rat der kebse). 33-34. Funfte und letzte stärkeprobe, von Hymir als solche auferlegt: Thor hebt den kessel auf das haupt. 35. Er trägt ihn fort; als er und Tyr sich umschauen, sehen sie sich verfolgt von Hymir und vielhăuptiger schaar. 36. Thor setzt den kessel ab und erschlägt mit dem hammer die felsriesen (von Tyr ist bei dem kampfe keine rede). [37-38 sind durch irrtum oder willkur hineingeraten.] 39. So bringt er den kessel zu der gōtterversammlung: aus ihm trinken die götter öl jede leinernte.

Diese schlussstrophe enthält den kern des kesselmythus: die götter trinken jede leinernte bei Oegir öl aus einem 
kessel:1) Wie kommt der kessel zu Oegir? or muss ihm nach dem ursprunglichen mythus, wie ihn die letzte strophe andeutet, eigentumlich zugekommen sein; da nun möglicherweise auch ein mythus bestand, dem zu folge Thor mit vielhauptigem volke um einen kessel kämpfte, so antwortet der dichter: den kessel hat Thor dem Oegir verschafft; wie er zu diesem liebesdienst kommt, wird in witziger weise erzählt: die beiden parteien, die sich wenig wolwollen, suchen sich gegenseits in verlegenheit zu setzen: Oegir mit grōsserem erfolg. Ganz charakteristisch beginnt das gedicht: die götter ersehen aus ihren weissagemitteln, dass dem Oegir ein kessel fehlt. Das ist nicht gerade eine hohe erkenntnis; aber der dichter braucht einen weg, in der beliebten dramatischen weise frischweg auf sein kesselmotiv loszusteuern. Ohne kessel kann Oegir kein mahl richten; darum verlangt Thor drohend sofortige herrichtung eines gelages. Oegir weiss sich zu helfen: sobald ihr mir einen kessel verschafft habt. Was fur einen kessel bringt nun Thor? Der dichter bleibt die antwort nicht schuldig: einen gebirgskessel (str. 27). Jenseits der Elivagar wohnen die bergriesen; bei denen gibt es kessel die fulle (str. 13).

Die wirkliche bedeutung des kesselmythus ist vergessen; man deutet ihn um. Die ausleger haben in dem kessel Oegis das meer sehen wollen. Das mulsste richtig sein, wenn der mythus aus derjenigen zeit stammte, zu welcher Oegir meerdåmon geworden war. Dass er vordem einen athmosphårischen dämon bedeutete, erweist 1. die vergleichende mytho-

1) Es ist eines der grundgesetze der mythenentwickelung, dass in der uberlieferung von mund zu mund die ehemalige auffassung eines immer widerkehrenden naturereignisses als ein einmaliges ereignis sich gestaltet. Man vergleiche bei Laistner, Nebelsagen s. 37 die sage von der gewittermilhle: im gewitter mahlt der teufel felsen; warum tut er das? er hatte sich einst eine kanzel errichtet; ein engel erbaute eine concurrenzkanzel und lockte ihm seine bürer weg; zornig sehuf er sich eine mlihle und ubertïnbte mit seinem felsenmahlen die engelsstimme, bis gott, dessen langmut riss, ihn wider den felsen schleuderte, an dem er sich abdrückte. Seitdem mahlt er nur noch im gewitter. Bedeutsam für die gesetze der sagengenesis ist die einverwebung der ganz anderweitig entstammten teufelskanzel und bergeindrlickung in den einmaligen fall der gewittermühle. 
logie durch ihre zuruckfuhrung des namens auf das in den Veden Ahi genannte wesen; 2. die benennung bergriese (str. 2), welche, wie sich erweisen lässt, nicht, wie Uhland glaubt, sich auf die wirklichen, sondern entsprechend dem vedischen glauben, auf die wolkeuberge bezieht. Der eddische dichter denkt tatsăchlich bei dem namen an wirkliche berge; und wenn dieser umstand nicht für den meerdămon passt die formel bleibt bestehn.

Zur ermittelung der ursprüglichen bedeutung bat man mit mehr recht an die volksanschauung eines brauenden gewitters erinnert. Wenn ferner im harz die nebel im 'gebirge aus dem wald steigen, sagt der bauer: die bergmutter braut (Kuhn, Westf. s. II, 88). Westfälisch wie holsteinisch verleihen und entlehnen die unterirdischen ${ }^{1}$ ) gern braukessel; hennebergisch besitzen sie einen grossen braukessel (ahnlich bei Scharfenberg); anderenurts betonen sie, vor der erfindung des bierbrauens gelebt zu haben (Mullenhoff, Sagen, mårchen etc. 279. 284; Kuhn a. a. 0. I, 200. 201. 214). Dazu vergleiche man die anrufung Oð̇ins beim bierbrauen (Uhland VII, 511), die im saale Brimir (rauscher) bier trinkenden riesen der Völuspa und die zusammensetzung prumketill = brausekessel (Grimm, Mythol. I, 151) neben der bekannteren pórketill. Auch die noch nicht gentugend klargelegte sage uber Orrœrir verspricht licht fur die erklărung des kesselmythus abzugeben, und zu empfangen.2) Vieles spricht fur eine anschauung des

1) Ueber die eine monographie recht wlinschenswert geworden ist, seitdem Mannhardt in bedanerlicher einseitigkeit den gessmten volksglauben in eine vegetationsdämonie vergraben hat, unter tibergehung eines nmfangreichen, gegen diese anschaung zengenden materials. Es ist dies gewiss kein vorwurf gegen den hochsinnigen, gediegenen forscher, dem die mythologische wissenschaft viel anregung und noch mehr material verdankt; aber eine eingehende kritik kann durch strengere sichtung von volkskunde und volksmythen und durch mythengeschichtliche erwägungen darlegen, dsss die folgerungen Mannhardts vielfach den sachverhalt getribt haben. Für alle 2 werggebilde ist mit wenig ausnabmen. jede urspringliche beziehung auf vegetative verhältnisse 20 verneinen und eine, wenigstens urspringlich, athmosphärische natur anzunehmen. Der stoff ist diesmal sehr reichlich gegeben. - $\mathrm{Zn}$ der bergmutter vgl. auch Rochhola, Sagen aus dem Aargau I, nr. 117.

2) Weiteres vgl. Mannhardt, Germanische mythen 96-105. 
gewitterhimmels als eines brauenden kessels, um welchen gōtter und dämonen kămpfen, oder, nach anderer auffassung, um den ein grosses, jăhrlich widerkebrendes mahl statt findet. Fur beides lassen sich belege beibringen.

Der Oegisdrekka hat der sammler eine prosa vorangesetzt, in welcher er das göttermahl bei Oegir stattfinden lässt, nachdem, 'wie vorher erzählt', der kessel beschafft worden sei. Zu anfang von Bragarōdur besucht Oegir die götter und wird von ihnen bewirtet. Skaldsk. 33 ist Oegir bei den gōttern zu gast gewesen und lådt sie bei der heimreise ein, ibn drei monate spăter zu besuchen. Daraus hat man gefolgert, das gelage, welches Thor in Hymiskviða fordert, sei 1. das in Oegisdrekka geschilderte, 2. das Sk. 33 mit beziehung auf Bragar. versprochene. Die letztere beziehung ist ausgeschlossen 1. weil das gelage in dem momente, wo die götter ihr eigenes mabl rusten, auf einen plötzlichen einfall hin von Thor gefordert wird; 2. weil das gedicht mit einem hinweis auf ein periodisch widerkehrendes gelage schliesst. Damit ist auch die erste folgerung hinfallig; der an sich bestehende mythus eines göttermahles bei Oegir wird nun in Oegisdr. als dichterische situation verwant, um ein mythologisches streitgedicht mit möglichst reicher beibringung mythischen materials ${ }^{1}$ ) dramatisch ins werk zu setzen. Auch der anfang von Bragar. ist nur situationsmacherei, welche Skaldsk. mit Oegisdr. in willkurliche beziehung setzt, wăhrend in wirklichkeit die situation von Oegisdr. die originalere ${ }^{2}$ ), die von Bragar. die nachgeabmte ist.

Auch in Hymiskv. ist der ehrwurdige kesselmythus nur benutzt, um eine abenteuerfahrt des volkstumlichen Thor wirksam einzuleiten. Denn nur um abenteuer handelt es sich fur

1) Gemäss den, in der verfallzeit des heidentums bereits vorherrschend gewordenen didaktischen tendenzen.

2) Alles in allem handelt es sich sowol in Oegisdr., in Hymiskv., wie in Bragar. um die dichterische anwendung eines ursprünglichen volksglaubens, indem der mythus des periodischen kesselgelages dreimal die künstlerische einzelsituation abzugeben hat: 1. fur ein mythologisierendes streitgedicht, 2. für den rahmen einer sbenteuererzählung, 3. (indirect) für den rahmen einer didaktischen, dialogisierten mythenaufzählung. 
dichter und publikum. Thor fährt einmal wider in das riesenland und misst seine stärke mit einem eisriesen in fünf stärkeproben. Man hat mit recht den starken, dummen Hans des märchens mit Thor in beziehung gesetzt; or ist ein analoger charakter: plump, gutherzig, furchtbar stark und besieger aller möglichen ungeheuer; kurz, das heldenideal des bauern, wenn er sich auf das fabulieren verlegt. Der sãnger des Hymiskv. singt vor dem volke; die einleitung, wie dem Thor, welcher, esslustig, im begriff steht sich an sein mahl zu machen, plötzlich der gedanke kommt den Oegir in verlegenheit zu setzen, und wie er in seiner eigenen grube sich fängt, ist schon ein derber spass; mit dem antritt der reise sind wir auf märchenboden. Da ist die hundertköpfige riesenmutter, die gar nichts mit der erzählung zu schaffen hat; da ist die gute riesenfrau, welche die fremden găste vor dem bösen eheherrn versteckt; da sind Thor und Tyr, die sich unter kesseln verkriechen und wozu schliesslich der lärm? Hymir sieht schlimmer aus, als er ist; or krümmt ihnen kein härchen. Und wie verträgt sich die ganze burleske, nach kindergraus schmeckende scene mit dem durchschimmernden mythischen einzelzug, dass Tyr als erwarteter sohn heimkehrt? Es ist die märchensituation im hause des menschenfressers, welche der dichter mit keckem humor zur ergötzung seiner hörer verwendet.

Das hauptstlick des gedichtes ist nicht die kesselholung, welche der abenteuerlustige dichter schnell aus den augen lăsst, sondern der fischzug. Indem wir ihn in Gylf. 48 in einer weit besseren uberlieferung haben, die uns erst in den stand setzt, die widerholten fluchtigkeiten des dichters der kviōa zu controlieren, ist es möglich den beweis zu fuhren, dass um den fischzug als den alten kern der kviðadichter freischöpferisch eine abenteuermasse gruppiert hat, fur welche die kesselbolung nur wider den rabmen abgibt. Das ganz vortreffliche, altertumliche, in sich geschlossene gedicht, welches Gylf. zu grunde liegt, hat den inhalt, dass Thor als junger gesell zu Hymir zog, sich gegen ihn zu messen, mit ihm auf die see fuhr, trotz Hymis protest die Mitgardsschlange angriff und unfehlbar erschlagen hătte, wenn Hymir nicht die an dem schiff befestigte angelleine, von welcher der wurm nicht loskonnte, durchschnitten hătte. Wutend erschlăgt Thor 
den riesen und watet an das land. Damit ist die geschichte zu ende. Hier erfährt man also, warum Thor in der kviða immer tiefer in die see rudern will und Hymir sich dagegen sträubt (str. 20): Hymir furchtet die Mitgardsschlange, auf welche es Thor gerade abgesehen hat; nun begreift man ferner, warum Thor str. 18 sveinn genannt wird: als ein gauz junger bursche hat er die fahrt unternommen; jetzt endlich wird klar, warum die versinkende schlange das boot, an dessen steuer Thor sie gebunden, nicht mit hinabzieht: Hymir hat das seil durchschnitten. Der kampf Thors mit der schlange ist die pointe des liedes gewesen; die beiden geborenen feinde mussten sich einmal begegnen. Indem die pointe in den hintergrund trat, wurde der fischzug im grunde gegenstandslos: ein abentever wie andere.

Das ergebnis der erörterung ist: der dichter der kviða hat auf grund eines vorhandenen fabel- und mythenmaterials eine, seinem eigenen wie dem geschmack seiner hörer als ganzes wie in den einzelheiten entsprechende, freie schöpfung componiert. Das mythenmaterial ist nur zu verwerten, indem man es isoliert; folgende umstãnde sind herauszuheben: 1. ein jăhrlicher göttertrunk bei Oegir aus einem kessel, zur zeit der leinernte. 2. Oegir der bergriese. 3. Tyr kehrt heim in das riesenland, erwartet, nach langer wanderung. 4. Hymir besitzer einer allschwarzen riesischen rinderheerde; der eine stier wird in Bragar. himmelbrecher genannt. 5. Hymir der eisriese. 6. Ein vielköpfiges riesenvolk jenseits der Elivagar. 7. Thors auch anderweitig bezeugte gefrăssigkeit. 8. Vielleicht: ein kampf Thors mit riesen um den gewitterkessel. Ob ein nachdruck auf die fischerktunste Hymis zu legen ist, ist sehr fraglich; sie stehen ziemlich vereinzelt in unserer kenntnis der riesenwelt da und scheinen nur erfunden zu sein, um den kampf mit der Mitgardsschlange zu ermőglichen.

Hiermit ist der standpunkt auch fur die ausnutzung der skalda bezliglich des Oervandilmythus gegeben. Ihre erzăhlung beginnt mit dem umstand, dass Thor zu Groa kommt um sich einen stein aus der stirne zaubern zu lassen, und endet damit, dass Groa ihre lieder vergisst und der stein stecken bleibt. Das ist der rahmen, in welchem sich jedenfalls zweierlei 
befand: 1. ein galdrgedicht ăhnlich Grogaldr: die hauptsache. 2. der bericht Thors uber Oervandil in gestalt einer gelegentlichen erwăhnung: eigentlich zur rahmenerzählung gehōrig, den rahmenschluss motivierend. Dieser bericht ergibt: 1. Oervandill weilte längere zeit jenseits der Elivagar im riesenlande und ist nunmehr auf der ruckkehr begriffen. 2. Oervandill, der gatte der Groa, die seiner rllckkehr harrt. 3. Eine anschauung, nach der Thor den Oervandil auf dem rlicken in einem korbe trăgt. 4. Ein nach Oervandil, und zwar Oervandils zeh, benanntes gestirn. Die zusammenfugung dieser ztige muss schon deshalb eine willkurliche gewesen sein, weil, wenn Oervandil uber die Elivagar getragen ist, man nicht begreift, wie Thor, der ihn hintubergetragen, vor ihm die gōtterwelt erreichte. Bei der endgultigen deutung werden die vier elemente genauer betrachtet werden.

Das endergebnis der vorstebenden untersuchungen ist: 1. es ist methodisch unzulãssig, die Oervandilsage aus der Hymirsage zu ergãnzen. Anzuerkennen ist, dass Ise und Hymir den charakter eines eisriesen haben; alle anderen analogieen sind hinfällig. 2. Es ist methodisch unzulăssig, die Oervandiluberlieferung aus der Orendeluberlieferung, oder diese aus jener zu ergănzen. Anzuerkennen ist, dass die nordische fassung mit der rtickkebr des helden das urspringliche bewahrt hat, und dass dieses ursprthngliche erst von dem legendenschreiber in eine brautfahrt umgewandelt wurde. Alle anderen vergewaltigungen der deutschen sage sind zu verwerfen.

Einen bedeutenden schritt hat also die erkenntnis der deutschen sage vorwartsgetan; ihr inhalt war: ein held scheitert auf einer fahrt, weilt lăngere zeit bei einem eisriesen und kehrt dann zu seinem weibe heim, das er aus den hănden eines (oder mehrerer) freier erlost. Und zwar kehrt er unkenntlich heim (in einem schlechten, grauen rock). Vielleicht endlich hat er dem eisriesen knechtesdienste getan und ist gehalten, dereinst in seine frohnde zurtickzukehren.

In einer derartigen fassung ist die sage als eine in Deutschland weit verbreitete zu erweisen. Das meiste material fur sie hat Wilhelm Muller in dem anhang der niedersãchsischen sagen beigebracht; allerdings verquickt mit einer theorie, von welcher es erst zu erlösen ist, um nutzbar zu werden. 


\section{3. Die Müller-Uhlandsche heimkehrgruppe and die totenreichtheorie.}

Die von Muller ${ }^{1}$ ) beigebrachte erzăhlungsgruppe, die zunăchst aus Uhland, Schriften VIII, $419 \mathrm{ff}$. und einigen anderen, wenig ergiebigen sammlungen, in zweiter linie aber sehr wert-

1) Schambach-Muller, Niedersächsische sagen $389 \mathrm{ff}$. Anderweitige verweise werden bei denjenigen berichten erfolgen, welche nicht nach Miillers zusammenstellung widergegeben sind. - Im uibrigen erbebt die aufzïhlung keinen anspruch auf lickenlosigkeit; ein inductive methode hat ja nicht alle, sondern die bewoiskräftigen belege beizubringen. Anhangsweise seien hier erwähnt die anglo-normannischen sagen von kUnig Horn (roman et les aventures de Horn, ed. Michel: besonders in Schottland populär) und von Pontus und Sidonie (das letztere franz8sische gedicht ist in Deutschland als volksbuch verbreitet gewesen: bei Simrock XI, 1); ferner das englische gedicht Orfeon (ed. Zielke). Schwerlich in betracht zu ziehen ist die sage von graf Uds/rich bei Ekkebard (mon. germ. II, 119, bei Uhland VIII, 397): vielmehr zusammenzustellen mit Aimoin I, 13. 14 (zu $\nabla g l$. auch Greg. Tur. II, 28; aufgenommen in Grimm, Deutsche sagen II, nr. 430). - In letzter stunde teilt mir Berger mit, dass er anf grund eines märchens in dem Cabinet des Fés die von Muller und Uhland beigebrachten märchen und sagen fast durchweg als aus dem orient eingewanderte von der folgenden analogieensammlung anszuschliessen wilnscht. Dieselben bilden einen minder wichtigen toil meiner beweisfluhrung; da sie mir einerseits nicht dnrchgängig in abbängigkeit von dem oricntalischen, angenscheinlich buddhistischen, vorbild zu stehen scheinen, spdrerseits die grenze, wo das originalgermanische sufhört und die sngleichung an die orientalische uberlieferung oder die directe ubernahmo der letzteren beginnt, schwer zu bestimmen ist: so fuhre ich mein material in unveränderter vollstindigkeit an und uberlasse es der erwägung der einsichtigen, wo sie den sohnitt zu legen gedenken. In eine mythengeschichtliche erörterung des buddhistischen märchens (das so anffallend mit, nach unserer kenntnis der uberlieferungsverhältnisse, originalen griechischen, indisch-hieratischen und germanischen tiberlieferungen ubereinstimmt) trete icb, bei unserer fast vollkommenen unkenntnis der stoffquellen buddhistischer legenden, nicht ein. - Dass die anfrechterhaltung meiner sammlung nicht unberechtigt war, beweist auch das, erst nach abschlnss dieser abhandlung mir bekannt gewordene, von Laistner ns. 86 f. reproducierte Eifelmärchen von dem Trierer, der von dem aralten anf dem bock zu seiner sich neu vermählenden gattin heim gesant wird; eine jener uberlieferungen, bei denen es schwer zu sagen ist, ob heimische elemente an ein fremdes wandermärchen oder fremde elemente an ein heimisches mythenmärchen angewachsen sind. - Weitere verweise s. Beitr. XII, 431 (Vogt, Moringer). 
voll aus den Gesta Danorum und den Edden zu ergänzen ist, hat den gemeinsamen inhalt, dass ein edler herr, auf einer fahrt, vornehmlich nach dem osten, begriffen, in der ferne die nachricht erhält, dass sein weib im begriffe stehe, eine neue ehe einzugehen, auf wunderbare weise, fast durchweg in tublem und unkenntlichem aufzug, im momente der hochzeit zurtickkehrt und seine rechte geltend macht. Die sage ist sehr beliebt gewesen und viel gewandert, zum teil vielleicht von spielleuten verbreitet worden; wenigstens kehrt mit einer gewissen hartnäckigkeit das in des volkstuberlieferung wenig häufige, in der spielmănnischen kunst beliebtere motiv wider, dass der heimkehrende gatte sich vermittelst eines ringes $\mathrm{zu}$ erkennen gibt.

Ein furst von Braunschweig, oder auch direct Heinrich der löwe, wallfahrtet zum heiligen grabe; scheidend teilt er mit seiner gattin einen ring. Nach einer langen abenteuerzeit erfährt er von einem bösen dămon, oder direct dem teufel, dass sein weib, ubberzeugt von seinem tode, eine neue ehe einzugehen im begriff steht. Der böse macht mit ihm einen pakt auf seine seele, bei dem er aber dann zu kurz kommt, und trăgt ihn dafür durch die luft vor seine burg. Unkenntlich, mit langem haar wie ein wilder mann, erscheint er just beim hochzeitsschmauss, erbittet sich einen trunk, in den er seine ringhälfte fallen lässt, und alles nimmt ein gutes ende.

Gerhard von Holenbach (Caes. Heist.) und Wernhart ron Strättlingen (Kohlrusch, Schweizer sagen I, 56) wallfahren jeder zu seinem besonderen heiligen, nachdem sie mit ihrer gattin den ring geteilt haben, Gerhard ibr ausdrucklich die erlaubnis gegeben, falls er innerbalb einer bestimmten frist nicht widerkehre, eine neue ehe einzugehen. Beide verabsåumen die zeit; ein dämon oder der teufel selbst, dem sie einmal gutes erwiesen, trägt sie rechtzeitig heim. Sicut barbatus (Caes. Heist.), wie ein wilder mann erscheint Gerhard bei der hochzeit seines weibes, lässt die ringhălfte in den becher fallen, und alles nimmt ein gutes ende.

Der Moringer ${ }^{1}$ ) des spielmannliedes (Uhland, Volksl. nr. 298)

1) Die widerlegung der theorie, dass nicht der bekannte lyriker Heinrich von Morungen gemeint sei, sondern die entstellung eines appellativ meringer = marinaro (seefahrer) vorliege, durch Vogt, Beitr. XII, 
und ein französischer ritter (bei Bosquet) wallfahren in das heilige land; jener verpflichtet sein weib sieben jahre $\mathrm{zu}$ harren und verabsäumt die zeit, dieser duldet siebenjährige knechtschaft; beide fuhrt ein heiliger heim, just als die gattin zu einer neuen ehe schreitet; unerkannt erscheinen sie, der Moringer als pilger; der ehering dort, die ringhălfte bier offenbaren den ankömmling, und alles nimmt ein gutes ende.

Grimm, Deutsche sagen II, 96 (nach dem cod. pal. 336, fol. 259-67): - könig Karl fährt nach Ungarn wider die heiden. Zehn jahre soll sein weib seiner harren. Sende or seinen goldenen ring, so solle sie der botschaft glauben. Nach neun jahren lässt sie sich um der not des landes willen tiberreden, sich wider zu vermählen. Karl, durch einen engel benachrichtigt, reitet durch gottes wunder in gestrecktem galopp heim und kommt am hochzeitstage an. Er lăsst ihn aber ruhig vortbergehen, dieweil er in einer wirtschaft schmaust und schlät; nur dingt er einen knecht um seinen goldring, dass er ihn mit dem singosläuten wecke. Das tut denn der knecht, und der kaiser, um in den dom zu kommen, muss unter der burgpforte durchschlupfen und setzt sich, bis zur unkenntlichkeit mit kot besudelt, auf den konigsstuhl, das schwert uber knie; denn es steht im Frankenrecht geschrieben: wer auf dem stubl im dome sitzt, muss könig sein. Allgemeine verbluffung uber den fremden gast und ruhrende erkennungsscene sind selbstverståndlich. Offenbar ist alles verschoben; der könig lăsst nicht die hochzeit erst vortbergehn, sondern gibt sich beim mahl durch seinen ring zu erkennen, und alles nimmt ein gutes ende.

Uhl. VIII, 419 ff.: Hans von Bodmann aus einem geschlecht, dem das landfahren im blute gesteckt hat, ist gegenstand verschiedener uberlieferungen geworden. Er macht eine lange oder eine siebenjährige reise an das ende der welt oder um die welt; er lässt sogar in einer fassung sein weib versprechen, sieben jahre seiner zu harren. Nach einer version scheitert er und kommt auf eine wtuste insel, nach anderen an das ende

437 ist mir zu spät bekannt geworden, um sie zu verwerten. Ich bin von der ansicht ausgegangen, dass der deutsche spielmann durch den marinaro eines ihm bekannten liedes auf den viel beliebten Moringer geraten sei. 
der welt, jedenfalls zu dem nebelmännchen, das ihn unter gewissen bedingungen (s. Uhl. a. a. 0 . und Laistner, Nebelsagen 184: hier ist eine andere sage eingewachsen) heimfuhrt in dem augenblick, wo sein weib sich neu vermăhlen will. Ebenso geht es dem herrn von Stadion: ihn trăgt eine nebelwolke heim. Herr Hans kommt als bettler oder pilger zum hochzeitsschmaus, an einem trauring fehlt es nicht, und alles nimmt ein gutes ende.

Etwas von der allgemeinen schablone weicht ein dănisches heldenlied (bei Grimm 213) ab. Herr Lowmann freit schön Ingerlild und geht auf reisen. Acht jahre soll sio seiner harren. Die zeit vergeht, der brăutigam bleibt aus. Die brthder zwingen die betrubte braut, herrn Jord die hand zu reichen. Doch wie es an die hochzeit geht, erscheint der brăutigam, und mit ihm noch einmal ein gutes ende.

Zum letzten mal; denn nunmehr fuhren die zeugnisse weiter ruckwărts, die tăndelei hört auf, und der ernst beginnt. Zuvor sollen noch einige mårchen citiert werden, auf welche die gruppe einfluss gewonnen $z$ baben scheint: Baader 405, Kinder- und hausmärchen 92 (II, 41. III, 167), eine von Köhler (Germania III, $199 \mathrm{ff}$.) beigebrachte mårchengruppe, in welcher mit der asiatischen wanderfabel von dem jungling, der eine leiche vor schăndung beschirmt und von dem dankbaren toten vergunstigungen und schliesslich eine frau erhălt, widerholt das motiv verwachsen ist, dass der held von seiner verlobten durch die rănke eines nebenbuhlers getrennt, auf eine witste insel ausgesetzt oder verschlagen, von dem dankbaren toten wunderbar heimgefuhrt wird, rechtzeitig, zuweilen in unkenntlicher gestalt, bei der hochzeit seiner braut mit dem nebenbuhler erscheint und sich zuweilen durch den ring ausweist. Eine interessante gruppe stellt Muller (a. a. o. 400) zusammen, die, in verschobener fassung, den inhalt erschliessen lăsst: ein mann verlobt sich mit einem mãdchen, dient dem teufel sieben jahre und wird reich unter der bedingung, dass er sich in dieser zeit nicht wăscht, nicht die haare schlichtet noch die kleider wechselt, so dass er abscheulich entstellt heimkehrt und sich durch den ring zu erkennen geben muss.

Auf eine besondere stelle habe ich mir die interessanteste erzählung der Mullerschen sammlung aufgespart: ein graf von 
Calw verlăsst seine gattin, wandert in schlechter kleidung ${ }^{1}$ ) in das gebirge (die Schweiz) und tut hirtendienste (in einem dorfe). Er kehrt heim (entlassen von den unzufriedenen bewohnern, weil er immer den nămlichen berg abweide), erscheint in dem moment, wo seine gattin hochzeit machen will, erbittet unerkannt einen becher, lässt seinen trauring hineinfallen - und zieht wider zurtck in das gebirge an seine hirtenbeschăftigung. ${ }^{2}$ )

Damit schliesse ich die erste teilgruppe, die modernen erzăhlungen, und gehe zur heldensage tuber. Wir haben drei, beztiglich vier beispiele zu vermerken, alle von Saxo uberliefert; die beiden ersten zweimal das nămliche berichtend, nur mit verănderten namen: der held wird das eine mal mit seinem echten namen Haldanus genannt, das andere mal mit dem dichterischen königstitel Gram ${ }^{3}$ ), den Saxo für den namen hielt; ein missverständnis, das ihm, abermals bei Haldan, noch einmal passiert ist.

Die Halfdansage bei Saxo gehört zu den interessantesten capiteln seiner tuberlieferung. Es ist ebenso schwer bei ihr festzustellen, wo die heldensage aufhört und die göttersage beginnt, als inwieweit die abenteuer dem belden sagengeschichtlich zukommen, und wo Saxo anfăngt anderweitige stoffe anzuflechten. Saxo scheidet drei verschiedene personlichkeiten: den als einen Halfdan durch eddische parallelstellen belegten könig Gram, sohn des Skioldus, den Haldanus Biargrammus, der für einen sobn des Thor gegolten habe, und den Haldanus wit der gespaltenen lippe, den sohn Borkars. Allen dreien ist es gemeinsam, dass sie jungfrauen von unerwunschten bewerbern befreien. Eine originellere physiognomie hat im grunde nur der sohn Borkars, und gerade er scheint sie aus einem ganz fremden sagenkreis empfangen zu haben; die verknupfung mit der Drottasage ist jedenfalls das werk Sax08, und auch dieser dritte Haldan ist, wie die folgenden erörterungen wahrscheinlich machen werden, Halfdan der alte, ein weit und breit im norden sagenberthmter held. Eines jeden-

1) Was an der falschen stelle steht.

2) Diese überlieferung steht jedenfalls ausser bertihrung mit der wanderlegende.

3) Uhl. VI, 111 u. 112. 
falls darf man aus Saxos bericht ersehen: dass des Halfdan anknlupfung an das Skiobldungengeschlecht nicht uberall durchgedrungen ist; wenn er als Biargramm seine feinde vernichtet, indem er mit htlle eines gewissen Thor ${ }^{1}$ ) steinmassen von einem felsen auf sie herabwallzt, wenn er den riesen Harthbenus mit einem ungeheuren bammer erschlăgt und schliesslich direct fur einen sohn des Thor gehalten wird, so zeigt sich eine local durchgedrungene, völlig ausgebildete genealogische ankntupfung an Thor, und man kann wider daraus ersehen, dass genealogieen sagengeschichtliche resultate, nicht ausgangspunkte sind. Als identisch aber mit dem Skiōldungen Haldan (genannt 'dem alten') erweist ihn Saxos bericht, er babe 'als alter mann' den Grimmo erschlagen und die von ihm begehrte königstochter sich vermählt.

Von Haldan, dem sohne des Borkar, weiss Saxo zu berichten ${ }^{2}$ ), er habe liebe gefasst zu einer königstochter Gyuritha oder Guritha, die ihm aber als dem sohne eines unebenburtigen und ob einer entstellenden wunde an der lippe wenig geneigt gewesen sei. Er aber habe erklärt, or werde die schmach dieser abweisung mit grossen taten tilgen; sie solle ihm ihre hand frei wahren, bis sie die kunde seiner widerkunft oder aber seines todes erhalten. So ziebt or aus in kriege und gefahren; aber während er einen hohen ruhm begrundet, gibt Guritha dem werben eines anderen königs nach. Die kunde dringt zu Haldan; er verlăsst eilend sein heer und erscheint just bei der hochzeit, von niemand erkannt. Da tritt er vor die braut und singt eine herbe strophe auf seine hohen taten und die unverlăsslichkeit der weiber; sie gesteht ihm in einer gegenstrophe ihre liebe: aber ob der ungewissheit uber sein schicksal habe sie sich durch das drängen ihres hauses zu der neuen ehe bestimmen lassen. Noch ehe sie geendet, durchbohrt er den bräutigam und erschlăgt seine trunkenen leute.

1) Uhl. VI, 114 fuhrt die herboirufung eines grossen kriegers Thoro, wie die folgenden erörterungen dartun werden, mit recht auf eine an rufung des gottes Thor im original zurück, welche Saxo wie so manches andere missverstand: mit um so mehr recht, als s. 73 (bei Holder) der gott Thor selbst mit dem namen Thoro bezeichnet wird.

2) A. a. o. 242. 
Der spielmannsroman, den diese darstellung ubermittelt, wturde nur wenig mit der heimkehrgruppe zu stimmen scheinen, wenn nicht anderweitiges sagenmaterial, das eingehend zu erörtern hier nicht der platz ist, auf die einmischung einer fremden fabel hindeutete. Nur soviel sei gesagt, dass der charakteristische sagenzug des belden mit der gespaltenen lippe darauf hinaus zu laufen scheint, dass die geliebte, die er sich ersehen, ihm ihre hand nicht reichen will, bis sich die scharte seiner lippe ausgefullt habe, und, als es eine gewalttat gilt, ihm zu verstehen gibt, diese tat könne wol die scharte seiner lippe ausftillen.1) Wir sind so gltucklich, die uns hier interessierende sage bei $\mathrm{SaxO}^{2}$ ) in reinerer, entscheidender gestalt nachzuweisen. Sie lautet: könig Gram zieht wider einen kőnig zu felde; er erblickt dessen tochter, sein herz wird entzundet, und ein verlöbnis besiegelt den frieden. Von einem grossen kriege fern gehalten, vernimmi er plötzlich, dass der treulose vater seine braut einem auderen könige versprochen habe. Heimlich verlăsst er sein heer und erscheint in niederer kleidung beim hochzeitsmahl, unerkannt an unwurdiger stelle sich lagernd. Als sich aber die feiernden halb berauscht, singt er ein măchtiges lied auf seine grōsse und die treulosigkeit der weiber, erschlägt den falschen brăutigam and die meisten seiner trunkenen genossen und reisst die braut an sich.

In einer ganz ahnlichen situation erscheint Haldan in einem weiteren bericht bei Saxo.3) Ebbo4), ein pirata von niederer abkunft, verlangt Sygrutha, die tochter des kōnigs Unguinus, und das halbe reich dazu. Dieses verlangen ist in den sagen bei Saxo und auch anderwarts ${ }^{5}$ ) ein hăufiges; und zwar ist der fordernde gern ein riese, und die folge der forderung ist in allen făllen, dass tochter und reichshălfte dem

1) Vgl. die Svarfdälasaga (angefuhrt auch bei Uhl. VI, 125).

3) A. a. 0. 18.

3) A. 2. 0. 224.

4) Ebbo der pirata soll andrerorts der vater des Other, des umwerbers der Syritha (einer mit Sygrutha identischen personlichkeit: 8. u.) gewesen sein (bei Holder 225); der name ist vielleicht von hier aus lubernommen, wie denn Saxo mit namen sehr willkürlich umspringt.

s) Zu vgl. z. b. Grimm, Altdän. heldenlieder 59. 
helden verheissen werden, welcher dem unwillkommenen bewerber das handwerk legt. In dem vorliegenden fall ist diese einfache entwickelung nicht gegeben. Unguinus bittet den Haldan um hulfe, und dieser răt ihm, scheinbar sein jawort zu geben und die hochzeit zu rusten. Bei dieser hochzeit erscheint Haldan unkenntlich in niederer tracht (aber so hoheitsvoll, berichtet der orzăhler, dass alle die grösse des fremden ankömmlings ahnen), beschimpft den Ebbo als einen unebenburtigen, zwingt ihn zum kampf und erschlaggt ihn.

Endlich 1) erfährt Gram, der sohn des Skioldus, dass der könig Sigtrugus seine tochter Gro einem riesen verlobt habe. Entrustet uber diese unebenburtige ebe erscheint er in der tracht eines wilden mannes unkenntlich und erschlăgt - man sollte meinen, den riesischen brăutigam? nein, den vater der jungfrau. Das missverstăndnis Saxos besteht darin, dass er aus dem brăutigam Sigtrugus den vater gemacht hat. Aus dem Hyndlulied str. 15 verkntupft mit Skaldsk. 64 ersehen wir, dass Halfdan der alte die tochter Almweig (Hndll.) oder Alvig (Sk.) eines nachmals ibm befreundeten Eymund ehelicht, nachdem er einen kōnig Sigtrygg im zweikampf erschlagen (nach Hyndll. mit dem schwerte). In diesem falle ist der bericht Saxos, abgesehen von dem bezeichneten missverstandnis, der glaubwürdigere; denn 1. ergibt sich aus ihm, dass die ehe mit der königstochter und die erschlagung Sigtryggs in innerer beziehung stehen: insofern nämlich letzterer der (riesische) umwerber der ersteren war; 2. dass Halfdan zu diesem kampf in entstellender verwilderung erschien: ein durch obige analogieen als echt belegter zug; 3. dass Halfdan seinen gegner in einer ausserst charakteristischen weise erschlug: Saxo erzåhlt, Sigtrugus sei ein mit waffen unbesiegbarer held, aber (nach einer wahrsagung) mit gold zu bewältigen gewesen; darum habe Gram an seine keule gold befestigt und mit ihm seinen gegner erschlagen.2) Der name der befreiten und nachmals Halfdan vermăhlten jungfrau scheint verschiedenerorts

1) A. 2. 0. 13.

2) Vgl. die keule mit eisernen knoten oder die durch ausreissen eines baumstammes improvisierte keule neben dem hammer als waffe des Haldanus Biargrammus, und in einer sage bei Saxo die baumkeule als waffe des Haldan, sohn Borkars. 
verschieden genannt worden zu sein. Da aber die darstellung des Saxo als die echtere sich herausstellt, hat auch der von ihr beigebrachte name Gro die vermutung der ursprunglichkeit fur sich.

Ist aber der name Gro der ursprthngliche, so ergibt sich eine uberraschende combination. Nach der an erster stelle angefuhrten erzăhlung verlobt sich Haldan (wahrscheinlich endgultig, zum mindesten einseitig) einer königstochter Guritha, die in seiner abwesenheit von einem anderen, ungeliebten bewerber in anspruch genommen, im augenblick der hochzeit von dem unkenntlich oder unerkannt zurtuckkehrenden Haldan befreit wird: der afterbrăutigam wird erschlagen. Bei der besprechung von Saxos Horvendil-fassung nun nahm Uhland ${ }^{1}$ ) die nachmals dem helden anvermăhlte Gerutha2) als eine der Groa der Oervandilsage wesensidentische persōnlichkeit in anspruch, indem er den namen taber dånisch groede auf altn. gróði, gróðr gleich fruchtbarkeit uberleitete; eine, trotz etymologischer bedenken, bei Saxos nicht allzugervissenhafter widergabe der ihm, wol vielfach nur nach dem gehör bekannten namen, durchaus nicht von der hand zu weisende hypothese. Weit gewagter erscheint eine derartige ableitung des namens Guritha, Gyuritha, wird aber durch starke wahrscheinlichkeitsgrunde -nahezu gefordert. In der lieblichen sage von Alfs werbung um Alvilda berichtet Saxo ${ }^{3}$ ), wie Alf und sein freund Borkar ${ }^{4}$ ) die als viking verkleidete Alvilda uberwăltigen und als weib erkennen. Alf erzeugt mit ihr Guritha, Borkar mit ibrer freundin Gro den Harald Byldetand. Nach Saxo 246 aber ist dieser Harald der sohn der Guritha und des Haldan, sohn Borkars. Eiwägt man nun, dass das eintreten des blutsbruderschaftsmotivs in der spăteren deutschen sagenliteratur

1) VI, 32.

2) Das 'nachmals' ist so nichtssagend wie moglich; im Hyndlulied erschlägt auch Halfdan den Sigtrygg und heiratet nachmals dio Almveig.

3) A. a. 0. 229 .

4) Das freundschaftsmotiv, das in der gesamten nordischen literatur eine sehr einflussreiche stellnng einnahm und auch für die entwickelung der Nibelungen- und der Hildensage von belang wurde, spielt anch bei Saxo eine rolle und verdoppelt widerholt die gestalt seiner helden: vgl. Gram - Bessus, Hading - Liserus, Hotherus - Gelderus. 
fast durchweg ein accessorisches ist, folglich eine gewisse verschiebung des sagenbestandes bedeutet, so ist anzunehmen, dass unter den beiden genealogieen Saxos die letztere die vertrauenswurdigere ist, dass diese nach rthckwårts auf den neu eingetretenen freund zurtickverlegt wurde, und dass dabei an die stelle der Guritha die gleichbedeutende Gro trat.1) Rechnet man hierzu, dass eine Gro wie eine Guritha durch einen Halfdan in niederer, unkenntlicher gestalt einem afterbrăutigam entrissen wird, so ist zu schliessen, dass Gro und Guritha in der Halfdansage verwechselt wurden, weil sie mehr gemeinsames als das $G$ und das $r$ in ihren namen hatten.

Nach einer anderen richtung wird die zu dritt angefuhrte fassung der Haldansage von wichtigkeit. Unguinus hat eine tochter Sygrutha, die ein, wie es scheint, riesischer bewerber begebrt; Unguinus ruft Haldanus Biargrammus, den man fur einen sobn des Thor bălt, zu halfe, Haldan erscheint in niederer tracht bei der hochzeit und erschlägt den bewerber.

Des Unguinus sohn hat eine tochter Syritha, und diese hat einen liebeshandel mit einem Othar. Nun hat bereits W. Muller ${ }^{2}$ ) darauf aufmerksam gemacht, dass Syritha ein beiname der Freya ist, und wenn der roman von Othar und Syritha, wie er bei Saxo vorliegt, eine ganz unmythische, frei und schön erfundene, menschliche llebesgeschichte bietet, so ist doch die wahl der namen bedeutungsvoll. Sicher ist, dass Sygrutha und Syritha der nämliche name ist ${ }^{3}$ ), von Saxo aus zwei liedern entnommen, deren heldinnen or wegen der namensgleichbeit genealogisch verknupfte. Unguinus hat unter diesen umstånden Muller mit gutem grund fur eine entstellende latinisierung des Frey-namens Ingvi genommen und daraus auf eine entstellte sagenuberlieferung geschlossen, deren urspringlicherer unterlage ich in folgender fassung nahezukommen glaube: Ingvis schwester Syritha wird von einem

1) $\mathrm{Zu}$ der verschiebung des Borkar, des vaters von Gurithas gatten und grossvater des Harald, zu Borkar, dem gatten der Gro und vater des Harald, vgl. die oben vermutete verschiebung des Ebbo, des vaters von Syrithas bewerber, zu Ebbo, dem bewerber Sygruthas.

2) System 238. 283. 293 a. 1.

s) Vgl. in der isländischen sage von Asmund und Egil (Sagabl, II, 611) Asmund, sohn des Othar und der Sigrid. 
riesen begehrt; der herbeigerufene Thor erscheint in niederer tracht und erschlägt den falschen freier.

Hiermit sind wir bei der dritten teilgruppe angelangt: del göttersage. ${ }^{1}$ ) I. Eine mythische fabel in der gestalt, dass ein riese die hand nach Freya streckt nnd der aus dem osten heimkehrendo Thor ihn erschlägt, ist eddisch nachweislich. Die wichtigste sagenform muss etwas genauer betrachtet werden. Nach Gylf. 42 baben die gōtter eben Mitgard erschaffen und Walhall erbaut, als ein baumeister zu ihnen kommt und sich erbietet, ihnen in drei halbjahren eine burg gegen die riesen zu erbauen um den preis der Freya, der sonne und des mondes. Die asen sind es zufrieden, bemessen aber die zeit auf einen winter; ist er um und fehlt ein stein, ist der lohn verfallen. Auf Lokis rat darf der meister sein ross gebrauchen. Dieses schleppt ungeheure lasten, der bau wächst riesenschnell; als noch drei tage an der frist fehlen, ist schon das tor in angriff genommen. Da fragen sich die götter, wer geraten bätte Freya den riesen zu ubergeben und luft und himmel so zu verderben, dass sonne und mond hinweggenommen und den riesen gegeben wurden. Resultat: wio immer der arge Loki. Nun muss Loki helfen; er hilft mit der bekannten list, dass er als stute den hengst weglockt. Der baumeister gerät in riesenzorn, und nun erst erkennen die götter, dass er ein riese ist, rufen den im osten abwesenden Thor herbei, und dieser erschlägt den riesen.

Die stelle aus Gylf.: 'da fragen sich die götter' bis: 'den riesen gegeben wurden' enthălt eine willkurliche umschreibung eines Volluspavierses, den Gylf. zum schluss der darstellung anfuhrt: die götter hielten rat, wer die ganze luft mit verderben gemischt und Freya den riesen gegeben habe. Der verfasser von Gylf. kennt also die Völuspa; aber, und das ist festzuhalten: or umschreibt sie nicht lediglich, sondern er gibt aus seiner persōnlichen sagenkenntnis die darstellung und

1) Indem ich das einschlägige eddische material heranziehe, darf ich mich (mit einer ausnahme) wol auf meine erörterungen gelegentlich der Hymirsage berufen und bei minder wichtigen oder allzu complicierten belegen von einer eingehenden kritik der einzelsage absehen. 
sucht, wo seine kenntnis der sage eine abweichende ist, sich mit Völuspa auseinanderzusetzen. Es ist also methodisch unzulăssig, einseitig die Völuspa aus Gylf. zu ergånzen; in erster linie ist der spăte und unzuverlăssige bericht von Gylf. aus der weitaus altertumlicheren Völuspa zu controlieren.

Gylf. setzt den burgbau unmittelbar nach der weltschöpfung an, Völuspa hinter den vanenkampf; Gylf. als abzweckend auf schutz der götter gegen die riesen, Völuspa als dem bedürfnis der asen nach einer neuen burg entsprechend, nachdem die alte im vanenkampf zerstört worden war. ${ }^{1}$ ) Beide sind in diesem punkte gleich unzuverlăssig; Gylf. motiviert kindisch darauf los: wenn die götter eine burg brauchten, war es natürlich gegen die riesen! Völuspa schafft aus vorhandenem mythenmaterial ein frei dichterisches, monumentales, epoche machendes werk, eine theorie der ersten und letzten dinge, von weltbeginn bis weltuntergang; aber kaum ein mythus der Völuspa ist in ursprünglichem sinne gefasst, und ferner erfolgt die zusammenordnung der mythen nach freier combination und kunstlerischen principien. Die Völuspa veiss: die götter schliessen mit einem riesen einen burgbauvertrag und setzen als pfand Freya; nach Gylfaginning wissen sie nicht, mit wem sie abschliessen, erkennen die riesische natur des baumeisters erst, als die wettgefahr beseitigt ist; und ferner setzen sie ausser Freya noch sonne und mond als pfand. Indem sich der verfasser aber bemuht, dep ihm vorliegenden Völuspavers mit seinem bericht in das reine $\mathrm{zu}$ bringen, interpretiert er einerseits in seine auflösung des verses kecklich sonne und mond hinein und lăsst sich andrerseits nicht durch den umstand stören, dass auch die also modificierte auflösung seinem bericht strikt widerspricht. ${ }^{2}$ ) Nach Völuspa ist Thor der retter in der not, nach Gylf. Loki durch eine list ${ }^{3}$ ), die der spåten

1) Vgl. Mtllenhoff, D. 2. V, 99.

2) Man vergleiche die gotterfrage in der Volusps, wer die luft mit verderben gemischt und Freys den riesen gegeben habe, mit deren umschreibung in Gylf., wer geraten habe Freys den riesen zu ubergeben und die luft so $\mathrm{zu}$ verderben, dass son $\mathrm{n} \theta$ und mond hinweggenommen und den riesen gegeben witirden? Sonne und mond sind also hinein interpretiert, die riesen versäumt anszumerzen.

3) Man hat aus Lokis list die geistreichsten athmosphärischen alle- 
Oegisdrekka bekannt ist, aber darum nicht der altertumlichen Völuspa vorgelegen zu haben braucht; keine quelle ist so thel geeignet einen mythischen wertmassstab abzugeben als die offenbar ungenaue und allenthalben verdăchtige Oegisdrekka. Nach Völuspa bricht Thor mit der tötung des baumeisters den vertrag, nach Gylf. ist der vertrag erfullt, indem die burg mit sommers anbruch noch unvollendet ist. Somit ergibt sich fur Völuspa folgende fassung der sage als wahrscheinlich: wahrend Thor den winter uber im osten ist, schliesst ein riese mit den göttern den wettvertrag, im verlauf eines winters eine burg fertig zu bringen; gegeneinsatz ist. Freya. Den rat gab Loki. Die götter verlieren, aber der im lenz widerkehrende 'Thor missachtet den vertrag und erschlaggt den riesen. Damit, kundet Völuspa in ihrer grossartigen weise, schuf Thor das vorbild fur alle vertragsbrtiche und so einen grund mehr fur den weltuntergang.

Diese gestalt der tuberlieferung ist natturlich kein primitiver mythus sondern ein roman, dem ein primitiver mythus, eine naturanschauung, zu grunde liegt. Diese hier klar zu stellen, wurde zu weit fuhren. Soviel ist jedenfalls der darstellung zu entnehmen: 1. dass die riesen, was noch mehrfach bezeugt ist 1), nach Freya strebten, sie wahrend Thors abwesenheit im osten in die hände zu bekommen suchten und wol auch ursprunglich bekamen, bis der ruckkehrende Thor ihrer misswirtschaft ein ende machte; 2. dass diese misswirtschaft und Thors abwesenheit auf den winter fiel.

Weit schwieriger klar zu legen ist die parallelerzăblung von Thiazi und Itun; schwierig besonders deshalb, weil die natur der loün ñoch nịcht genugend festgestellt ist. Sie scheint sich in ihrer mythischen bedeutung sehr nahe mit Freya za berthbren; immerhin erscheint es gewagt ihren viel umstrittenen mythus in den bereich dieser untersuchungen $\mathrm{zu}$ ziehen. Ueber die natur der Freya herrscht verhăltnismåssige klarheit; gesichert jedenfalls ist ibre enge beziehung zur fruchtbarkeit.

gorieen hersusdeuten wollen, während sie ksum mehr ist als ein derber spielmannswitz!

1) Vgl. Brymskvioa und die weiter unten erfolgende analyse des Hrungnirkampfes. 
Eine fernere wichtige paralleluberlieferung verdanken wir dem Alvismal: einem lehrhaften wettgedicht ganz im geschmack der sinkenden kunst und des sinkenden heidentums, dessen ausgeduftelte wechselreden aber in, einen wertvollen rahmen gespannt sind, eine altmythische situation, des inhaltes, dass wăhrend Thors abwesenheit im osten ein zwerghaftes wesen Alvis sich seiner tochter verlobt habe; in dem augenblick, da Alvis die braut abholen will, folglich die hochzeit statt finden soll, kehrt Thor zurtick - und, meint man, erschlăgt ihn? Aber wo bliebe dann die mythische haarspalterei des verfassers! nein, er lässt sich auf einen wortkampf mit ihm ein, bis die aufsteigende sonne den 2 werg in stein verwandelt.

Man darf sich, um die situation zu verstehen, nicht auf den zwerg versteifen. Riese und zwerg sind mythisch keine gegensătze sondern differenzierungen. In der vedischen wie der germanischen mythik lässt sich aus zahlreichen belegen feststellen, dass sie in einander tbergehn.1) Sie sind urspringlich dămonen des winters, der finsternis, des athmosphärischen ubels; purs bedeutete fur ein nordländisches obr nicht riese sondern săufer, iōtunn nicht riese sondern fresser; der trōll steht fur den volksglauben zwischen riesen und zwerg mitten inne, und wenn Thor an Alvis etwas thursenhaftes bemerkt, so ist das nicht hohn sondern bitterer ernst.

Die tochter des Thor könnte uns hier leicht zu weitgehenden untersuchungen verleiten. Es ist uns ein name bruor fur sie uberliefert, der ein valkyrjennate ist. Eine untersuchung des valkyrjenmythus, die erst noch zu fuhren ist, kann belege fur die ansicht beibringen, dass die valkyrjen keineswegs von anbeginn ein monopol Oðins waren, dass sie, oder vielmehr die athmosphärischen dämonen, aus welchen sie nachweislich hervorgiengen, auch eine starke beziehung zu Thor hatten. Hier wage ich mythengeschichtlich aus dem angefuhrten material nur folgende schlusse zu ziehen: 1 . Thor ist den winter uber im osten. 2. Wăhrend dessen sucht eine tharsische macht sich einer göttlichen jungfrau athmosphärischer natur zu bemăchtigen, welche von wichtigkeit fur -die sommerliche frucht-

1) Vgl. Mannhardt, Germ. mythen $207 \mathrm{ff}$. 
barkeit der erde ist. 3. Im fruhjahr kebrt Thor zurllck und vernichtet den thurs.

Diese auffassung von Alvismal findet eine bestätigung in dem bruchstuck eines skaldenliedes (bei Rask, Sn. E. 162; schon von Uhland VI, 48 beigebracht), welches Hrungnir als dieb der Thruð bezeichnet; eine bezeichnung, welche zugleich die handhabe bietet fur das mythische verstăndnis der in cap. 17 der skalda erhaltenen spielmannsuberlieferung von Hrungnis kampf mit Thor. ${ }^{1}$ )

In Snorris widergabe lăsst dieselbe fünf teile unterscheiden. Der erste berichtet, dass, während Thor im osten weilt, um unholde zu bekämpfen, Oðinn auf Sleipnir nach Jötunheim reitet (also auch in den osten), wo er mit Hrungnir, einem riesen (also einem jener, von Thor zu bekämpfenden unholde, und zwar, wie spăter gesagt, deren stărkstem) einen wettkampf um den preis seines kopfes eingeht, ob sein ross Sleipnir oder Hrungnis ross Gullfaxi das schnellere sei. Hrungnir, in seinem jötunenzorn und ubereifer, den siegenden Ođ̌in zu tiberholen, gerăt unversehens innerhalb der asenmauern, hat somit die wette verloren und, da in der wette einsatz gegen einsatz steht, seinen kopf verspielt. 2. Davon ist jedoch keine rede; vielmehr laden die asen in liebenswurdigster weise ihren erbfeind zum trinkgelage. Es folgt eine derbe, in den ubermutigsten zugen gehaltene schilderung, wie der riese trunken gemacht wird und sich in den argsten prahlereien ergeht, Valhall davontragen, Asgard versenken, alle götter tōten, aber Freya und Sif fur sich behalten will; augenscheinlich zum vergntugen seiner göttlichen umgebung; wenigstens schenkt ihm Freya immer von neuem ein, bis das trunkene ungetum (wir hören wahrhaft sein lallen) sich vermisst, den gōttern all ihr öl wegzutrinken. Seines tollen treibens endlich mude, berufen diese den Thor, der, seinen hammer schwingend, sich uber eines riesen bewirtung in Valhall sehr aufgebracht gebårdet. Der bedrohte Hrungnir, durch den anblick seines erzfeindes offenbar erntichtert, beruft sich auf Oð̇ins frieden, den er, von ihm geladen, geniesse

1) Eine analyse der sage $\mathrm{gab}^{\mathrm{ab}}$ bereits Mannhardt, Germ. myth. 181 ff., wozu zu vergleichen 180. 154 ff., besonders 163 und 164. 
(wozu allerdings Thors feindselige berufung wenig passt), wirft Thor ein neidingswerk vor, wenn er ibn wehrlos tôte, und erbietet sich zu einem holmgang bei Griottunagary. Eine solche herausforderung ist Thor noch nicht vorgekommen; um so mehr willigt er ein. 3. Thor wird begleitet von Thialf. Dieser zweizahl gegenuber ist auch eine zweizahl der gegner erforderlich. Die jötune, fur ihren stärksten helden besorgt, fertigen ihm, merkwurdiger weise kunstlich, einen gefahrten, widerum merkwurdiger weise, aus lehm. Der kampf wird mit mehr ausfuhrlichkeit als anschaulichkeit beschrieben. Man stelle sich vor: Hrungnir schleudert auf den, in blitz und donner heranfahrenden Thor seinen schleifstein, der im flug von Thors hanmer zerschmettert wird; ein teil fährt in Thors stirn und wirft ihn kopfuber zur erde; zugleich sturzt Hrungnir vorwärts mit zerschelltem baupte und zwar so, dass sein fuss auf Thors bals zu liegen kommt. Wer glaubt dem dichter, dass er sich diesen vorgang klar gemacht babe?

An diesen ausgang kntupen sich zwei weitere episoden: a) des riesen fuss ist nicht von Thors hals zu entfernen. Da kommt Magni, Thors dreijähriger knabe, stōsst ihn fort und sagt: schmach und sehande, dass ich zu spăt gekommen bin; ich hătte den riesen mit der faust zu Hel gesant. Thor steht auf, belobt ihn, er werde ein tuchtiger mann werden, und schenkt ibn zum lohne Gullfaxi, zum ărger Oðins, der das ross selbst gern gehabt hătte. b) Das bruchstuck des schleifsteines ist nicht aus Thors stirn zu entfernen; und daran schliesst sich die Groaepisode.

An diesen bericht fugt Snorri ein bruchstuck aus Haustlong, einem, unter oyclischem gesichtspunkte verfassten gedichte des skalden Thiodolf aus dem neunten jahrhundert, das so wenig seine quelle war wie die Völuspa fur seine widergabe der baumeistersage. In einer grossartigen gewitterscene kămpft Thor wider Hrungnir und făllt ihn auf den schild (wol skaldisch fur: tōtet ihn). Ein stuck von des riesen schleifstein fliegt in Thors haupt und wird nachmals von Oelgefjun, d. i. der trankspenderin, entfernt. Das gedicht offenbart eine von Snorris bericht völlig abweichende uberlieferung; nichtsdestoweniger hat man jene in diese hineingelesen: bei Snorri will Thor seines steines durch Groa ledig 
werden, bei Thiodolf durch Oelgefjun; folglich ist Oelgefjun gleich Groa; obgleich Oelgefjun, die trankspenderin, unausweichlich ein valkyrjenname, Groa aber nicht allein nirgends unter letzteren aufgezăhlt, auch nach ihrer sinnfälligen bedeutung als valkyre unmöglich ist; obgleich ferner bei Thiodolf Thor des steines ledig wird, also für die Groaepisode kein raum verbleibt; obgleich somit sich fur eine vorurteilsfreie kritik der schluss ergibt, dass die ursprungliche uberlieferung, nach welcher Thor seines steines durch runenzauber einer göttlichen jungfrau ledig ward ${ }^{1}$, von einem galdrdichter, um als rahmensituation fur ein runengedicht nutzbar zu werden, auf den gehalt der Oervandilsage hin umgeprăgt wurde.

Eine tatsache ist jedenfalls mit der uberlieferung gegeben: dass der kampf Thors wider Hrungnir als solcher abgeschlossen besungen wurde. Es fragt sich nun, ob Thiodolfr einen teil der sage besungen oder Snorri, beztiglich seine vorlage, verschiedenartiges verschweisst hat.

Die uberlieferung Snorris fordert allerlei bedenken heraus. 1. Die ersten abschnitte widersprechen sich selbst: der erste: Thor zieht nach dem osten riesen zu bekampfen; zu derselben zeit reitet auch Orinn aus, und zwar auch er zu den riesen, nach dem osten, und zwar schliesst sich auch an seinen ausritt ein kampf: ein wettkampf. Dieser wettkampf wird widerum nicht ausgetragen, denn nachdem Oðinn gesiegt hat, bleibt der riese am leben. Der zweite: die gōtter gewăhren dem riesen Oðins frieden; als sie aber seiner trunkenen spassse uberdrussig sind, berufen sie Thor: naturlich, ibn zu tōten. Auch diese wendung fubrt noch nicht zur entscheidung: Hrungnir scheidet unversehrt; nur ein späterer kampf wird be-

1) Eine einfache logische consequenz der, wahrscheinlich, mythisch bedentsamen uberlieferung von 'Thors verletzung, welche für die phantasie nnmöglich endgultig sein konnte (nm so weniger, als die auffassung des also entstellten gottes weiterhin nicht selbständig belegt nnd ohne mythisches analogon zu sein scheint). Es ist uberhaupt für die sagenkritik wol zu beachten, dass die phantasie stets die consequenzen der gegebenen verhältnisse zieht: den sturmjäger, den sie auf der wolkenjagd ein weib verfolgen sieht, ebenda, die erbentete quer uber pferd, auf der rilckkehr wider findet. 
redet. 2. Die einzelnen teile des berichtes zeigen die tabermutige band eines echten und rechten spielmannes: a) Hrungnir sieht Oðin reiten und meint bewundernd, er babe ein gutes pferd. Oð̌inn erwidert höhnisch, er verwette sein haupt, dass Hrungnir kein so gutes habe. Hrungnir, erbost, will diese schmach nicht auf seinem ross Gullfaxi sitzen lassen, wirft sich auf dasselbe und setzt dem fliehenden Oðin nach. Sollte man glauben, dass ein mythologe diese scene ernst zu nehmen gedāchte? b) Die schilderung des asengelages: Hrungnis durst und unmåssigkeit, seine trunkenheit, seine prahlereien und als deren höhepunkt, dass er den asen all ihr öl austrinken will: eine scene von solch köstlich drastischem realismus, dass man die bänselung des ungefügen gastes von seinem ersten becherzug bis zu seiner plötzlichen schlimmen ernuchterung durchlebt: ein echtes spielmannsstuckchen. c) Hrungnir, obgleich der stărkste riese, soll einen helfer im kampfe haben und zwar keinen riesen, sondern einen kunstroll belebten lehmkoloss. Der koloss ist aber so ungeflig geraten, dass sich kein herz fur ihn findet, bis man ihn mit - einem stutenherzen versieht: vermutlich zur hebung seiner tapferkeit. Gegenuber dem steinriesen mit dem steinherzen der lehmriese mit dem stutenherzen - eine echt spielmännische erfindung. Er bezeigt sich auch seines herzens wüdig: als er Thor kommen sieht, lăsst er vor angst das wasser. Wer denkt da nicht an den entdeckten Morolf, der vor angst seinen wind fahren lässt? d) Hrungnir steht mit ungeheurem schild beschutzt; der schnellfussige Thialfi, seinem genossen voraufeilend, afft ihm vor, dass Thor ihn gesehen habe und nunmehr, unterhalb der erde einherfahrend, ihn von unten ankommen werde. Der geprellte riese wirft den schild unter die fusse und entblösst so sein haupt dem hammer. Diese erfindung ist so nair, dass sio sehr gläubige gemuter voraussetzt. e) Die episode mit Hrungnis fuss: die kraftprobe des dreijāhrigen Magni, seine burleske klage, dass or zu spät komme, um dem riesen mit einem faustschlage den garaus zu machen, Thors vaterstolz, der sich genau so ausnimmt wie der stolz eines behäbigen landmannes auf seinen krăftigen erstgeborenen, und Oซins ărger, dass ihm das schöne riesenross vor der nase weggeschenkt wird. f) Die bemerkung, dass aus den trummern von Hrungnis schleifstein 
såmtliche wetzsteine der welt entstanden seien, ist einerseits von einem durchaus băurisch-burlesk praktischem charakter und stimmt andrerseits zu der schliesslichen anknupfung eines volksbrauches, schleifsteine wegzuwerfen, an die zu funft orzählte Groa-Oervandilepisode.

Unter diesen verhältnissen ist es geboten, anzunehmen, dass 1. sämtliche fün teile des Snorrischen berichtes von spielmănnischer, und zwar der nămlichen hand herrtuhrten; 2. der hiermit gegebene grosse spielmannsgesang a) in bäuerlichen kreisen gesungen wurde, b) in durchaus willkturlicher woise gestaltet und rornehmlich auf die lachlust der hörer berechnet war, c) ähnlich den grossen deutschen spielmannsgedichten des zwölften jahrhunderts und ahnlich andrerseits der, ebenfalls in băurischen kreisen gesungenen Hymiskviða, einer, augenscheinlich sehr ausgebildeten hörelust durch verknlipfung möglichst vieler abenteuer zu gentigen suchte.

Hiermit ist die oben aufgeworfene frage dahin entschioden, dass der skalde Thiodolfr nicht einen teil der sage besang, sondern dass der in seinem lied enthaltene kern derselben von dem spielmann mit anderweitigen bestandteilen versetzt wurde. Gegeben war also ursprtinglich ein kampf Thors mit einem riesen Hrungnir. Diesen begrtundete der spielmann mit einer, wie wir gleich sehen werden, selbståndigen oder selbståndigem vorbild nachgebildeten uberlieferung, nach welcher Oð̌inn und Hrungnir in einem wettritt auf tod und leben nach Asgard kommen und Hrungnir unversehens in die asenmauern hineingerăt. Diesen wettritt hat der spielmann mit burlesker willktur eingeleitet und mit dem holm. gang durch ein burlesises mittelglied verbunden, das jedoch, wie sich zeigen wird, eines ernsthaften hintergrundes nicht entbehrt.

Widerum ist der holmgang seinerseits von dem spielmann burlesk ausgeschmuckt worden: den skaldenstrophen fehlen sowol Thors begleiter Thialfi wie der stutenherzige lehmriese, womit alle oben als spielmånnisch bezeichneten elemente in wegfall kommen. Allein da Thor und Thialfi eine durch allitteration beglaubigte $z$ weiheit bilden, so ist eine therlieferung nicht ausgeschlossen, der zu folge sie auch in den kampf mit Hrungnir verbunden eintraten. Diese zweiheit wïrde dann, 
wie schon oben angedeutet, den spielmann bewogen haben, dem Thialfi einen Möckurkalfi ${ }^{1}$ ) gegentuberzustellen, woraus sich denn alles weitere ergab. Dass im tubrigen die zweiheit Thor-Thialfi die verkntupfung von donner und blitz bedeute, hat Simrock, Handb. 300 erraten und Weinhold, Zs. fda. VII, 16 mit grunden nahe gelegt und ist durch Mannhardts untersuchungen uber den bockmythus (Germ. mythen 8. 43-63) nahezu bis zur gewissheit erhoben.

Die situation, mit welcher der spielmann den holmgang einleitet: der wettritt Oð̌ins und Hrungnis, kann nur zu einem einzigen ergebnis gefuhrt haben: zu Hrungnis tod nach verlorener wette. Die bedeutsame wendung der uberlieferung, dass der ubereifrig verfolgende Hrungnir unversehens, gleichsam im schuss, innerhalb der asenmauern gerăt, gibt den fingerzeig fur die auffassung des weiteren verlaufs: sie stellt sich zu der verfolgung des falken Loki durch den adler Thiazi, der seinen flug nicht mehr aufbalten kann und innerhalb der asenmauern gerät, wo er in, wio es scheint, verschieden uberlieferter weise getötet wurde²); und ferner zu dem wettflug des adlers Oð̇in und des adlers Suttung, dessen ende in der äusserst complicierten, verwirrten und unvollstandigen uberlieferung nicht erzählt wird. Bemerkt sei bier, dass Suttungr der brauser und Hrungnir der rauscher (schaller: vgl. Weinhold, Wiener sitzungsber. 1858 s. 272-73) wol zu einander passen.

Um so weniger passt diese, von Weinhold aufgestellte wahrscheinlichste etymologie des namens Hrungnir zu seiner eigenschaft als steinriesen. Als einen steinriesen bat ibn der spielmann gefasst: darum findet der kampf bei Griottunagaro, der geröllgrenze, statt, hat der riese ein steinernes herz, ein steinernes haupt, einen steinernen schild und eine steinerne waffe, und darum ist sein feiger gefăhrte ein gebilde von lehm. Es ist schon fruber angedeutet worden und kann auch

1) Es ist nicht ausgeschlossen, dass der spielmann in dem wasserlassenden Mückurkalfi einen verbreiteten, auch westgermanisch belegten ursprïnglichen regenmythus verwendete, der auch zur ausschmückung von Thors Geirröðfahrt herbalten musste.

2) Es kann bier nicht ausgefubrt werden, dass auch diese uberlieferung von sehr $\mathrm{zweifelhafter}$ ursprünglicbkeit ist. 
hier nur mit hinweis auf eine andrenorts zu fuhrende nähere begrundung wider hervorgehoben werden: dass die angeblichen stein- und felsriesen in wahrbeit bergriesen, und diese bergriesen riesen nicht der erdenberge sondern der wolkenberge waren: eine anschauung, die sich indogermanisch wie germanisch gentigend begrtinden lässt. Wie sich oben ergab, dass Oegir und Hymir keine irdischen bergriesen waren, so wird der riese Suttungr, der den himmelstrank in einem berg verbirgt, der vater der reifriesen genannt (vgl. Weinhold, W. s. 273), und so ist Hrungnir, der rauscher, mit seinen steinigen attributen unveroinbar.

Aus der gesamten tuberlieferung der Snorra-Edda ist somit zunăchst nur zu entnehmen: 1 . vielleicht ein mythus von einem wettritte des alten windgottes Oðin und des (sturmriesen?) Hrungnir. 2. Bestimmt: ein mythus des inhalts, dass Thor einen Hrungnir im kampfe erschlăgt. Der anlass dieses kampfes erbellt 1. aus der angefuhrten benennung Hrungnis als des răubers der Thruð. 2. aus seiner drohnng, Freya und Sif mitzunohmen: beides gottheiten, die in den angefuhrten heimkehrsagen die rolle der bedrohten spielen; eine bemerkung, die um so wichtiger ist, als aller wahrscheinlichkeit nach die vielen erzählungen von dem, stets rechtzeitig vereitelten fahnden riesischer măchte auf gottliche jungfrauen fortbildungen eines mythus sind, dem zu folge die begehrte jungfrau in der tat zeitweise in die hănde des bublerischen riesen fiel.1) 3. aus dem umstand, dass in Thors abwesenheit im osten Valhall von einem riesen besturmt und, wio es scheint, bedroht wird: denn eine bedrohung der götter war wol die veranlassung fur die ruckkehr des Thor, die der spielmann in einer tollen trunkenheitsscene begrub. ${ }^{2}$ ) Resultat der gesamten untersuchung ist somit die wahrscheinlichkeit eines mythus, dem zu folge während Thor's abwesenheit im winterland ein winterlicher

1) Belege fuir letzteren bieten der diebstahl der Thruo und der loun, die zu erwähnende buhlerei der Sif, der Frigg und, vielleicht, der gattin des Tyr, endlich die rahmenerzählung von Alvismal.

2) Dass die letztere an ein mythisch gegebenes moment des Thorglaubens anknilpfte, hat Mannhardt, Germ. myth. 101 wahrscheinlich gemacht. 
(sturm-?) dămon auf erden und im himmel sein wesen trieb 1 ), Freya, Sif oder Thruo (jo nach der uberlieferung) sich zu eigen zu machen suchte und schliesslich von dem beimkehrenden Thor erschlagen wurde. ${ }^{2}$ )

II. Es lässt sich ferner aus der Liederedda der beweis für einen mythus erbringen, dass Thor im lenze aus dem osten zurückkehrend in niederer, übler kleidung erscheint, ganz geeignet, ihn unkenntlich zu machen. Beizubringen ist für Thor persönlich allerdings nur ein einziges gedicht; doch kann man mit der fabel sagen: eines, aber ein löwe! Das Harbaroslied ist eines der kecksten, willkurlichsten, aber auch kunstlerisch bedeutsamsten und an altmythischem gehalt in relativ urspringlicher gestalt reichsten gedichte der Edda. Auf unwahrscheinlichkeiten und widerspruche hin darf man es freilich nicht prufen; es strotzt von beiden. Gleich die situation wåre ein kreuz für mythische hermeneutik. Thor kommt an einen sund: wo liegt derselbe? ist or die grenze zwischen riesen- und götterland? nein, denn Thor kommt aus dem osten, und spăter ist die rede von einem fluss, den er im osten gegen die riesen verteidigte. Fliesst er noch auf riesischem gebiet? es scheint so, denn Thor hält es für gefährlich, an dem ort, an welchen er sich befindet, seinen namen zu nennen: er ist dort vogelfrei. Wie aber kommt dann Obinn an den sund? wie kommt Oð̌inn uberbaupt dazu, den făhrmann zu machen? und wie kann er sich als viehhirten vorstellen in diesem zusammenhang? Der dichter wollte ein mythisches streitgedicht gestalten, didaktischen inbalts, aber von dramatischer form, ein grosszligiges kunstwerk; er braucht eine wirksame situation, und er schafft sie mit kecken strichen: irgendwo kommt Thor auf seinem wege vom riesen- zum götterland an einen sund, und just hier hat sich Oð̇inn aufgestellt, um ihn zu bänseln; der sund ist blosse situationsgehoben.

1) Immer als einmaliges ereignis aus der anschaung heraus-

2) Der kampf donnerkeil gegen steinkeil scheint, wie andrenorts auszufuhren ist, einen kampf im (früblings-?) gewitter, blitz gegen blitz zu bedeuten: widerum eine bereits indogermanisch belegbare naturanschanng: vgl. dies schlagende vedische analogon Mannhardt, Germ. myth. 163 . 
mache. Denn dass ein sund den grossen durchwater der himmelsströme aufhält, so dass er ihn tatsächlich nicht zu therschreiten vermag, wlirde entweder bezeugen, dass der glaube an den watenden Thor nicht, oder doch zur zeit der entstehung des gedichtes nicht mehr gemeingultig gewesen wäre, was nicht zu erwarten ist, da er in dem, an altertumlichkeit und eigenartigkeit der mythischen einzelzlige nicht hinter dem Harbarosliede zurlickstehenden Grimnismal bezeugt. ist; oder aber er ist mit souverăner laune uberschlagen. Man muss sich uberhaupt buten, die situation nach irgend einer seite hin ernst zu nehmen, etwa ein feindseliges verbăltnis Thors und Oð̌ins zu folgern; ein solch eingreifender mythus musste doch uberzeugender belegt sein als durch dieses harm. los scherzende streitgedicht. Schon Mullenhoff hat es mit recht als das charakteristische machwerk eines spielmanns bezeichnet, gesungen, wie Liliencron bewies, in ritterlichen kreisen: Orin kennzeichnend als das kecke, galante ritterideal gegenuber der im schweisse ihres angesichts bei kerger kost gegen naturgewalten ringenden bauernkraft; hier der adelige lebensgenuss, dort der 'stinkende atem' des niederen volkes; hier schneidiger witz, dort tölpelhaft zuschlagende bauernplumpheit.

Aber dieser gegensatz erklärt nicht alles in dem gedicht, erklärt namentlich nicht die ganz unbäuerliche erscheinung des Thor. Ich scheide darum folgende, für diese erörterungen betrăchliche mythischen zuge aus: 1. Thor kommt aus dem osten zurlick: im bettlergewand (baarbeinig, ohne hosen, schier wie ein strolch oder rossdieb), einem landstreicher ăhnlicher denn einem gott. 2. Thor findet aus dem osten zurluckkehrend seine mutter tot oder in einem totenähnlichen zustand. 1) 3. Thor findet aus dem osten zuruckkehrend bei seinem weibe einen bublen. 4. Thor wird einen korb auf dem rlucken dahinschreitend gedacht. Hierzu ist zu erinnern, dass fur den entwicklungsgrad eddischer mythenauffassung Thors mutter unzweifelhaft, Thors gattin wahrscheinlich die erde bedeutet.

1) Vgl. dass nach dem zeugnis von brymskv. Thor einem mythus zu folge den winter über schläft; und hierzu die eigentlimliche phrygische überlieferung, der $z u$ folge der jahreszeitengott den winter uber schlöft (Preller I, 107). 
Auf eine mythische buhlerei der Sif mit Loki scheint Oegisdrekka anzuspielen; aber es ist schon bemerkt, dass Oegisdrekka ein durchans unzuverlăssiger zeuge ist, widerholt 1) controlierbare mythen von anderen erzăhlt, als sie sonst berichtet werden, und namentlich die Lokimanie, die eine gewisse periode der nordischen mythengestaltung beherrscht hat, auf die ăusserste spitze treibt: geschieht eine buhlerei, ist Loki der buhler ${ }^{2}$ ); und 80 soll er auch der buhler der Sif gewesen sein. Das ist an sich sehr unwahrscheinlich, und man wird, wenn nicht beide zeugnisse auf Thor und Sif einen mythus tbertragen ${ }^{3}$ ), welcher zum mindesten ebenfalls, wie sich zeigen wird, zwischen Orin und Frigg gespielt hat, den mythus: 'Thor findet aus dem osten zurlickkehrend bei seiner gattin einen buhlen', nach analogie der parallelmythen zu erklären haben, nicht nach den faseleien der Oegisdrekka.

Einen weiteren beleg 4 ) fur einen mythus des inbalts, dass ein gott aus dem winterland in tubler, entstellter, unkenntlicher gestalt heimkehrt, bietet eine sagensippe, die von Fiölsviðmal, Skirnismal, Svendallied ${ }^{5}$ ), Grogaldr, Himinbjargarsaga ${ }^{6}$ ), Rindrsage ${ }^{7}$ ) gebildet wird. Ohne mich auf eine eingehende analyse dieser, eine eigene grosse untersuchung beanspruchenden sippe einzulassen ${ }^{8}$ ), scheide ich folgende selbständige, in den erwahnten gedichten in einander verwachsene primitive mythen aus: 1. Ein gott oder balbgott wirbt um eine jungfrau, die sich ihm nicht ergeben will und erst durch list, gewalt oder

1) Str. 17. 20. 26.

9) So in äusserst verdächtiger weise str. 40 mit Tys weib (hierliber wird weiter unten gehandelt werden) und str. 52 mit Skadi: an die letztere angabe schliesst sich das anf Sif bezügliche strophenpar.

3) Was spätere erörterungen uber die Tyrsage ebenfalls sehr unwabrscheinlich machen werden.

4) Ein dritter wird später beigebracht werden.

5) Bei Grundtvig, Danm. gaml. Folkv. II, 239 ff. (übersetzt von Llining Edda 23 ff.).

\%) K. Maurer, Isländische volkssagen 312.

7) Besonders ausfuhrlich bei Saxo a. a. 0.78.

8) Ich verwahre mich aber ausdrücklich gegen den, vielleicht nahe liegenden verdacht, als ob ich den mit dieser sippe getriebenen unfug mitmachte und beispielsweise die stiefmutter des Svendalliedes in Fiølsviomal hineinprakticierte. 
drobungen bezwungen werden muss. 2. Eine jungfrau wird gefangen gehalten hinter gewaltigem gitter, behtitet von heulenden hunden und einem furchtbaren wächter (die waberlohe erlaube ich mir zu ubergehen; sie erfordert ein eigenes capitel); ein gott oder halbgott erschlägt dieselben und befreit sie. 3. Ein gott oder halbgott muss den winter tber in einem fernen lande verweilen, fern von einer geliebten, welcheseiner harrt. 4. Die jungfrau wird zuweilen in dieser zeit schlafend vorgestellt (eine vielfach belegbare und bis in den heutigen volksglauben $\mathrm{zu}$ verfolgende anschauung). ${ }^{1}$ ) 5. In einem fall orscheint der jungling (Svipdagr) in schlechter land streicherhafter tracht, unkenntlich selbst der geliebten, bis er sich nennt. In der ganzen gruppe aber handelt es sich nachweislich um lauter jahreszeitenmythen ${ }^{2}$ ); freilich in sehr verschobener und dichterisch individualisierter gestalt.

Man sieht also, dass die ruckkehr aus dem winterland 1. keine innerlich naturnotwendige beziehung $\mathrm{zu}$ der bublerei der gattin hat (Svipdagr), 2. ohne das moment der bettlertracht vorkommt (Srendal).

Nunmehr haben wir den thberblick gewonnen, um mit bestimmtheit erklären zu können: entweder sind in der beldensage an die persönlichkeit Halfdans des atten eine reihe Thorsagen angewachsen, oder sie sind auf ihn von Saxo ubertragen worden. Haldanus, der in unkenntlicher geetalt herbeieilt einen riesen $\mathrm{zu}$ erschlagen, welcher um eine jungfrau, seine gegenwărtige oder zukuuftige braut, buhlt, und ihn mit einem hammer oder einer keule bewaltigt, vollbringt eine Thorstat; der riese, der nur mit der vergoldeten keule erschlagen werden kann, wird mit dem goldleuchtenden blitze dabingerafft; Haldan, der auf den bulferuf des Unguinus in unkenntlicher niederer gestalt erscheint und Sygrutha aus den armen eines unwtirdigen bräutigams reisst, ist direct Thor, der aus dem osten, dem winterland, zurlickkehrend den riesischen umwerber der Freya erschlăgt. Hier ist noch eine interessante uberlieferung zu orörtern. Gram (Haldan) der die Gro aus Sigtrugs hănden er-

') Vgl. das oben zu der schlafenden mutter Thors bemerkte.

2) Hier sei nur darauf verwiesen, dass Svipdagr sich sohn des Frublingskalt nennt. 
löst, heisst der sohn des Skioldus und der Avilda (bei Saxo gleich Alf hild). Guritha, die durch Haldan (Borkars sohn) aus den hănden eines unwillkommenen freiers erlöst wird, heisst die tochter des Alf und der Alvilda. Die tochter eines Alf namens Alfhild nun wird Forns. I, $412 \mathrm{ff}$. von einem riesen Starkad geraubt, der vater ruft Thor zu hulfe, und dieser erschlăgt den răuber. Von dem nämlichen Starkað wird (ebenda) berichtet, dass eine ihm verlobte jungfrau während seiner abwesenheit jenseits der Elivagar das weib des riesen Hergrim (nachmals vaters eines Grim) geworden sei, Starkaðr aber zurtickkehrend den nebenbuhler erschlagen habe. Die anknupfung der so gestalteten sage an den riesen und frauenräuber Starkað ist auf den ersten blick äusserst unwahrscheinlich; in der tat haben wir bei Sax01) den interessanten bericht, dass Haldan einen Grimmo ${ }^{2}$ ), welcher eine königstochter Thorhilda begehrte, erschlagen und diese geehelicht habe. Nach den obigen erörterungen uber Haldans sagengeschichtliche bedeutung ist es gestattet zu schliessen, dass ursprtanglich Thor von den Elivagar zurtickkehrend den Grim oder Hergrim erschlug, so dass sich aus einer sage: Thor erscblägt den riesen Starkað, der eine jungfrau umbuhlt, und einer weiteren: Thor erschlaggt, von den Elivagar heimkebrend, den riesen Grimm, der eine jungfrau umbuhlt, eine verwirrte taberlieferrung sich bildete, nach welcher Starka or seinen nebenbuhler Grim erschlug.

Mit diesen ergebnissen ist ferner der standpunkt gewonnen, um einen weiteren sagencomplex heranzuziehen, dessen uberlieferung an schwierigkeit ihresgleichen sucht und fur den hier in betracht kommenden Theil ihre aufklărung wesentlich dem scharfsinn Laistners verdankt. Die Baldrsage ist in zwei sippen von gedichten und traditionen erhalten, deren eine in den Edden, deren zweite in den gestis Danorum uberliefert ist. Die erstere ist ganz in den, einen grossen teil der eddischen mythik beherrschenden weltuntergangscyclus eingearbeitet; für das göttersystem, den götterhimmel der Edden ist Baldr lediglich der junge, allgeliebte gott, dessen tod den welt-

1) A. a. 0. 223 .

2) Vgl. 8. 40 a. 1 Thoro für Thor. 
untergang eröffnet. Darum sind an die schilderung dieses welterschutternden ereignisses mit liebevoller sorgfalt kunstlerische zutaten gekntipit worden, welche, ganz anderen anschauungskreisen zugehörig, durch ihre innere grossartigkeit die bedeutsamkeit des ereignisses hervorzuarbeiten und in eine dustere, ahnungsschwere, abendliche gewitterbeleuchtung $\mathrm{zu}$ versetzen geeignet sind. ${ }^{\text {) }}$ Aber der alte jahreszeitenmythus schimmert durch: nachdem Baldr gestorben ist, erzeugt der jahreszeitengott Oðinn mit der starren, winterlichen erde einen neuen frubling; oder aber: nachdem der fruhere sommergett dem wintergott erlegen, erscheint sein bruder, der neue frthbling und erschlägt den widersacher: ein mythus, der, in unseren uberlieferungen mit dem ersteren verwachsen, ursprunglich wol, unabhängig, dem deutschen zwillingsmythus angehörte, dem ihn Mullenhoff zugeordnet hat.

Ich habe die Saxosche uberlieferung der Baldrsage als eine sippe von liedern und traditionen bezeichnet. In der tat tritt nirgends so grell die unvereinbarte mannigfaltigkeit der quellen des dänischen chronisten hervor wie in dieser partio seiner pseudogeschichte. Als ein typisches beispiel hierfur, wio fur seine art, die ihm zu gebote stehenden vorlagen zu verarbeiten, benötigt sie eine eingehende bohandlung. ${ }^{2}$ )

I. Hotherus ist der sohn des schwedenkönigs Hodbroddus und bruder des Athislus, mit dem er einem gewissen Gewarus (einem verdienten mann: s. 52; nach s. 69 ff. einem konig, 8. 82 scheint es: von Norwegen) zur erziehung ubergeben wird. Nachdem sein vater auf einem kriegszug gegen Danemark durch Helgo dem Hundingtōter gefallen ist ${ }^{3}$ ) (8.53), verbleibt or allein an des Gêwairius hof (die taten des Athislus werden 53 f. erzählt). II. Herangewachsen, zeichnet er sich durch grosse leibesstărke4) und in allen körperlichen tubungen wio

2) Eine eingehende klarlegang dieser ersten sippe wird an anderem ort erfolgen.

2) Sie ist im wesentlichen im dritten buch der gesta enthalten (bei Holder 69 ff.). Weiteres im 2 weiten buch (b. H. 52. 53).

s) Sehr bezeichnend fur Saxos verkntipfung seiner helden mit sagenberïhmten geschlechtern.

4) Das muss collacteis et coaevis summa corporis firmitate praestabat $(69,11.12)$ bedeuten, wenngleich 70,35 sacram corporis firmitatem 
schwimmen, bogenspannen, riemenkampf aus; besonders aber war er jeder art saitenspieles măchtig und beherrschte mit ihm alle guten und schlechten leidenschaften der menschen. III. Durch diese kunste entztindet, begehrte Nanna, die tochter Gewars, nach Hothers umarmung (folgt eine sentenz uber die ursachen der liebe). IV. Es geschah aber, dass des Othinus sohn Balderus Nanna im bade erblickte und in heftiger leidenschaft zu ihr entbrannte (denn der stärkste anreiz der begierde ist die schōnheit). Darum beschliesst or Hother zu tōten. V. Zu der nämlichen zeit etwa verirrt sich Hother auf der jagd im nebel und gelangt in das gemach von waldjungfrauen, die ibn mit namen anreden und, tuber ihre wesenheit befragt, sich als valkyrjen bekennen: sie walten des kriegsschicksals, unsichtbar den schlachten beiwohnend und unvermerkt ihren schutzlingen zur seite stehend. Sie belehren ihn, dass Balder seine (des Hother) milchschwester beim bade belauschte und in liebe zu ihr entztundet sei. Sie warnen ihn ferner, den gegner, so hassenswturdig er sei, mit waffen zu bekămpfen, als einen halbgott aus göttlichem samen. Nachdem sie also gesprochen, schwinden behausung und wald, und auf freiem feld, unter freiem himmel findet Hother sich wider. VI. Er berichtet Gewar sein erlebnis und balt sofort um Nanna an. Der vater bedauert, ihm nicht, seinem berzen folgend, sein jawort geben zu können; aber er furchtet Balders hass, dessen werbung dem nebenbuhler zurorgekommen. Denn die heilige unverletzlichkeit seines körpers sei jeder waffe unzuganglich. Nur ein ihm verderbliches schwert gibt es: es bofindet sich in den handen eines waldgeistes Miming, zugleich mit einem schatze mehrenden armring. Der zugang aber sei schwierig fur menschen zu gewinnen: uber, von entsetzlicher kălte starrende joche fuhre der pfad, den er am ehesten mit einem schnellen birschgespann uberwinden werde. Angelangt, habe er sein zelt, der sonne abgekehrt, so zu richten, dass es den schatten von Mimings grotte empfange, ohne, bei wechselnder $\left.{ }^{1}\right)$ beleuchtung, den geist mit seinem ungewohnten schat-

anf die unverwundbarkeit Balders geht. Andrenfallo wirde sich Saxo anders ansgedritickt haben.

1) Dies ist die bier allein mơgliche tbersetzung von mutua (obumbracione). 
ten von dem ausgang der höhle (zurtick) zu scheuchen (nämlich: wenn er sie verlassen will). VII. Hother befolgt den gegebenen rat. Nachts hăngt or im zelte seinen sorgen ${ }^{1)}$ und vorbereitungen nach, tags versieht er sich jagend mit lebensmitteln. Als er einst nachts in seinen sorgen erschlaffit, trifft der schatten des geistes sein zelt ${ }^{2}$ ); er schleudert ihn mit der lanze nieder, fesselt ihn und erzwingt mit schlägen die herausgabe der kleinodien (folgt eine sentenz ther die liebe zum leben). Mit anderen worten: Hother lauert allnăchtlich, ob der geist nicht die höhle verlăsst. In dem moment, wo er des wartens mulde wird, fällt der schatten des geistes auf sein zelt, und er bewalltigt inn.

Saxo spricht sich zu anfang des dritten buches uber die grundsătze aus, nach denen er die geschichte Hothers erzăhlt.3) Er will pragmatisch verfahren, nicht die uberlieferungen widergeben sondern auf grund des uberlieferten die dinge darstellen, wie sie auf einander folgten und sich auseinander entwickelten. Er nimmt also aus seinen quellen vorauf, was ihm fur die darstellung vorauf zu gehören scheint, und ergänzt, die handlung schritt fur schritt weiter fubrend, die sprunge der uberlieferung nach eigener phantasie, die einzelnen scenen widerum nach eigenstem dichterischem nachempfinden ausgestaltend. Erste frage ist: von wem stammt Hother, wann ward er geboren, wie reiht er sich in die nordiscben kōnigsreiben und geschichtlichen verkettungen ein. Die năchste lautet: wie ward or mit Nanna bekannt? Die antwort wird gemäss einer sehr verbreiteten 4) nordischen sitte gegeben: Hother wird in Gewars haus erzogen. An eine derartige erziehung eines jungen edlen in befreundetem hause knulpfen sich gern blutsbrtderschaften; Hother findet zwar keinen blutsbruder, aber eine milchschwester. Indem der dichter nun den herrlich heranwachsenden jüngling schildert, wie er an körper-

1) So ist curss zu übersetzen: $\nabla g l$. 71,18 attonits curis mente.

8) 'Irotz der verbltifienden construction: obumbrantem tabernaculo ist dieselbe sinnfällig notwendig anzunehmen.

3) huius tempora, si ab etatis eius origine cepero, aptius explicabuntur. pulchrius enim pleniusque extrems annorum illius curricula perstringuntur, ubi prima silencio non damnantur, b. H. $69,6 \mathrm{ff}$.

4) Vgl. Weinhold, Altnord. leben $285 \mathrm{f}$. 
stårke und jeglicher leibestugend alle altersgenossen ubertrifft, zieht er eine eigenschaft seines helden heran, thber die ihn ein später benutztes spielmannslied (XIX) belehrte: Hother war auch ein grosser spielmann. ${ }^{1}$ ) Bei solchen eigenschaften war es kein wunder, dass Nanna ihr herz an ihn verlor.

Diese kritik der uberlieferung Saxos ist um so berechtigter, als sie sich an der erzählung von Balders erwachender liebesnot beståtigt. $\mathrm{Z}$ weimal wird dieselbe berichtet: einmal pragmatisch vorausgenommen, das 2 weite mal innerhalb einer ausfuhrlich widergegebenen quelle. $\mathrm{V}$ ist augenscheinlich ein in sich geschlossenes lied: Hother, auf der jagd durch nebel irre geleitet, kommt zu der behausung ron waldjungfrauen. Sie reden ihn mit namen an. Er befragt sie erstaunt nach ihrer wesenheit. Sie bekennen sich als valkyrjen, belehren ihn, dass Balder Nanna liebt, und warnen ihn, Balder zu bekämpfen. Als sie gesprochen, zerfliesst und verschwindet, alles, und Hother steht auf offenem feld unter freiem himmel.

Die begründung ihrer warnung vor einem kampf mit Balder ist allerdings von echtem geprăge mönchischer chronistenerfindung. Hother ist ein schwedischer könig, Balder ein gott; wie kann ein mensch gegen einen gott kămpfen? Mit diesem wirrsal sucht sich Saxo in seinem ganzen boricht vergebens abzufinden.

Andrerseits kann das gespräch schon okonomisch mit der warnung nicht abgeschlossen haben; die warnung muss vernthftig begrthndet worden sein. Die folgende unterredung mit Gewar, die mit einer naiv banalen familienscene beginnt (hervorgerufen durch das pragmatische bedurfnis, nunmehr die werbung Hothers eintreten zu lassen, und weiter unten (X) in verstärkter kindlichkeit sich widerholend) widerholt die war-

1) Man hat in sehr unvorsichtiger weise die spielmannskünste Hothers als eine altmythische vorstellung mit den sturmesmelodien des wilden heeres zusammengestellt, ohne auch nur den geringsten anhalt fur eine sturmnatur Hothers oder gar ein einherfahren in der wolkenjagd zu haben. Mit derselben berechtigung kơnnte man aus Sax0s bericht schliessen, dass Hother ein grosser jäger war wie Uller, ein grosser schwimmer wie Beownlf und Breks, gewaltig mit dem kampfriemen wie - nun, wenn sich kein anslogon findet, so vielleicht eine geistreiche homonymie, um anch hier die liberliefernng wort fur wort anszadenten. 
nung, aber nit einer ursprünglicheren begrundung: Balder ist unverwundbar. Es gibt allerdings ein werkzeug, ihn zu vernichten; dieses aber ist in den eisregionen, den winterbergen verborgen und schwer zu gewinnen. Hother gewinnt es in einer stimmungsvollen mondscheinscene.

In diesem teile der uberlieferung hat die eddische sippe das ursprtinglichere. Ein gott, der allein unter seinesgleichen unverwundbar ist, ist als solcher ein mythisches unding und der heldensage angehörig ${ }^{1}$ ); in der eddischen uberlieferung aber sehen wir dieses motiv organisch aus dem bedurfnis erwachsen, den götterliebling, mit dessen tod der weltuntergang anhebt, am leben zu erhalten. Er ist nicht unverwundbar, aber alle dinge haben sich verpflichtet ihn nicht zu versehren; ubersehen wurde nur die mistel, und diese verdankt wol ihre wahl dem zusammenklang mit mist nebel. Das lied, welches Saxo vorlag, steht auf dem standpunkt der eddischen sippe: Balder soll sterben. Es gibt aber diesen sagenstand in einer noch späteren, entstellenderen weiterbildung: Balder ist unverwundbar, nur ein bestimmtes schwert vermag ihn zu töten, dieses ist nicht in sondern jenseits der eisregion ${ }^{2}$ ) verborgen, diese mit einem schnellen hirschgespann zu therwinden, der huter ein Miming, in dessen hănden ausserdem noch der typische schätze mehrende ring. Offenbar eine inhaltlich verschobene, und ferner willkurlich ausschmtlckende dichtung; wie sich noch eine zweite quelle (XIX) der dänischen sippe als eine sagengeschichtlich spåte ergeben wird.

Die beiden abenteuer, welche Saxo an die gewinnung von ring und schwert kntupt, sird sehr bezeichnend fur sein ver; fahren. Das erstê (VIII) ist ein kampf mit einem Sachsenkönig Gelderus, der, in einer kriegslist gipfelnd, in dieser eigentlich seinen inhalt hat. Angeknupft wird or durch Gel-

1) Auch in anderer beziehung gehört diese vorlage Saxos der heldensage an: Hother und Balder stehen einander nicht als götter sondern als heroen gegenliber; der siegreiche held ist der von den valkyrjen bevorzugte; und indem nach beliebter schablone der sagengehalt in ein prophetisches gespräch gekleidet wird, ergeht der siegverheissende nornenrat an den unholden winterdämon.

9) Die eierschalen des jahreszeitenmythus hat der nordischo weltuntergangscyclus nie abzustreifen vermocht. 
ders begierde, die beruhmten kleinodien ihrem glucklichen gewinner zu entreissen; der abschluss ist verdiente niederlage, versöhnung und freundschaft. Das zweite (IX) ist die ubliche werbung durch einen gewichtigen gönner ${ }^{1}$ ), die Hother fur einen Helgo von Halogaland um die tochter des stolzen Finnenkōnigs tubernimmt: eine, augenscheinlich ubel widergegebene schablonenerzählung. $X$. Während dieser abwesenheit Hothers?) erscheint Balder mit heeresmacht, um Nanna zu verlangen. Der vater zuckt die achseln und verweist ibn an die tochter; die tochter erteilt ihm einen regelrechten korb: eine ehe zwischen göttern und menschen könne nicht zum guten ausschlagen: einmal, weil der unterschied zu gross sei; sodann, weil auf die treue der gōtter nicht zu bauen; sodann, weil der unterschied zu gross sei, sodann, weil noch einmal der unterschied zu gross sei, endlich aber, weil noch einmal der unterschied zu gross sei. Und Balder zieht mit seinem heere wider ab. Diese partie ist auch für den tollsten spielmann zu einfältig und trägt ganz das gepräge Saxoscher erfindungsgabe. ${ }^{3}$ ) Sie ist, wie vieles andere, von der kritik der uberlieferung einfach zu kassieren.

XI. Hother ist uber Balders frechheit auf das ausserste entrlistet und beklagt sich bitter bei Helgo (folgt eine sentenz uber die woltat freundschaftlicher herzensergiessungen). Nach langem schwanken wird krieg beschlossen. XII. Eine seeschlacht von göttern wider menschen: gegen Hother, Gelder und Helgo mit ihren heeren streiten Balderus, Othinus und Thoro mit den heiligen gotterschaaren. Hother, in einem undurchdringlichen gewande, whtet unter den göttern, soweit das ein mensch unter göttern kann; Thoro aber schmettert alles mit einer einer entsetzlichen keule nieder (4), bis es Hotber gelingt, dieselbe durch abschlagen des griffs untauglich $\mathrm{zu}$ machen. Dieser waffe beraubt, fliehen die götter: unglaublich, aber wahr; es waren eben nur sogenannte götter. Balder rettet die flucht.

1) Vgl. Weinhold $239 \mathrm{f}$.

2) Man beachte die pragmatische verknlipfung.

8) Vgl. 76, 19-23.

4) Er fordert die feinde auf, mit gleicher zahl wider gleiche zahl zu kämpfen (73, 30. 31): also ein zweikampf, den aber Saxo sofort wider fallen lässt: irgend eipe erinnerung klingt in seinen obren. 
XII a. Die feindlichen schiffe werden zerstört, der fliehende rest verfolgt (folgt eine sentenz uber die masslosigkeit des erfolges). Das andenken der schlacht bewahrt die ortliche bezeichnung: Balders hafen. Der in der schlacht gefallene Gelder wird feierlich begraben, Helgo und seine junge gattin in herrlichkeit heimgeleitet. Hother heiratet nun seine geliebte Nanna, damit nicht von neuem etwas dazwischen kommt. Er fubrt seine junge gattin nach Schweden: so ruhmreich durch seinen sieg wie Balder lächerlich durch seine niederlage.1)

Die uberlieferung dieses abschnittes erklärt sich durch Saxos vorliebe für schlachtenschilderungen in romanhafter breite. Ein kampf Hothers einerseits gegen Balder, Othin und Thor ist selbstverstăndlich mythisch nie tuberliefert worden, vielmehr ein kampf lediglich 2 wischen Hother und Balder. Immerhin schmuckt die uberlieferung diesen kampf. mit echten ztigen; dass Thor nach einer (fur sich bestehenden) jahreszeitlichen anschauung den winter ther des hammers verlustig war, lehrt der anfang von Drymskviða, und den verkurzten hammerstiel hat bereits Grimm (M. 150) durch eddische thberlieferung als (an sich) mythisch belegt..2) Beide umstande sind hier, wie die ortsbenennung: Balders hafen, ganz willkurlich herangezogen und ein, weiterhin (XIII. XIV) durch andere belege gestutzter anbalt, dass Saxo alles, was sich irgend an Balders oder Hothers namen kntupt: lieder, traditionen, ortsbennungen, in seine gesamterzählung einzuflechten bestrebt war.

XIII. Aber Hother musste bald den wankelmut des gluckes erfabren. Von Balder geschlagen, floh er zu Gewar. Der siegreiche Balder, um seinem verdurstenden heere labung zu verschaffen, wublte den boden auf und erweckte einen quell, der noch heute seinen namen trăgt.s) Im tubrigen blieb der sieg

1) Eine für Saxos missverstz̈ndnis des eigentlichen mythischen gehaltes seiner vorlagen sehr bezeichnende bemerkung.

2) Vielleicht sogar eine indogermanische anschanng: vgl. Mannhardt, Germanische mythen 108. Einen weiteren, sehr bedeutsamen beleg des deutschen hammermythus bringt Wolf, Beiträge z. d. m. I, 66 bei.

3) Mit ihm erscheint auch der götter statthalter Fro und nimmt den sitz zu Upsala ein, allda scheusliche opfer empfangend: ein neuer beleg, dass Saxo keine gelegenheit sich entgehen lïsst, irgend eine ihm bekannte locale oder sonst traditionelle mythische beziehnng einzuflechten. 
resultatlos, denn Nanna blieb ungewonnen, und gleich darauf erfahren wir, dass Hother, sich Seelands bei ihm gunstigen politischen umständen bemächtigend, könig von Dänemark und, nach seines bruders tod ${ }^{1}$ ), könig von Schweden wird. Dagegen fuhlt sich Balder von liebessehnsucht und -aufregungen so erschöpft, dass er nur noch auf einem zweigespann einherfăhrt. XIV. Er folgt (wann? sogleich?) dem Hother nach Seeland, während derselbe gerade in Schweden ist, gewinnt die herrschaft uber Dänemark (so wankelmutig waren unsere vorfahren) und schlägt den herbeieilenden Hother zam zweiten male, der sich nunmehr, nachdem er zuvor in Jutland die winterquartiere bezogen (hybernis peractis) und einem platz daselbst den namen gegeben, verzweifelnd in die einöde zurtickzieht (folgt eine sentenz uber die vereinsamende wirkung des schmerzes).

Diese chronologisch haarsträubende uberlieferung ist nach jeder richtung bin verdächtig. Hother wird geschlagen; trotzdem bleibt ihm zeit, erst Dänemark und dann Schweden zu gewinnen; erst während or hier weilt, folgt ihm Balder, wird Dänenkönig und schlägt den herbeieilenden gegner. Diese zweimalige schlacht ist fur die ursprungliche uberlieferung ein unding. Ein lächerliches unding ist die erotische erschöpfung Balders, die Saxo augenscheinlich lediglioh erfand, um eine ihm bekannte, sehr merkwurdige anschaung einzuflechten, der zu folge Balder auch auf einem, von zwei rossen gezogenen wagen vorgestellt wurde; wie er nach klassischem muster die jutischen winterquartiere erfand, um einen, nach Hother benannten platz einzuflechten. ${ }^{2}$ )

Auf diese weise erklät sich auch die erste schlacht. An einen Baldersbrunnen knupfte sich der mythus, dass der gott nach (vielleicht auch: wăhrend) einer siegreichen schlacht seinen durstenden schaaren eine quelle schlug. Dass diese fassung der fabel geprăgt vorlag, beweist ihre widerkehr in der Karlsage und anderen tiberlieferungen. ${ }^{3}$ ) In allen diesen fällen

1) Der nunmebr erzühlt wird.

2) Weitere belege für einflechtung disparater elemente.

3) Karl der Grosse nach einer siegreichen schlacht. Karl V. während einer belagerung; ähnlich Gangolf. Oswald nach einer siegreichen schlacht (aber zu legendarischem zweck). Vgl. Grimm M. 783. Laistner, 
mag sie angewachsen sein; aber als typus ist sie hiermit erwiesen. Ist in unseren quellen von sonstigen kämpfen Balders keine rede, so weisen der von einem heer begleitete Balder, der reitende Balder des Merseburger spruches ebenfalls uber die grenzen unserer uberlieferung hinaus. Es ist unabweisbar und wurde schon von Grimm angedeutet, dass Balder zu einer zeit, zu welcher ihn die ausbildung einer götterhierarchie noch nicht auf einen kleinen wirkungskreis beschränkte, als der leuchtende gott der athmosphärischen orscheinungen mittelpunkt einer eigenen mythenwelt, und jedenfalls vertreter des götterkampfes wider die dämonen war so gut wie Oðinn und Freyr, die beide in unseren quellen von dem specifischen dämonenbekämpfer Thor bis auf wenige anhaltspunkte zurluckgedrängt sind. Das göttersystem ist nicht der ausgang sondern die letzte phase der mythischen entwickelung, und es lässt sich nahezu schlagend beweisen, dass die einzelnen götter, verschiednenorts entstanden, sich in ihrer bedeutung sebr nahe beruhrten, in ihren wirkungskreisen nabezu deckten und erst, als sie durch die, in allen stadien der sagenentwickelung so stark waltende wanderung gemeingut grösserer distrikte geworden, in einem naturlichen ausgleich sich in die functionen teilten und genealogisch verkntipften; wie ja auch ursprünglich gleichbedeutende wurzeln und stanmme, verschiednenorts entstanden und dann durch wanderung gemeingut geworden, in unwillkurlichem auggleich auf begrenzte nuancierungsgebiete eingeschrănkt wurden.

In der tat verläuft, wie bemerkt, der erste kampf völlig resultatlos; der zweite aber hat ein sehr wichtiges resultat: Hother wird vertrieben. Und somit lassen sich aus den bisherigen abschnitten des Saxoschen berichtes vier uberlieferungen herausschälen: 1 . Balder und Hother sind nebenbubler um Nanna. 2. Hother yewinnt eine, in den eisregionen geborgene waffe, mit welcher allein der unversehrbare Balder zu vernichten ist. 3. Hother besiegt und vertroibt Balder. 4. Balder zurlickkehrend besiegt und vertreibt Hother. Unter diesen

Nebelsagen 199. Wolf, Beiträge I, 133. 194 (woselbst weiteres bedeutsames material); diese Beiträge XI, 400; ebenda 445 weitere verweise. Schwediech das dürstende heer bei Afzelius III, 246. 
vier tuberlieferungen nimmt die zweite ${ }^{1}$ ) eine sonderstellung ein: unvereinbar mit der dritten und vierten, widerstrebt sie auch dem folgenden bericht: das schwert Hothers und die unverwundbarkeit Balders kommen nie wider vor, und Hother bedarf ganz anderer mittel, um Balder zu bewăltigen.

XV. Hother, in der einsamkeit irrend, gelangt auf unbetretenen wegen unversehons in die grotte unbekannter jungfrauen. Es waren dies aber die nămlichen (setzt der berichterstatter hinzn $\left.{ }^{2}\right)$ ), die ihn einst mit einem unverletzlichen gewande ausgestattet hatten. Befragt, wie or an diese stätte komme, klagt er sein missgeschick und beschuldigt sie des wortbruches, weil der verbeissene sieg ausgeblieben. ${ }^{3}$ ) Sie trösten ibn mit seines feindes ehemaliger niederlage, und dass das blutbad auf beiden seiten das gleiche gewesen. Sie verheissen ihm sieg, wenn es ihm gelinge, einen fur Balder ersonnenen stårketrunk zu geniessen. XVI. Diese verheissung erfullt Hother mit der höchsten kampflust, obwol es fur menschen schwer wider götter zu streiten; daher ihm manche den kampf widerraten. Aber die begierde besiegt seine ehrerbietung vor der götter hoheit (wie nicht immer die vernunft gegenluber der tapferkeit zu ihrem rechte kommt); vielleicht auch vertraute er auf die unbeståndigkeit der macht. XVII. Balder erscheint mit einem Dănenheer; eine blutige schlacht folgt, entscheidungslos von der nacht unterbrochen. XVIII. Wahrend alles ruht, schleicht Hother, von niemand vermerkt, auf kundschaft in das feindliche heer (folgt eine sentenz uber die schlummerlose sorge) und kommt gerade dazu, wie drei jungfrauen, die trăgerinnen des stårketrunks, Balders lager verlassen. Er folgt ihren spuren im thauigen gras 4) bis zu ihrer behausung, (XIX) gibt sich fur einen spielmann

1) Die als der eddischen sippe zugehð̈rig gekennzeichnet wurde.

2) easdem esse constabat. wurden.

3) Man bemerke, dass sie soeben als ihm unbekannt bezeichnet

4) Man sollte also annehmen, dass sie so schnell entschweben, dass Hother ihnen nicht folgen kann; bei dem gesammtcharakter dieser, später zu erörternden, partie ist aber eher anzunehmen, dass sich Saxo überhaupt nichts vernunftiges dabei gedacht hat sondern einen irgendwo aufgelesenen poetischen zug unpassend verwertete. 
aus und bewährt sofort seine kunst in bezaubernder weise, während die jungfrauen aus dem geifer dreier schlangenweibchen den wundertrank brauen. Die eine in ihrer menschenfreundlichkeit hätte gern Hother an dieser speise anteil gewährt; aber die älteste wehrt den verrat an Balder, seines feindes kräfte zu stärken. Der spielmann leugnet Hother zu sein; er sei nur einer seiner gefährten. Dieselben jungfrauen nämlich (heisst es wörtlich), beschenken ihn in ihrer gute mit einem leuchtenden gurt und einem siegmăchtigen gütel. XX. Als er den pfad zurtickwandelt, begegnet er Balder (der augenscheinlich soeben seinem stärketrunke nachgeht), verwundet ihn tōtlich in der seite und lässt ihn halbtot liegen. Dort grosser jubel im einen, jammer in dem anderen lager. XXI. Balder, der seinen tod nahen fuhlt, lăsst sich in die, um seiner wunden schmerz erneute schlacht tragen, um nicht im zelte zu sterben. XXII. In der folgenden nacht erscheint ihm Proserpina (Hel) und verkundet ihm, dass er am folgenden (also $z$ weiten) tag in ihren armen ruhen werde. Am dritten tag stirbt or und wird feierlich begraben.

Diese letzte uberlieferungsmasse rechtfertigt die an dem voraufgehenden geubte kritik. Hother kommt ein zweites mal zu waldfrauen; es sind dies die nämlichen, die ihm einst ein unverletzliches hemd verliehen und sieg zugesichert haben. Beide zlige sind der ersten begegnung (V) vollkommen fremd; dagegen erscheint in der grossen see- und gōtterschlacht (XII) Hother mit einem undurchdringlichen gewand bekleidet. Dass beide zlige in jener luckenhaften partie $\mathrm{V}$ gestanden, ist darum fraglich, weil die verknupfung mit VI, dessen echte zllge genau da einsetzen, wo die echten von $\mathrm{V}$ aufhören (bei der warnung vor einem kampfe mit Balder), fur Saxos vorlage das winterschwert als siegesmittel Hothers wahrscheinlicher macht wie das gänzlich physiognomielose undurchdringliche hemd, welches nichts ist als ein mussiges wanderrequisit, während Balders unverletzlichkeit und die waffe in den eisregionen als natirliches ergebnis einer uberschaubaren sagenentwicklung sich darstellten. Ob Saxo eine weitere uberlieferung $\mathrm{zu}$ gebote stand, der zu folge einer unterredung Hothers mit waldfrauen jene beiden zuge eigen waren; mit anderen worten: ob die prophetische valkyrjenbegegnung Hothers auch in anderer ge- 
stalt gesungen wurde und Saxo bekannt war, muss dahin gestellt bleiben. Sicher aber ist die XV geschilderte begegnung ein Saxosches machwerk. Die jungfrauen sind Hother unbekannt; nichtsdestoweniger bezichtigt er sie des wortbruchs. Und womit verteidigen sie sich? dass Hother nicht minderen schaden zugefugt wie erlitten habe! Farbloses ungeschick ist das gepräge des ganzen abschnittes gegenuber der knappen geschlossenheit jener vorlage. Weil in ihr des winterschwertes gewinnung von nornen prophetisch angektundigt ward, musste der raub des stärketrankes mit gleichem aufwand in scene gesetzt werden, die gespenstische nebelscene in verschlechterter auflage figurieren. Der ganze abschnitt $\mathrm{XV}$ ist unecht, um so unechter, als natürlich die drei den stärketrank brauenden jungfrauen valkyrjen sind; Saxos ungeschick somit eine valkyrjenscene mit einer anderen ankundigt.

Wie töricht widerum, wie stumperhaft wird die echte valkyrjenscene eingeleitet! Hother, auf nächtlichen schleichwegen, sieht die trankjungfrauen Balders lager verlassen. Dass diese situation schon deswegen ganz sinnlos ist, weil Balder seine schutzerinnen später um des trankes willen aufsucht, klimmert Saxo nicht; ihm schwebte eine scene vor, in der ein held nebelfrauen nachschleicht, und er flocht sie frischweg ein. Der verlauf ist des anfanges wert. Hother kommt zu den jungfrauen um des stärketrunks willen, und or verlăsst sie, ohne ihn genossen zu haben. Der stärketrunk wird ihm versagt, weil er Hother sei, und er gibt sich, um ihn von Balders schutzerinnen zu erhalten, fur einen genossen Hothers aus. Warum uberhaupt Hother als spielmann eingefuhrt wird: auf dass die macht seiner kunst ihm den trank gewinne, hat Saxo vergessen; und die schliessliche spende der freundlichen jungfrauen, der kraftgurtel, verwandelt sich aus der dichterischen schilderung der vorlage: ein stärkegurt, ein leuchtender gürtel! für Saxos verständnis in das geschenk zweier gürtel.

Es ist offenbar: Saxo hatte seine quelle weder verstanden noch recht im gedächtnis. Die einleitung durch einen unentschiedenen kampf ist nach der schablone der kriegsberichte, das nächtliche schleichen auf kundschaft vermittelt die sinnlose episode von den, dem lager entwandelnden jungfrauen. Da nun an der sinnlosesten partie des ganzen letzten teiles, 
dem abschnitt XV, erst recht nichts zu halten, so ergibt sich: $\mathrm{XV}$-XVIII sind lediglich machwerk Saxos, in der therlieferung nicht begrundet. Fuir den ganzen abschnitt XV-XXII lag Saxo im wesentlichen eine uberlieferung vor: Hother kommt unversehens zu der behausung dreier valkyrjen. Er fragt, was sie treiben; sie erklären ihm, dass sie aus schlangengift einen stärketrank fur Balder brauen. Durch spielmannsk (unste ${ }^{1}$ ) gewinnt er ihnen denselben ab und einen kostbaren stärkegtrtel dazu. Als er sie verlãsst, begegnet er Balder, der sie gerade aufsucht, und verwundet ihn tötlich.

Diese quelle Saxos ist ein spielmannslied. Die stimmungsvolle situation: die jungfrauen in der grotte, unter gemurmelten zauberworten den herabtrăufenden geifer von den lippen dreier schlangenweibchen auffangend, bezeugt, dass es ein gutes lied war, wenn auch ein lied von wenig altertumlichem gepräge. ${ }^{2}$ In der mythischen entwickelung tritt auf allen stufen eine umbildung hieratischer tuberlieferung zu menschlichen nutz- und hausgebräuchen ein: der amuletismus. Dinge und ceremonieen hieratischer bedeutung sollen die menschheitsschranken erweitern: wunden und krankheiten heilen und verhuten, unuberwindlichkeit und unverletzlichkeit schaffen. Diese abergläubischen ${ }^{3}$ ) gebrăuche werden widerum in den götterhimmel ubertragen: so gut die gōtter vor dem mahle aus dem blute der (wem?) geopferten tiere weissagen (Hymiskv.), bereiten die norven dem bedrohten Balder einen stärketrunk.

Iu der bedrohung Balders aber liegt das wichtige moment der uberlieferung. Balder ist bedroht; darum wird ihm ein stärketrunk bereitet, der ihn unuberwindlich macht. Aber

1) Hier ist die quelle fur Hothers sangeskunst in II anzunehmen.

2) Wie schon die ganz überflüssige häufung des stärketrunkes durch das wanderrequisit des stärkegürtels vermuten lässt.

3) Es gibt christlichen so gut wie heidnischen aberglauben; aberglaube ist entartung religiöser anschauungen und ceremonien, entarteter glaube. Er besteht im wesentlichen aus amuletismus (handlungen, die unheil verhüten, bezüglich: deren unterlassung unheil nach sich zieht) und schamanismus (gespensterglauben, spuk). Der von der völkerpsychologie für ersteren geprägte name ist fetischismus. Doch ist dieser begriff dahin zu erweitern, dass unter ihn alle 'wunschdinge' und viele 'unmögliche handlungen', besonders der märchenwetten, fallen, 
Hother gewinnt durch spielmannskunste den genuss dieses zaubermittels, und Balder erliegt. Man sieht: diese therlieferung ist 1. weit ursprünglicher als die von V-VII, 2. mit der letzteren concurrierend, also unvereinbar. Die eddische sippe verkundet: Balder muss nach einer prophezeiung sterben; darum suchen ihn die götter zu schutzen (denn sein tod eröffnet den weltuntergang): alle dinge verheissen ihn nicht zu verletzen - bis auf eines. Daraus erklărt sich V: Balder ist unverletzlich, aber eine im winterland ruhende waffe wird ihn durch Hothers hand tōten; und XIX: Balder ist bedroht; die valkyrjen bereiten ihm zum schutze einen stärketrank, aber diesen gewinnt Hother als spielmann, und Balder muss sterben. V vergisst den anlass der untiberwindlichkeit, XIX fuhrt als mittel derselben ein amulet ein.

Auf die bedrohung Balders aber ist jedenfalls XXII zurlickzufuhren: Hel erscheint Balder und verkundet ihm seinen untergang. Der tod am dritten tag ist wol nach der legendenschablone und stimmt nicht mit Saxos eigenem bericht des sachverlaufes; der zug, dass der totwunde Balder sich in die schlacht tragen lässt, nach einem berluhmten muster. $\mathrm{Ob}$ die verwundung in der seite nicht auch mythisch sinnlos und tibernommen ist, bleibe einstweilen dahingestellt. Jedenfalls sind XXI und XXII willkurlich und unursprlinglich, und der einzige echte zug, die todesprophezeiung Hels, wahrscheinlich herauszunehmen und in der bezeichneten weise zu verwerten: als die veranlassung des trankschutzes.

Alles in allem hat die kritik der dănischen uberlieferung folgende sagenzlige herausgeschält: 1. Hother und Balder sind nebenbubler um Nanna (III-V). 2. Hother besiegt und vertreibt Balder (XII). 3. Balder kehrt zurlick und vertreibt Hother (XIII. XIV). 4. Balder ist unverletzlich; aber ein in der eisregion ruhendes schwert wird ihn durch Hothers hand töten (VI). 5. Balder ist bedroht, darum bereiten ihm valkyıjen einen stärketrunk, der ihn untuberwindlich machen wird: Hother aber gewinnt diesen (durch spielmannskunste) und erschlägt Balder (XV-XXII). Von dieser luberlieferung stehen 4. und 5. der eddischen sippe, wie dargetan, nahe: die unverletzlichkeit wie die bedrohung fuhren zurtick auf den weltuntergangsmythus. Dagen enthalten 1.-3. eine ganz neue 
aberlieferung: Hother und Balder sind nebenbuhler um Nanna; Hother vertreibt Balder, muss aber dann selbst vor dem zurlickkehrenden entweichen. Diese uberlieferung stellt Saxo so dar, als ob Hother der beglinstigte, Balder der verschmăhte liebhaber sei; jener der herrliche, ruhmreiche heldenjungling, dieser der hassenswurdige (V.), schmachrolle (XII a) buhler. Der irdische liebhaber steht dem mönche näher am herzen als der verfluchte heidengott. Diese an sich tendenziös gefärbte (XII a) darstellung weicht in einer weise von der besseren eddischen tuberlieferung $a b$, welche sie richtet. Der allgeliebte lichtgott, dem sein treues weib Nanna nachstirbt, konnte mythisch nie zu dem hässlichen nebenbuhler eines, in rechtmăssiger ehe eben jener Nanna vermăhlten winterdämons werden. Und hier setzt Laistners geniale bemerkung (Nebels. 201) ein: auch in der dänischen sippe war Nanna Balders weib; ein winterlicher dämon verdrängt ihn von ihrer seite, an der nunmehr er sein bublerwesen treibt, bis der rulckkehrende gott der wirtschaft ein ende macht.

Laistner kommt auf die Hothersage bei gelegenheit seiner besprechung der Gangolflegende (196-204), die or in innere beziehung zu jener zu setzen geneigt ist. In der tat werden von Gangolf (Wolfgang) mythisch klingende dinge berichtet ${ }^{1}$ ), und er ist andrerseits ein sebr zweifelhafter heiliger; historisch 2) weiss die legende nur von ibm, dass er, ein Burgunder, zu Pippins zeiten ein grosser kriegsmann vor dem herrn gewesen sei; die ihm zugeschriebenen wunder sind teils schablonenhaft ${ }^{3}$ ), teils accessorisch 4 ); daraus freilich zu folgern, dass

1) Ėr ist ein grosser jäger (b. L. 196): eine elgenschaft, deren vereinbarkeit mit einem heiligen leben den theologen kopf zerbrechen verursachte (Heiligenlexicon II, 373); nach einem volksglauben (b. L. 200) fährt Wolfgang zu wagen uber das wasser; vgl. (ebenda) einen Gangolfberg als wetterpropheten, ferner seine verehrung zu pfingsten, den fall seines gedenktages auf den 11. oder 13. mai: den schlnss der fruhlingszwölften, zu deren anfang der Balder geweihte Pfultag steht; den 13. Servatius, den 14. Bonifazius, beides quellerweckende hcilige (b. L. 202); uber letzteren vgl. wichtige nachweise bei Wolf, Beitr. z. d. m. I, 194. 133.

2) Heiligenlexicon II, 373.

3) Die von vielen heiligen erzählte quellweckung.

4) Der kesselfang, der lediglich eine combination des quellenwunders mit der untreue der frau. 
Gangolf ein heidnischer gott gewesen sei, wäre gewagt, da wol göttliche zluge auf heilige ubertragen wurden, kaum aber wol ein gott zum heiligen erboben. Die zu der Baldersage (bei Saxo) stimmenden zuge der legende sind: 1. eine quellerweckung. 2. Untreue der gattin (?). 3. Tötung des heiligen durch den buhler, 4. uud zwar durch verwundung in der seite. 5. An seinem sterbelager engelische paradiesesprophezeiung. Den letzteren zug, der nur dem dichterisch verbreiternden bericht der Hroswitha eigen ist, mit Hels todesverkundung zusammenzustellen, ist gewagt: nicht allein, weil der zug in Saxos lesart schwerlich an der rechten stelle steht, sondern namentlich, weil derartige engelsbotschaften in der legendenschablone beliebt sind; man vergleiche ihre widerholte anwendung in dem spielmannsgedicht Orendel. Ebensowenig kann die quellerweckung Gangolfs für die gleichsetzung beider uberlieferungen in frage kommen; abgesehen davon, dass die quellerreckung Gangolfs einer ganz anderen sippe der quellsagen und -legenden 1) angehört, wird sie auch in dieser gestalt von sebr verschiedenen heiligen berichtet (Laistn. 203. 204); und ferner ist es äusserst fraglich, ob die quellerweckung Balders zu seinem kampfe mit Hother in beziehung steht. Bleibt also fur die begrundnng der combination als mögliche thereinstimmung die bublerei der gattin, als tatsächliche der tod durch den buhler einerseits, die verwundung in der seite andererscits. Letzteren zug anders als durch zufall oder, in letzter linie, gemeinsamer vorlage zu erklären, vermag ich nicht, bevor mir die mythische bedeutung desselben dargetan ist; jene beiden zlige mögen einen mythus enthalten: ibn fur diese sammlung $z u$ verwerten, wage ich nicht, noch weniger aber, ihn mit Saxos Hothertberlieferung zusammenzustellen.

Diese erörterungen haben den rahmen der Mullerschen sammlung bereits wesentlich uberschritten; das hauptstück derselben und ein angelpunkt seiner theoretischen ausfubrungen ist noch, um seiner eigentumlichkeit willen, in einer kleinen gruppe für sich, getrennt von der göttergruppe, zu untersuchen.

1) Nämlich den quellübertragungen, gegentiber der erweckung durch hufschlag, lanzen- (schwert-, stab-) stoss, nachgrabung. 
Es ist von Saxo nach 2wei berichten niedergeschrieben ${ }^{1}$ ): das eine mal in sehr geschmacklos ausgeschmlickter weise, entweder auf gruna eines frivol motivierenden spielmannsliedes oder unter zutat eigenster albernheiten; das zweite mal in unvollstãndiger, aber einfacher und vielsagender widergabe. Ein gewisser Othinus, der in ganz Europa einer unverdienten heiligkeit genoss, verweilte mit vorliebe in Upsala. Ihn zu ehren, santen die nordischen fursten ihm seine schwer umgoldete, mit geschmeide verzierte bildsäule nach Byzanz (offenbar seiner residenz), uber die sich der gott nicht wenig freute. Aber Frigga, sein böses weib, liess aus blosser schmucksucht die statue des goldes (d. i. wol des geschmeides) berauben, und als der erzurnte besitzer die frechen diebe hängen liess, gab sie sich einem diener hin, auf dass er die statue zerstören helfe, mit deren gold sie sich nunmehr schmtickte.2) Und solch böses volk, ruft der fromme Saxo mit mönchischer entrüstung, konnten die menschen anbeten! Othinus, nicht minder betrubt uber die zerstörung seines bildes wie uber die schăndung seines bettes, wandert in die ferne. Nach seinem weggehn erwirbt ein zauberer Mithotynus ${ }^{3}$ ) durch gaukeleien bei den menschen göttliche verehrung. Jene nutzen ihm aber nichts, als Othinus heimkehrt: er muss den nsurpierten thron răumen, mit ihm die ganze sippe von kleinen und grossen usurpatoren, die sich unterdes breit gemacht haben; Othinus zerstreut sie gleichsam durch den siegreichen glanz seiner got theit.

Wilhelm Muller hat mit recht aus dieser fassung lediglich gefolgert: 1. dass Frigg dem Oðin untreu wurde, 2. dass Oðinn in die ferne 200 und ein Meðoðinn an seine stelle trat, der aber wider verschwand, als Oðinn zurückkam, und 3 . dass die

') A. 2. o. 25 und 81.

2) Man beachte die zweimalige anwendung des nämlichen motivs, an die sich noch die wendung schliesst, dass die säule mit der rede begabt wurde.

3) Die schreibung -otynus für -othinus, welche letztere sich durch die zweite überlieferung als die richtige ergibt, ist ein beleg für die ungenauigkeit Saxos in der widergabe der, ihm wol meist nur aus dem gehör bekannten namen. Als eigentliche gestalt des namens ist Meðd. Jinn anzunehmen. 
untreue Friggs nicht die ursache ron Oðins abwesenheit war sondern während dieser erfolgte, das heisst, dass sie dem zweiten Orin auch als gattin angehörte.

Die zweite erzählung berichtet, Othin, der mit den göttern in Byzanz residierte, habe durch seine unanståndige werbung um Rindr sich als götterkōnig unmöglich gemacht, derartig dass die götter ibn ausgestossen und an seine stelle einen gewissen Ollerus gewăhlt hătten, den sie ebenfalls Othinus nannten. Nach lăngerer zeit aber hätten sie, in mitleid mit dem, in bettlergewand sich kleidenden, vertriebenen gott, ihm erlaubt in die alte wurde zurlickzukehren; der falsche Othinus sei entwichen.

Bemerkenswert ist, dass in dem $\mathrm{zweiten}$ fall der andere Orinn seinen platz von rechtswegen inne hat, in beiden fallen mit dem namen Oð̇in benannt und somit als gleichberechtigt anerkannt wird; so dass auch darin die zweite fassung recht behält, dass er mehr abdankt als flieht: wie denn von einer tōtung durch den beimkehrenden gatten und herrscher nirgends eine rede ist. Bemerkenswert ist ferner, dass Oðins gegner in der zwoiten uberlieferung Ollerus, das ist Ullr heisst: also den namen eines bundig belegten wintergottes trăgt. Unter diesen umstănden ist kein zweifel, dass auch hier eine jabreszeitensage vorliegt, des eigenartigen inhalts: der Oðinn, der im sommer herrscht, weilt im winter in fernem land und tritt seine gesamte machtsphăre in dieser zeit einem andern Oðin $a b$, welcher mit seinem weibe lebt, aber bei der rluckkehr des sommer-Oðins zu weichen hat. Sommer- und wintergott wechseln in bester ordnung, und so beisst ja auch Ullr der beste freund Baldrs.

Um die byzantinische residenz Oðins recht zu beurteilen, ist Yngls. c. 5 heranzuziehen: Oঠinn hatte in Turkland grosse besitzungen ${ }^{1}$ ); ferner Paul. Diak. I, 9: Wodan .... qui non

1) Nordlich rom schwarzen meer liegt Schweden, durch Schweden fliesst der 'lanais: das land zwischen seinen armen ist Vanaland; 8stlich von ihm liegt Asaland (Asien), westlich Earopa (c. 1-4). Ein von nordost gen slidwesten verlaufendes gebirge trennt Schweden von anderen ländern, unter denen Türkland ist. Oðinn herrscht in Asaland (das, wie bemerkt, einen teil von Schweden ausmacht), hat aber besitzungen in Türkland. (Der rationalistische verfasser verlegt gemäss 
circa haec tempora sed longe anterius .... in Graecia fuisse perbibetur. Bei Paulus: Wodan, der frther einmal in Griechenland gewesen sein soll - bei Snorri: Ozinn, der eigentlich in Schweden residierte, aber auch in Turkland sich grosser besitzungen erfreute - und dem gegenuber bei Saxo: Othinus, der in Byzanz sass, aber zuweilen nach dem norden kam: man kann nicht zweifeln, wer das ursprtingliche gibt. Oðinn herrscht im norden, aber zeitweise ist er fern im osten; der osten ist schlechtweg Byzanz, Griechenland, der Yngls. Türkland: und so wird aus Orins ostfahrt eine orientfahrt. Diesen ubergang wollen wir uns bemerken.1)

Oegisdrekka, die es ja nicht allzugenau mit namen nimmt, wirft der Frigg buhlerei mit Vili und Ve vor, und wol im anschluss an sie ${ }^{2}$ ) erzăhlt Yngls. c. 2 unsere sage in folgender gestalt: Oðinn machte öfters grosse reisen, bei denen er viele jahre fort blieb. Wăhrend dessen walteten seine bruder Vili und $\mathrm{Ve}$ des reiches; als er aber einmal gar keine miene macht widerzukommen, geben sie das warten auf, teilen unter einander das reich und eignen sich sein weib zu. Da unversehens erscheint Otinn wider und tritt in seine alten rechte. Man hat aus dieser uberlieferung schliessen wollen, dass die sage lediglich eine schlechte erfindung sei zur erklărung einer alten dreieinigkeit Oঠinn, Vili, Ve, der naturlich weib und herrschaft gemeinsam war eben um der einheit der drei willen. Ist eine solche aufassung nach den obigen analogien unhaltbar, so steht es um die angebliche ursprunglichkeit der dreieinigkeit nicht besser; nicht allein, dass jede dreieinigkeit be-

seinen geographischen kenntnissen Türkland nach dem sliden, wie er Assland zu Asien macht; er weiss aber doch noch, dass die alten gütter in Schweden herrschten, und dass Ozinn nur zeitweilig in Türkland, d. $i$. dem osten, verweilt).

1) Dafür, dass 0ðin überhaupt ostfahrten und kämpfo im osten eigen waren, lässt sich manches anfuhren: besonders dio Bäsrmagasaga, dann die rahmensituation von Grimnismal, ferner Vafproðnismal und, vielleicht, die einleitung des Hrangnirkampfes, vergl. Otins wandernamen.

2) Dafuir spricht auch die tubereinstimmang beider quellen in dem bericht von des $\mathrm{Njör}$ geschwistcrehe. - Vielleicht erklärt sich die entstellung der Mitoð̇insage aus einer liberlieferung, der za folge die beiden jabreszeitengütter brïder waren wie Baldr und Höorr. 
reits die phase der (mystischen) systematisierung reprăsentiert, ist eine dreieinigkeit ethischen, abstracten inhalts besonders spät anzusetzen.

Muller hat sich uber die welt, in der Oojinn die zeit seines fernweilens verbrachte, eine eigene anschauung gebildet: Oðinn weilt in totenreiche. 1) Alle belden der heimkehrgruppe waren forn im totenreiche. Grlunde: 1. sie kehren in unkenntlicher vernachlăssigung zurluck, und ebenso sieht Thorkill ganz welk aus, als er von Utgardloki zurluckkommt, erscheinen tote entstellt und ubel gekleidet, der tod selbst und die geister nicht besser, kehren menschen, die in geister- oder teufelsgesellschaft waren, blass und mit entstellten zligen zurtick, werden leute, die jahrhunderte wie stunden im geisterreich zugebracht haben, bei dessen verlassen von niemand mehr erkannt: Alles belege, dass die unkenntlich und verwildert heimkehrenden götter und helden aus dem totenreich kommen. Umgehrt kehrt ein mann, der im paradies gewesen, ganz unkenntlich schön zurück. 2. Alle jene helden sind in die ferne gezogen; und das totenreich wird gern im äussersten westen (also warum nicht auch osten?) auf eine insel (z. b. die britischen inseln) verlegt. Der letztere beweisgrund verdient die widerlegung, dass man sich das totenreich jenseits eines stromes ${ }^{2}$ ), und darum jenseits des kanals dachte. Die ersteren grtinde sind kaum ernst zu nehmen und widerlegen sich am besten durch gruppierung des in diesem capitel gewonnenen materials.

Wir fanden: I. eine reibe von helden, die eine wallfahrt

1) Die andere hälfte seiner theorie wird Muller wol selbst nicht mehr anfrecht erhalten. In dem methodischen irrtum, die sagenuntersuchung mit einer synthese des getrennten statt mit einer analyse des aneinandergeratenen zu beginnen, hat er die Rindrsage mit der Ullrsage verknlupft: 0ðinn ist nicht um der buhlerei mit Rindr willen vertrieben sondern buhlt mit Rindr, weil er vertrieben ist; Rindr ist ein wesen des totenlandes. Also 0zinn in der unterwelt mit Rindr buhlend und gleichzeitig Mitoðinn auf der oberwelt mit Frigg buhlend. Dem entsprechend ergänzt Muller die heimkehrgruppe durch eine brautfahrtsgruppe, der z. b. der künig Rother zugehören soll: der vertriebene könig huhlt während seiner abwesenheit mit einem wesen des totenreiches.

2) Auf diesen interessanten glauben, zu dem besonders Mannhardt in den germanischen mythen wertvolle belege beigebracht hat, nüber einzugehen, muss ich mir hier leider versagen. 
beztiglich orientfabrt oder grosse reise unternehmen, zu hause nach ablauf einer bestimmten frist (widerholt sieben jahre) für tot gelten, in dem moment, wo ihre gattin zu einer neuen vermăhlung schreitet, unkenntlich und in niederer tracht (von geisterhand getragen) zurtickkehren und, nachdem sie sich zu erkennen gegeben, friedlich in ihre rechte eintreten. Der eine dieser belden scheint in einem spielmannsgedicht schlechtweg marinaro, der seefahrer, genannt worden zu sein. Dazu gehört $I^{2}$ ein märchen, dessen held in dieser zeit ( 7 jahre) knechtesdienst (beim teufel) geleistet hat; $I^{\text {b }}$ eine sage, deren held nicht in den orient sondern in die berge zieht, dort als knecht heerden weidet, unvermutet, als sein weib, an seiner heimkehr verzweifelnd, sich eben neu vermählen will, erscheint, sich zu erkennen gibt und dann in die berge zu seinen heerden zurick wandert.

II. a) Halfdan verlobt sich mit einer jungfrau, zieht in den krieg, hört nach längerer zeit, dass seine braut im begriff steht einem andern vermăhlt zu werden, erscheint in niederer, unkenntlich machender tracht bei der hochzeit und erschlägt den nebenbuhler. Die braut heisst in dem einen fall Guritha, in dem anderen trăgt sie einen durchschnittsnamen. b) Halfdan hört, dass eine jungfrau einem riesen vermăhlt werden soll, erscheint in niederer, unkenntlich machender tracht, erschlägt ihn und vermählt sich mit der jungfrau. Die jungfrau heisst Gro. Ergebnis: ein held hört in der ferne, dass seine braut einem unliebsamen freier, oder gar einem riesen vermählt werden soll, erscheint in niedriger, unkenntlich machender tracht, in einigen fallen bei der hochzeit, und erschlaggt den nebenbuhler. Die jungfrau heisst Gro oder Guritha, der held steht mit Thor in enger beziehung.

III. Thor, von der ostfahrt ende winter zurlickkehrend, oder herbeigerufen (oder der ihm wesensverwante held Halfdan herbeigerufen), erscheint in niederer, unkenntlich machender tracht bei einer hochzeit, zu der ein riese eine jungfrau zwingen will, und erschlägt ihn (oder findet, in niederer trachț aus dem riesenland zurtickkehrend, bei seinem weib einen buhlen).

IV. Oð̌inn, in niederer tracht aus dem osten zurluckkehrend, Beitrăge zur gesohichte der deutechen sprache. XUI. 
macht den wintergott Ullr von seinem thron und seinem weib entweichen.

V. Baldur, durch den wintergott Hőður vertrieben und der gattin beraubt, kebrt siegreich wider, verjagt den usurpator und tritt in seine alten rechte.

VI. Svipdagr kehrt in niederer, unkenntlich machender tracht zu der seiner harrenden geliebten.

Man sieht, dass I, IV und V, II und III gruppenweise einander näher stehn, während VI ihnen gegenuber steht. In I, IV und V kehrt der rechtmässige gatte zuruck, und der unrechtmåssige entweicht. In II (III) erschlãgt der rechtmãssige den unrechtmässigen. In $\mathrm{V}$ ist gar kein unrechtmăssiger vorhanden.

Soviel ist bereits jetzt mit voller bestimmtheit zu sagen: in der gesammten heimkehrgruppe handelt es sich um jahreszeitenmythen. Thor ist im osten im winterland und kehrt im lenz heim. Oð̌inn ist im osten im winterland und kehrt im lenz heim. Die befreite gottheit, wenn sie Freya, Thruor, Sif, Nanna, Gro oder Guritha heisst, hat eine beziehung zur 80mmerlichen fruchtbarkeit. Oðins nebenbuhler Ullr ist notorischer wintergott. Und so ist auch Oervandill-Orendel im winterland und kehrt im lenz heim. Und so ist Horvendils kampf mit Kollr dem kalten ${ }^{1}$ ) jedenfalls ein holmgang um Gerutba und ein jahreszeitenmythus wie alle anderen.

Dieser kampf mit Koller hat bei Saxo ${ }^{2}$ ) ein interessantes seitenstluck. Skioldus und Skatus sind nebenbubler in der liebe um eine Alvilda. Sie fordern sich zum holmgang, und Skioldus erschlăgt den Skatus. Das klingt sehr einfach und oft dagewesen. Aber wenn man Saxos ungenaue schreibung der namen in betracht zieht, so liegt die vermutung nahe, dass Skiölds gegner jener Skadi war, der in der Völsungasaga c. 1 als schöpfer eines namens fur grosse schneebaufen auftritt ${ }^{3}$ ), und der auch durch die natur seiner namensschwester als ein winterlicher dãmon belegt wird. Sehr zu statten wirde es dieser hypothese kommen, wenn es uns gelănge auch den

1) Vgl. Unland VI, 31 a. 1.

2) A. a. o. 12.

3) Vgl. Beiträge III, 291. 
Skiöld durch analogiensammlung in den kreis unserer jabreszeitenmythen zu ziehen. ${ }^{1}$ )

Ehe wir also an die endgultige dentung und sagengeschichtliche klarlegung der Orendelsage und ihrer epochen gehen, werden noch einige analogien zusammenzutragen sein. Zuvörderst einige wichtige ausserdeutsche.

\section{Ausserdentsche analogien mit dentschen parallelen.}

Eine episode des, die entwicklungsphase der heldensage repräsentierenden, indischen Mahabharata ${ }^{2}$ ) enthält einen roman, der, in seiner allerdings sehr fortgebildeten gestalt, eine auffallende ubereinstimmung mit der erzăhlung von Mitoðin bekundet. Indra streitet mit Vrtra ohne ibn uberwinden zu können. Für beide teile ist ein frieden nicht unwillkommen, und die gōtter schliessen mit Vrtra einen vertrag, der den letzteren gegen jede schädigung durch seine erbfeinde sicher stellt. Aber als sich eine allzugunstige gelegenheit bietet, kann Indra nicht widerstebn, und indem er sein gewissen mit reiler klugelei niederlıält, erschlägt or den nebenbubler. Die wirkung wird geschildert wie sonnendurchbruch nach wetterdunkel oder lenzeseinkehr nach winternacht. Aber Indra kann sich seiner tat nicht freuen; von reue gepeinigt entflieht er und birgt sich in zusammengeschrumpfter gestalt am himmelsende in den wassern in einem lotosstengel. Wie er aber verschwindet, fällt furder kein regen, verdorren die wălder, versiechen die ströme; allenthalben waltet not und elend. Die götter, nach abbulfe begohrend, erwäblen den frommen menschen Nahusha an Indras statt. Aber der mensch kann die macht nicht vertragen; er wird ein ubermutiger tyrann, und die gōtter zittern vor ihm. Als er schliesslich seine hand nach Indras gattin ausstreckt, ersinnt ein brahmane, zu dem die beängstigte entflieht, eine list, welche den gewalthaber zu tiefster versundigung verleitet. Er wird als schlange vom

1) Als Skioilds gattin nennt Heimskringla Gefjon: eine wesenheit, deren athmosphärische natur durch weitere mythen belegt ist.

2) Uebersetzt von Holtzmann, Indische sagen I, $11 \mathrm{ff}$. 
himmel gesturtzt, während Indra, von den göttern gesucht, gefunden und entsuhnt, seine alte herrlichkeit wider erhält.

Ich habe die erzählung, wie sie uns erhalten, als einen roman gekennzeichnet. Ich unterscheide dabei in der sagenentwickelung scharf drei phasen: den primitiven mythus, das ist die einfache naturanschaung; die fabel, das ist die naturanschauung gefasst als ein motiviertes ereignis; und den roman, das ist die phantasievolle ausgestaltung der primitiven fabel. Wenn zum beispiel ein mythus existierte, dass ein jahreszeitengott periodisch in ein fernes land verschwinden muss, so ist dies eine schlichte naturanschauung; wird dieses verschwinden mit einer verschuldung motiviert, so haben wir eine fabel; und werden die unstănde und die folgen dieser verschuldung und dieses verschwindens ausgestaltet, so ist der roman fertig. Wăre eine derartige genetische unterscheidung von unseren vergleichenden mythologen beobachtet worden, so wäre ihnen viel arbeit - und viele irrtumer erspart geblieben.

Von diesem standpunkt aus ist die obige erzăhlung $z u$ beurteilen. Sie ist, wie alle spăteren sagengestaltungen der Inder, nach dem princip der verherrlichung des brahmanentums $\left.{ }^{1}\right)$ zurechtgestutzt; eine dem entsprechende starke neigung $\mathrm{zu}$ moralisieren hat die motivierung der handlung allenthalben deutlich beeinflusst ${ }^{2}$ ); aber tberall schimmern, die alten, echten zuge durch. Die erschlagung des Vrtra ist als ein athmosphă-

1) Man vergleiche den brahmanen, der die heilige opferflamme, den gott Agni, als boten aussendet den Indra zu snchen: liberall sucht Agni, aber in das wasser wagt er sich als feuer nicht; der brahmane muss ihn zuvor durch zaubersprliche schlitzen. Nun durchfährt Agni alle gewässer; widerum, als er den Indra endlich entdeckt, ist er nur der bote und muss den brahmanen benachrichtigen. Indra ist zusammengeschrumpft um seiner sinden willen; aber ein erhebendes wort des brahmanen gibt ihm seine alte grösse zurïck. Der brahmane fordert Indra auf, den Nahusha zu stïrtzen, aber ein rishi ist es, der ihn als schlange vom, himmel schleudert.

2) Vgl. $\nabla .183 \mathrm{ff}$. die moralische rede über die heiligkeit und woltätige wirkung des feuers, $127 \mathrm{ff}$. über die bestrafung des mannes, der einen schutzfliehenden seinen verfolgern preis gibt; dem entsprechend die einfuhrung des Nahusha als eines menschlichen königs, der, anf erden ein edler fürst, die allmacht nicht vertragen kann und zum wollistigen frevler wird, und die begründung von Indras verbannung mit einem vertragsbruch. 
rischer mythus längst dargetan; die flucht Indras offenbart sich in unverkennbarer weise als ein jahreszeitenmythus. Der indische winter ist die zeit entsetzlicher dürre; die zeit, wo Cušna, der austrockner, die macht hat, an dessen stelle auch Vrtra genannt wird '), fur welchen wideram der name des als schlange, drachen gefassten Abi eintritt.2) Diese drei dämonen, welche im grunde verschiednenorts aus verschiedenen beobachtungen entstandene namen des nămlichen wesens gind, halten die wasser zurluck, bis sie Indra im gewitter erschlägt, wobei von Vrtra-Abi berichtet wird, dass er als schlange zur erde stürtzt. Auch dass sich der abwesende gott im wasser (in einem lotosstengel) verbirgt, erinnert an ähnliche mythen. ${ }^{3}$ )

Namentlich der letztere zug ist ein deutlicher wink, dass der vorliegende mythus viel alter ist als die ausprăgung der göttergestalt Indra. Es gab einen mythus, nach welchem der die sommerliche fruchtbarkeit gewährende gott ther winter fur abwesend galt, die berrschaft einem ausdörrenden dåmon tuberlassend; wenn er aber im lenze heimkehrte', sturtzte der dămon, wol von dem blitze des gottes getroffen 4), als schlange herab; woltätige wasser strömten erlöst, die natur atmete auf und feierte die widerkehrende schöne jahreszeit. Nachdem auch dieser mythus an Indra angewachsen war, lag es nahe, sobald seine bedeutung vergessen wurde, die flucht des Indra mit seiner eigentlich typischen tat, der erschlagung des Vrtra, in beziehung zu setzen. Indra hatte mit ibr eine schuld auf sich geladen; er musste entweichen. Hier setzte die brahmanische entstellung ein, so frei gestaltend, dass alles, was uber den einfachen rahmen des jahreszeitlichen ferneweilens und widerkehrens des hauptgottes, der durre während seiner ab-

1) Vgl. Ludwig Rigveda 457, 10.

2) Ebenda 484, 21.

3) Auch vedisch flieht Indra, nachdem er den (schlangengestaltigen) Ahi erschlagen, über die 99 ströme (Mannh., G. m. 214). Indra wird genannt der aus dem wasser geborene, desgleichen der schlangenbekämpfende wesensgleiche Trita (Mannh. 213. 215) und Agni der feuergott. Letzterer wird auch als im wasser weilend betrachtet (Zeitschr. f. mythol. II, 323); ebenda wahren die meeresgotter (Mannb. 107) Indras blitzbogen.

4) Vgl. 8. 69 a. 1, dass der brahmane ihn auffordert den nebenbuhler zu vernichten, 
wesenheit und des jubels uber seine rluckkehr; des interregnums eines bösewichtes und seines sturzes vom himmel in schlangengestalt') hinausgeht, als verdächtig bei seite zu schieben ist. Namentlich das verlangen Nahushas nach Indras gemahlin hat einen höchst romanbaften anstrich und schmeckt zu sehr nach dichterischer ausgestaltung der situation, um als analogon zu anderweitigen mythen geltend gemacht zu werden.

Aber auch unter diesen einschrănkungen jst das ergebnis äusserst wertvoll und wird noch wertvoller, wenn es gelingt einschlägige griechische analogien anzuziehen.

Mullenhoffs scharfsinn verdanken wir die entdeckung des auffallenden parallelismus des alten nostos der Odyssee und der deutschen heimkehrgruppe. Allerdings weigerte sich der entdecker, die analogie für die mythenvergleichung nutzbar zu machen; Orendelsage und Odyssee waren ibm schiffermythen und die in ibnen vorausgesetzte seebefahrenheit erst in der zeit der vollzogenen völkerscheidung anzunehmen. Nachdem das oben beigebrachte material fur die deutsche uberlieferung mebr und mehr die schiffersage gegen den jahreszeitenmythus zurucktreten liess, kōnnen wir letzteres bedenken bei seite schieben. Die Odyssee trägt allerdings die zulge einer schiffersage; aber bereits Mullenhoff betonte, dass der name des belden erst aus seinem geschick erwachsen, folglich der sage dieser so geartete held unursprünglich, oder schărfer gefasst: die sage mutter des helden, nicht der held vater der sage war. Wenn nun der alte nostos, unangeseben die individualităt des aus ihm heraus benannten belden, den inhalt hat: ein heros weilt gezwungen eine, mit hieratisch-mythischer zahl näher begrenzte zeit fern von seinem lande und seinem weibe auf einer insel, welche sich aus dem namen ihrer sagenhaften herrin als ein wolken-nebelland darstellt, und findet zurlickkehrend weib und land usurpiert von einem oder mehreren gewalthabern, so ist, in anbetracht, dass genau die nămliche formel deutsch wio indisch widerkebrt, anzunehmen, dass der nostos die sagenhafte verschiebung eines uralten indogermanischen mythus dar-

1) Vielleicht auch die auffindung Indras durch das hin- und widerfahrende himmelsfeuer: eine anschauung, welche im kreise der gewitterwythen interessante parallelen finden dürfte. 
stellt: sofern dieser mytbus in anderweitigen gestaltungen sich als griechisch erweisen lässt.

Zunächst ist der Hyperboreermythus ${ }^{1}$ ) in das auge zu fassen. 1. Nach der delischen version, die Herodot therliefert hat, kamen zwei byperboreische jungfrauen nach Delos, um der Eileithyia den danktribut fur die schnelle geburt der Leto zu bringen: weizengarben, die eine opfergabe umschlossen. Mit ihnen schickten die Hyperboreer der sicherheit halber funf

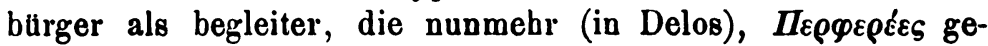
nannt, sehr verehrt würden. Nachdem aber die entsanten nicht heimkehrten, firchteten die Hyperboreer, dass es jedes mal so geschehen wirde, und brachten ihre garbengaben nur bis an die grenze des nächsten stammes, von wo aus sie von stamm zu stamm weiter befördert wurden, bis sie in Delos eintrafen. Auch von zwei anderen hyperboreischen jungfrauen wird eine ähnliche fahrt berichtet. Endlich kommt Leto selbst von den Hyperboreern nach Delos um zu gebären. 2. Die delphische sage (enthalten beşonders in einem Päan des Alkäos bei Himerios) ${ }^{2}$ ) berichtet: als Apoll (in Delos) geboren war, entsante ihn Zeus, geschmückt mit goldener mitra und lyra, auf einem schwanenwagen, in Delphi den Hellenen das recht zu verkunden. Er aber leukte sein schwanengespann zu den Hyperboreern. Als die Delphier dies vernehmen, rufen sie den gott durch einen päan, von jünglingen um einen dreifuss gesungen, von den Hyperboreern zu ihnen zu kommen. Apoll, nachdem er ein jahr den Hyperboreern geweissagt, hält es flir an der zeit, dass der delphische dreifuss töne, und erscheint, von seinen schwänen gezogen, in sommersmitte untêr dèm sàng dèr nachtigallen, schwalben, cicaden und dew aufrauschen des kastalischen quells und des hochwogenden Kephissos. 3. Hekatäos von Abdera verlegte die Hyperboreer auf eine insel im norden jenseits des Keltenlandes. 4. Fur Claudian ist Apoll der alljährlich von den Hyperboreern zur frublingszeit widerkehrende gott.

Mannhardt, der in verdienstvoller weise antike culte durch

1) Das material in guter übersicht zusammengestellt von Welcker, Griechische gøtterlehre II, $349 \mathrm{ff}$.

2) A. a. 0. 359 . 
analogie heutiger volksbrăuche aufzuhellen suchte, hat endgultig dargetan 1), dass hinter dem delischen Hyperboreermythus sich ein alter ackercult verbirgt: die periodische darbringung einer ländlichen opfergabe an dem heiligtum des fruchtbarkeit spendenden Apoll. Im anschluss an andere gelehrte vertritt er die ansicht, dass aus dem namen der, vielleicht nordlåndischen, uberbringer des opfers $\pi \varepsilon \rho \varphi \varepsilon \rho \varepsilon \varepsilon \varsigma$ gleich

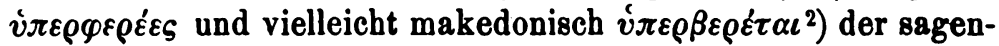
name eines, im norden angenommenen volkes, der Hyperboreer, entstanden sei. Diese annahme, wenn sie auch nicht allgemein geteilt ist, hat viel fur sich; der boden vorsichtiger folgerung wird aber verlassen, wenn Mannhardt, im anschluss an Ottfried Muller, der, wie alle schöpferischen naturen, seine epoche machenden principien in der praxis zu straff spannte, auch die delphische therlieferung aus dem ackercult herauswachsen lässt, indem er annimmt, dass ihr ein historisches, völlig unverbürgtes factum zu grunde liege, etwa des inhalts, dass thessalische Griechen festtheorien nach Delos entsant hätten. Denn wenn es richtig geschlossen ist, dass die garbengabe der delischen sage keine einmalige sondern eine cyklische war, so ist es auch erlaubt, ja geboten zu schliessen, dass jener päan der delphischen junglinge, der den gott von den Hyperboreern herbeirief, ein regelmässig widerkehrender gewesen sein nuss. Nun ist es zwar belegbar, dass aus einem unverstandnen cult eine fabel erwuchs, schwerlich aber, dass aus einer missverständlichen fabel ein cult. Der name der Hyperboreer konnte eindringen; tatsăchlich aber bleibt bestehn, dass die Delphier jährlich in einem festlichen päan den gott in das land riefen.

Der päan bei Himerios setzt die ankunft des Apoll in Delphi auf mitte soumer. Roscher ${ }^{3}$ ) hat die ungenauigkeit dieser angabe schlagend erwiesen. Apollon erscheint in Delphi mitte fruhjahr (etwa im april): 1. weil der sommer für schädlich galt, für die zeit des tōtenden Apoll, der frubling fur die zeit der lust und wolfahrt, 2. weil bei des Apoll ankunft

1) A. W. F. $232 \mathrm{ff}$.

2) Vgl. Rhein. mus. XVII, 341.

3) Apollon und Mars $33 \mathrm{ff}$. 
quellen und flusse schwellen, 3. die schwăne mit ihm erscheinen, die nachtigallen und schwalben ihren gesang anstimmen, 4. und dies ist ausschlaggebend: bei seiner ankunft der dreifuss tōnt, dass ist: die pythia weissagt, was ursprtinglich nur einmal, und am siebenten tage des frublingsmondes Bysios geschah. Dem entsprechend wurde auch Apoll als im lenz geboren gedacht: eben am siebenten Bysios; und eben darum weissagte an diesem tage die Pythia.1)

Um den beweis vollzumachen, verweist Roscher ${ }^{2}$ ) auf die angabe des Hesiod Erga 526, dass die sonne (und Apoll ist nachweislich in orster linie sonnengott) im winter verschwinde und bei den Aethiopen weile; so auch auf die sitte der vैuvo $x \lambda \eta \tau \iota x o l$, mit denen Apoll im frubjahr eingeladen wurde, wăhrend ihm bei winters eintritt geradezu mit entlassungsgesanngen $\left({ }^{\prime \prime} \mu \nu 0 \iota ~ \alpha \jmath \pi о \pi \varepsilon \mu \pi \tau \iota x o l\right)$ das geleite gegeben wurde. Auch stellen des Theognis und des Dion. Perieg. ergeben, dass Apolls widerkehr im frthling festlich begangen wurde. Derartige feiern geschahen ausser in Delphi und Delos nachweislich in Milet, Megara, Bōotien.

Wenn also eine sage entstand, dass Apoll, in Delos geboren, von da zu den Hyperboreern und von da nach Delphi zog, so sind an ihr drei elemente sohöpferisch gewesen: 1. die sage von seiner delischen geburt; 2. die sage von dem wunderbaren jungling, der, von schwänen gezogen, licht bringend, aus einem unbekannten land im frubling kommt und in dieses land im herbste heimkehrt; 3. der name des Hyperboreerlandes für die angebliche heimat des gottes.

Nach dem volkgglauben ${ }^{3}$ ) war Apoll unmittelbar nach seiner geburt von feindseligen dämonischen gewalten, drachen oder riesen, gefäbrdet. Nach sieben tubereinstimmenden, durch bildwerke noch weiterhin als populär belegten zeugnissen erlegte er unmittelbar nach seiner geburt, noch auf dem mutter-

1) Wenn die delische geburtsfeier des Apoll getrennt von dem frühlingsfeste der epiphanien am siebenten tage des attischen Thargelion, also zu sommeranfang gefeiert wurde, so weist Roscher (a. a. o. 37) darauf hin, dass allem anschein nach beide feste urspringlich $\mathrm{zu}$ sammenfielen und erst bei einer widererneuerung getrennt warden.

2) A. a. 0. 31 .

3) A. a. $0.39 / 40$. 
arm, oder nach delphischer traditiou doch als knabe, einen drachen, der ihn vernichten wollte.') Roscher deutet diesen kampf des sommergottes unmittelbar nach der geburt auf die mit seinem erscheinen zusammenfallende uberwältigung des winters; und der Germane wird unwillkurlich an Vali erinnert, der den wintergott Höor kaum geboren erschlägt; ursprünglich, das ist vor der cyklischen verkntupfung, wahrscheinlich ohne bezug auf die ermordung Baldrs, nur als sieg des jung erstandenen lenzgottes uber den winter. ${ }^{2}$ ) Immerhin kommen wir hier uber die vermutung nicht hinaus. Von wichtigkeit aber wird uns der mythus, insofern er in Delphi dramatisch dargestellt wurde. Ein knabe erschlug das ungetum, musste aber dann als befleckt fliehn und entstihnt werden. Aus diesem cult soll sich die sage entwickelt haben, dass Apoll acht jahre lang als knecht die stuten des Admet oder die rinder des Laomedon gehutet habe. Grund des zweiten teils des ceremoniellen spieles sei gewesen, dass Apoll als Katharsios sich auch selbst von seiner bluttat habe entsuhnen nulussen.

Es muss nun jedem uberlassen bleiben, sich mit der wahrscheinlichkeit dieser hypothese abzufinden; eine mindestens nicht geringere wahrscheinlichkeit jedoch wird fur eine weitere theorie zu beanspruchen sein: nachdem dargetan ist, dass ein altgriechischer mythus (fur sein alter spricht sein auftreten in durchweg verschobener gestalt) den Apoll als im sommer anwesend, im winter fern weilend betrachtete; nachden die wahrscheinlichkeit hervorgehoben wurde, dass Apoll der drachentöter den uber den winter triumphierenden neugeborenen fruhlingsgott darstelle, ist, bei der sofort in einem weiteren cultus zu belegenden neigung der Griechen, anfang und ende des cyklisch aufgefassten jahresverlaufs in einer einzigen zusammenhängenden culthandlung darzustellen, anzunehmen, dass die drachentötung als winterbesiegung, das entweichen im herbst

1) Vgl. eine entsprechende indische überlieferung Mannh., G. m. 233.

2) Ich mache ausdrücklich darauf aufmerksam, dass, die richtigkeit der Roscherschen hypothese vorausgesetzt, von Apoll zwei jahreszeitenmythen in schwang waren: 1. dass er, im winter abwesend, im lenz heimkehre, 2. dass er, im lenz geboren, den winterdämon erschlage. Eine ganz ähnliche doppelüberlieferung wird uns auf deutschem boden als wahrscheinlichkeit begegnen. 
und die widerkebr im lenze in einer handlung zusammengefasst, und später durch missverstăndnis das entweichen auf befleckung und die widerkebr auf entsuhnung gegrlundet wurde; denn Apoll ist erst später ein Katharsios geworden. In dieser gestalt wurde der cultus eine interessante ähnlichkeit mit der indischen sage haben, in der auch dämonentōtung, flucht und widerkehr einen cyklus bilden, der fälschlich durch das befleckungs- und entslihnungsmoment motiviert wird.

Unter diesem gesichtspunkt wird Otfried Mtallers') hinweis

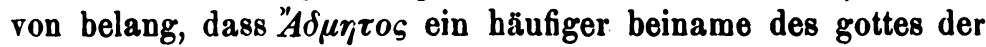
unterwelt ist und dem entsprechend Apoll wol eigentlich nicht dem frommen Admet von Pherä die stuten weidete. ${ }^{2}$ )

Der letzte ausserdeutsche mythus, dem wir in diesen erörterungen einige aufmerksamkeit zu schenken haben, ist der des Adonis. Er ist uns um so wichtiger, als er, ursprunglich semitisch, sich als ein drittes neben die indische und die griechische parallele stellt. Das einschlägige material ${ }^{3}$ ) ist folgendes: 1. das Alexandrinische fest (nach den Adoniazusen des Theokrit): auf einem prachtpolster ruht der junge Adonis neben Aphrodite gebettet. Eine săngerin singt ein uppiges festlied, welches, beginnend mit der schilderung, wio nach jahresfrist die Horen den Adonis von dem Acheron zurluckgefuhrt haben, mit der aufforderung schliesst: jetzt möge die göttin des geliebten sich erfreuen; in der fruhe werde man inn unter grossem geleite zum meere tragen, unter ekstatischen schmerzensgebärden und rufen: komm, theurer Adonis, einzig bevorzugter hier wie am Acheron, sei uns glinstig jetzt und im kommenden jahre! Freundlich kamst du; sei uns freundlich, wenn du ividerkehrist! Die săngerin weiss mebr, als sie kundet. - Also zwei feste an zwei tagen: eines der freude,

1) Dorier I, 320.

2) Diese bemerkung würde von grösster wichtigkeit, wenn Preller (I, 107) mit recht einen kleinasiatisch-griechischen Zeusmythus und -cultus annahm, dem zufolge Zeus als im frühling geboren, im winter gestorben betrachtet und gefeiert wurde. In eigentlimlicher parallele stünden zu einem derartigen mythus die nordischen tiberlieferungen uiber Freys, 0ชins, Baldrs tod, uber die W. Miiller, System 267, Simrock, Handbuch 366, Uhland VII, 70 gehandelt haben.

s) Zusammengestellt von Engels, Kypros II, $537 \mathrm{ff}$. 
eines der klage. Charakteristisch ist, dass das liebespaar auf dem lager umgeben ist von frichten des jahres, lauben, salben, vögeln. Auch Adonisgärtchen wurden angelegt, indem in gewisse gefässe weizen und gerste oder fenchel und auch lattich gepflanzt wurden; die rituelle verwendung und bedeutnng der letzteren kann hier nicht erörtert werden. ${ }^{1}$ ) 2. Auch die mysterienfeier von Byblos (Lukian, Syr. gött. c. 6 ff.) betont zwei tage: an ersten schlug man sich unter leidenschaftlichen klagen mit fäusten und opferte dem Adonis als einem toten, am folgenden verktundete man seine auferstehung. 3. Kyrill (z. Jesaias c. 18) bemerkt: die Griechen trauern und jammern mit Aphrodite um den tod des Adonis; sobald er aber aus der unterwelt zurlickkehrt, sagen sie: er ist gefunden! und beglickwunschen sich und jubeln in ausgelassener freude. - Das fest scheint mitsommer statt gefunden zu haben. 4. Nach der einen sagenform liebt Aphrodite den Adonis und tubergibt ihn der Persephone zur pflege, die ihn nunmehr ihrerseits lieb gewinnt und nicht mehr entlassen will. Zeus, als schiedsrichter angerufen, entscheidet, dass Adonis einen teil des jahres bei Aphrodite, den anderen bei Persephone verweile. 5. Nach der anderen uberlieferung liebt und raubt ihn Aphrodite. Von einem eber auf der jagd getötet, steigt er in die unterwelt, wo er bei der ihn liebenden Persephone weilt, darf aber im lenz zu Aphrodite zurlekkehren und bis zum herbste mit ibr leben.

Die griechische sage hat den semitischen mythus jedenfalls sehr stark fortgebildet, wie schon aus der verwandlung des phönizischen gottes (fur einen solchen zeugt der name Adon = herr) in das liebreizende kind der blutschande erhellt. Klar aber tritt aus allen gestaltungen hervor: 1. Ein gott, der im winter fern weilt, im lenz widerkehrt (der griechische sterbliche jungling weilt naturlich in der unterwelt; dies ist auch das einzige, was die liebe der Persephone bedeutet, während Aphrodite als eine mit der befruchtung in beziehung stehende gottheit erweislich ist), 2. dass dieser gott eine innige beziehung zu der chthonischen fruchtbarkeit hat (vgl. die Adonisgärtchen).

1) Vgl. hierüber Mannhardt, A. W. F. 279/80, dessen folgerungen ich mich allerdings nicht durchweg anschliesse, 
Unter den anderen griechischen mythen ist wahrscheinlich der von den Dioskuren ähnlicher natur; der von Kore kommt erst sehr in zweiter linie in betracht.

Das ergebnis unserer ausserdeutschen analogiensammlung ist also: I. ein indisches analogon: ein jahreszeitengott, der im sommer zugegen, im winter abwesend ist und einem usurpator platz macht, den er dann im lenze heimkehrend vertreibt oder vernichtet. 11. Drei griechische analoga: 1. Apoll weilt tber winter in einem unbekannten lande, aus dem er im. lenze von schwånen gezogen heimkehrt. 2. Apoll tber winter in hirtenfrohnde: vielleicht in der unterwelt; das angegebene zeitmass hat wol katharsische bedeutung. 3. Ein held (Odysseus), ursprunglich ein gott, weilt eine hieratisch bemessene zeit in einem nebellande, kehrt unkenntlich als bettler heim und erlöst sein weib und reich von gewalthabern. 1. 2) Anzumerken ist, dass Apoll als im lenze geboren betrachtet wird. III. Ein phönizisches analogon: der gott Adon im winter fern, im lenze widerkehrend zu seiner sehnstlchtig harrenden gattin.1)

Zu II ist eine ganz merkwtrdige deutsche parallele anzufuhren. Unter den rätseln der deutschen sagenforschung, welche Muller mit seiner synthetischen methode mehr verwirrt als gelöst hat, gehört die sage vom schwanenritter. Eine betrăchtliche anzahl von uberlieferungen berichtet ron einem herrlichen jungling, der, aus einem unbekannten lande, von schwănen gezogen, erscheinend, einer bedrăngten frau beisteht, ihr gatte wird, längere zeit bei ihr verweilt und dann in sein wunderland heimkehren muss. In zwei therlieferungen, bei Wolfram und im Lohengrin, ist der bedranger ein ungestumer frejer. Die motivierung der heimkehr des helden fliesst der

1) Zur stlltze diese belege sei noch auf den paphlagonischen mythus verwiesen, dass der jahreszeitengott im winter gebunden und eingesperrt und im sommer befreit sei (vgl. Preller I, 107); wozu als bedeutsame deutsche parallelen anzufuhren sind: 1. die worte der carm. bur.: serato ver carcere exit ( $\mathrm{vgl}$. Grimm, Mythol. III, 75). 2. Oðins gefangenschaft bei Geirroð (verwendet in der offenbar verworrenen rahmenerzählung von Grimnismal, welche die verschiedensten überlieferungen combiniert; dass ein derartiger mythus erzählt wurde, zeigt die ubertragung der gefangenschaft auf Loki im achtzehnten capitel der Skalds; vielleicht auch die sage von Thorsteinn Bäarmagn). 
uberlieferung aus der eigenen unkenntnis: sie weiss nicht, von wannen der held kam; ein heiliges geheimnis waltet daruber, und webe, wer es zu luften versucht! Sein weib kann der neugierde nicht widerstehn; sie fragt trotz seiner warnung und er zieht, von seinem schwane geholt, von dannen.1)

Der schwan als zugvogel kehrt im lenze zurtick und scheidet im herbst; der schwan ist erweislich als das bild der sommerwolke und scheint vielleicht belegbar zu sein als bild der sonne. Ein interessanter umstand erhöht den mythischen zauber der uberlieferung: in mehreren versionen erscheint der held in dem schwanennachen schlummernd auf einem. schilde. Der schild ist eddisch und anderwärts erweislich als bild der sonne. Aber mehr als dies: wir haben zwei sagen, die einander fast gleich lauten: nach dem Beowulf erschien Skyld, der sohn des Skeaf, auf einem kahn als kind, man wusste nicht, woher, und als or als greis verschied, setzte man ihn auf den nămlichen kahn, und er entschwand, man wusste nicht, wohin. Năhere umstände uber seine ankunft erbellen nicht; da aber der als sein vater genannte Skeaf seinen namen daher hat, dass er in gleicher weise schlummerd auf einem getreideschaub landete, so wird sich der name Skyld auf seine ankunft schlummernd auf einem schild beziehn. Diejenigen unserer mythologen, die bei ihren forschungen mit dem genealogischen element anfangen statt mit ihm aufzuhören, haben kurz entschlossen erklärt, dass das Beowulfslied sich habe eine verwirrung zu schulden kommen lassen und kecklich den mythus von Skeaf auf seinen sohn tbertragen babe; da aber die Skiöldunge nicht nach Skeaf sonderu nach Skyld benannt wurden und in der tat die genealogische anknlipfung an Skeaf nicht einmal durchgedrungen, zum beispiel eddisch schlechtweg durchbrochen ist ${ }^{2}$ ), so ist anzunehmen, dass die vaterschaft des Skeaf eine accessorische und wol gerade durch den umstand veranlasste ist, dass von beiden helden eine ganz ăhnliche sage erzăhlt wurde.3)

1) Es kann nicht entschieden genug darauf hingewiesen werden, dass die sagen aus sich hersus organisch weiter wachsen, und dass die volksphantasie ganz logisch ans den prämissen die folgerungen zieht.

2) In der jüngeren Edda ist Skiöld der sohn Oðins.

3) Die sage von Skeaf ist Ubrigens zuerst bei Ethelwerd (gestorben 
Die angelsächsischen genealogien machen es wahrscheinlich, dass Skeaf wie Skyld ursprunglich götter waren, und zwar von einer Frey ähnlichen, das heisst: in befruchtender weise wirkenden natur. Die mythische bedeutung des namens Skeáf ist schlechtweg unaufgeklärt, wenn auch aus mancherlei beobachtungen eine dereinstige aufklärung zu erhoffen ist. Soviel lässt sich aber aus der einreihung der drei beispiele in unsere sammlung schliessen: in allen drei făllen liegt ein jahreszeitenmythus vor, dass ein sommerlicher gott im winter fern weilt und im lenze widerkehrt; in der schwanensage zu einem sehnlich harrenden oder gar von einem freier bedrăngten weibe. Und zwar wird in der ursprtinglichen mythenform Skyld nicht auf dem schilde in dem nachen sondern auf dem schilde als nachen, und desgleichen Skeaf auf dem schaube als fahrzeug erschienen sein; der schild als sonne ist wio gesagt erweislich, und in dem sinne eines sonnenwesens fuble ich mich angeregt meinerseits den Skiöld zu verstehn.

Aus dieser mythenmasse heraus orhellen sich auch die rätselw.orte des angelsächsischen liedes zu der rune Ing 1): Ing war zuerst unter den Ostdänen; spăter ging er ostwărts uber die flut. Die widerkehr verschweigt das.lied, wie die sagen von Skeaf, Skyld und dem Schwanenritter: die sage kennt in der regel nur einmalige ereignisse. Vielleicht erbellt sich auch in dieser weise die bertichtigte tuberlieferung des Tacitus c. III: Ulixes sei auf seiner berthmten irrfahrt auch nach Deutschland gekommen, habe Asciburg (kann heissen: schiffsstätte) gegrindet und sogar einen altar mit seinem vater gemeinsan gehabt: wenn nur die ganze nachricht nicht von vornherein dưchb dâs quildam opinantur in die luft gehoben wurde, das ebenso auf unzuverlässige gewährsmånner wie zwiespältige nachrichten gehen kann.

1090) tiberliefert (vgl. Grimm, Mythol. III, 391): bei dem compilatorischen charakter der angelsächsischen genealogien ist somit kein grund vorhanden, ihnen zu liebe dieser späten nachricht den vorzug vor dem bericht des Beowulf zu geben. Sehr zu bemerken ist, dass bei Ethelwerd Skeaf nicht auf einer garbe ruht (wenigstens weiss E. nichts von einer solchen zu berichten) sondern armis circumdatus erscheint wie der Skyld des Beowulf liedes.

1) Grimm, Ueber deatsche runen 231. 
Dem Ingvi-Frey schliesst sich billig sein 'vater' Njörðr an, der wol auch einmal eine sonderexistenz ohne familienbelastung gefuhrt hat und jedenfalls sehr verschiednenorts vater des Frey und gatte der Skadi geworden ist; wenn es auch vielleicht an stimmen nicht fehlen wird, welche auf grund einer späten eddischen compromiss-nachricht darauf schwören, dass Freyr der sobn der Skadi sei.1)

Die einschlägige sage von Skadi und Njöro hat in einem in sich geschlossenen gedicht dem verfasser von Gylfaginning vorgelegen; wahrscheinlich einem der beliebten streitgedichte, welches die wirksame situation der unglucklichen ehe der beiden ungleichen gatten zu einem schalkhaften, allerliebsten kleinen roman ausnutzte. Man darf unter solchen umstănden naturlich nicht an die lustigen verse das bleigewicht tiefsinniger mythendeutungen bängen; doch lässt sich etwa ersehen, dass der arme Njöror in dem ehelichen streit den kürzeren zog und, seinerseits die verabredung einhaltend, neun monde des jahres (neun năchte, sagte das lied) in den winterlichen bergen frieren musste, welche Skadi nicht wider verliess. Denn der augenscheinliche grundgehalt der altmythischen situation ist ein periodisches langes verweilen des befruchtenden vanen in dem winterland.

Und somit zeichnet sich auch dieser mythus durch eine eigentumlichkeit aus, welche einem teil der mythen des paragraphen eine inhaltsschwere bedeutung gibt: Apollon kommt aus seinem heimatlichen wunderland und kehrt in dasselbe zurtlck. Adonis ist der unterwelt verhaftet: er kommt aus ihr, aber er kehrt in sie zurtck. Der schwanenritter erscheint aus einer wunderheimat und kehrt in sie zurllck. Skeaf und Skyld kommen aus unbekannter ferne und kehren in sie zurluck. Njöror kommt aus den winterbergen, muss aber in sie zu Skadi zurtick kehren. Und so erinnere ich an Orendel, der aus Ises knechtesdienst zu frau Bride kommt, aber zu Ise zuruckzu-

1) Vgl. dagegen die, allerdings vielleicht aus 0egisdr. stammende nachricht der Yngls. c. 4, dass Njöror als vane seine schwester zur frau and mit ihr Frey und Freya zu kindern gehabt habe, dass aler diese geschwisterehe bei den asen (kann heissen: bei den völkern und zeiten, unter und za welchen das asensystem herrschte) nicht erlaubt und anerkannt gewesen sei. 
kehren hat. Und an den grafen von Calw, der seine berge und heerden verlässt, um seine gattin vor einer zweiten ehe zu wahren, aber wider in seine berge und $\mathrm{zu}$ seinen heerden zurlickkehrt.

Und noch eine fernere eigentumlichkeit: Apollon erscheint im lenze neugeboren. Skeaf, Skyld erscheinen neugeboren, ebenso Vali. Hierzu aber halte man vorläufig die eigentumliche anschauung, dass Thor den Oervandil in einem korb auf dem rucken uber die Elivagar trägt: eine zehe lugt aus dem korb und erfriert. Ist dies das bild eines erwachsenen mannes? oder eines kindes?!

An das periodische scheiden und widererscheinen dentscher und ausserdeutscher götter und helden ist noch eine interessante therlieferung anzureihen. Bei der analyse der Hymiskviða haben wir als ein mythisches einzelgebilde die nachricht herausgehoben, Tyr kehro heim in das riesenland, von langer wanderung, erwartet von seiner mutter und deren riesischem gemahl, oder von seinem vater und dessen kebse. Die frage, in welchem verhältnis Tyr zu seiner riesischen verwantschaft steht, ist eine äusserst heikele; es ist aber mit einiger sicherheit aus der rede der kebse: sei freundlich, dein sohn ist heimgekommen - auf ein directes kindesverbältnis Tys zu einem riesen (der naturlich ursprunglich nicht gerade Hymir geheissen haben muss, wenn auch der dämmerer als vater des sonnengottes fur allegorische gemuter etwas sehr uberzeugendes haben mag) zu schliessen. Daraus allerdings eine entstammung der götter von den riesen zu folgern, wie es Weinbold und andere getan, ist unmöglich geworden, nachdem die untersuchungen Kuhns und besonders Mannhardts (in den von Kuhn so hart verurteilten, aber bei viel jugendlicher fluchtigkeit und methodischer unfertigkeit epoche machenden germanischen mythen) den nachweis gefuhrt haben: 1. dass die germanische götterwelt eine zweigentwickelung eines indogermanischen mythenstammes ist, 2. dass dieser mythenstamm bereits den kampf der götter und dămonen zu energischstem ausdruck brachte. Nur ist fest zu halten, dass jener, den ungetrennten Indogermanen gemeinsame mythenstock aus elementen bestand, die im wesentlichen die entwickelungsstufe undifferenzierter naturanschauungen einnahmen, vielleicht hier 
und dort die ersten primitiven motivansätze zur fabelbildung aufwiesen, local gewiss vielfach in dem ubergang zu complicierteren gebilden begriffen waren: nur dass letztere gebilde schwerlich bereits uber grössere gebiete verbreitung gefunden hatten. Dieses verhältnis ergibt sich aus den erfolgen und misserfolgen der vergleichenden mythenforschung, die jeden enttăuschen mussten, der sich auf ein gemeingut ganzer romane rechnung gemacht hatte, so dass gar mancher uber der enttåuschung das kind mit dem bade ausschuttete. Eine summe primitiver mythen aber ist als gemeinsames ureigentum bereits nachgewiesen worden und wird noch fernerbin nachgewiesen werden.

Von diesem standpunkt aus gesehen, und in anbetracht der beigebrachten analogien erscheint der mythus, dass Tyr nach langen wanderungen in das heimatliche riesenland, das Ostland (in den osten verlegt ja Hymiskviða die Elivagar) heimkommt, als der periodische jahreszeitenmythus von dem sonnengott, der, im winterland beimisch, allsommerlich uber der orde erscheint und allwinterlich in die kalten regionen zurlickkehren muss.

Und im anschluss an diese orwägungen wage ich eine weitere combination. In einem viel umstrittenen passus der Germania leiten sich nach Tacitus die Germanen ab von einem Mannus, dem sohve eines Tuisko oder Tuisto (beides gleich gut tuberliefert), der widerum als ein sohn der erde gelten soll. Mullenhoff bevorzugt mit Lachmann die lesart Tuisto und deutet den 80 bezeichneten gott auf den zweifachen, das ist: den himmel und erde umspannenden: eine deutung, so geistreich, dass sie das geprăge der unmoglichkeit auf der stirne trăgt: es wăre wol das einzige (wenigstens alt tberlieferte) beispiel eines nach einer mathematischen abstraction benannten gottes.1): Die andere, von Mullenhoff zurlickgestellte lesart hat man auf ein ursprungliches Tivisko zuruckgefuhrt, mit

1) Ein gott als träger des von Lachmann und Mullenhoff angenommenen inhaltes hätte vielleicht 'der umfassende' oder 'der allmächtige' geheissen; obwol auch solchen namen kein hohes alter wahrscheinlich ist. Die von anders denkenden wissenschaftlern geltend gemachten benennungen wie 'sohn der kraft' bedeuten nichts als: 'der kraftrolle', sind also durchans concreten inhalts. 
mehr recht, als Mullenhoff zugesteht, da die veränderung der uberlieferung eines 'liuisko in Tuisko durch verlust des ersten i eine paläographisch unwesentliche ist. Ist diese lesart richtig, so ist zwar Tivisko sohn der erde, aber Mannus nicht sohn des Tivisko, so wenig wie Sigmundr sobn des Völsung ist, sondern Mannus ist selbst Tivisko (abkömmling des Tiu), wie sein abkömmling, mennisko, der mensch, ist. Ist aber Mannus Tivisko und sohn der erde, somit die erde gattin des Tiu, so ist es gestattet die tberlieferung der Oegisdrekka heranzuziehen, die str. 40 der gattin des Tyr buhlerei vorwirft: nach dem von Oegisdr. beliobten verfahren naturlich mit Loki, der hier so wenig in betracht kommen wird wie fur die buhlerei der Sif. Erlaubt man sich die combination beider nachrichten, so ergåbe sich ein mythus, dem zu folge Tyr, mit der erde vermählt, ihr zeitweise fern weilte, indes ein buhler sich ihr zugesellte. Eine vermählung des lichten himmelsgottes mit der erde ist ein mythisch allenthalben zu belegendes factum; die winterliche buhlerei eines chthonischen wesens ein in dieser erörterung für die germanische mythik mehrfach belegter zug. Es wüde dann von Tyr genau wie von Orendel erzahlt werden: 1. dass wăhrend seiner winterlichen abwesenheit ein winterlicher dămon sein weib umbuhlte; 2. dass er die zeit seiner winterlichen abwesenheit im winterland verbracht habe. Die scheinbare unvereinbarkeit dieser beiden zlige wird später erörtert werden.

Wenn es gestattet ist, noch eine fast uberk thne hypothese aufzustellen, so wăre es mőglich, dass auch Lokis behauptung von Skadis buhlerei eines berechtigten hintergrundes nicht entbehrte: insofern hier die buhlerei des mannlichen Skadi (uber dessen kampf mit Skiōld oben gehandelt ist) irrtumlich auf seine namens- und wesensschwester ubertragen wăre.

\section{Ein hypothetisches analogon.}

In der folgenden erörterung wage ich weit weniger sicher aufzutreten. Das gebiet ist ein strittiges, die methode unsicher. Der erste anblick meines analogons zeigt allerdings eine verbluffende ubereinstimmung mit Mahabharata und $\mathrm{Mi}$ toðinmythus; eine ausgezeichnet geschickte, wenn auch metho- 
disch nicht unanfechtbare arbeit Varnhagens ${ }^{1}$ ) in Benfeys bahnen scheint diese ganz uber den haufen zu werfen - und widerum bei einer eingehenden kritik dieser, auf den ersten blick durchaus tberzeugenden auseinandersetzung bleibt von der hypothese genug ubrig, um sie, mit aller vorsicht, als hypothese aufrecht zu erhalten.

Es handelt sich um die sage von Salomon und Aschmedai, deren inhalt kurz gefasst lautet: Salomon wird durch list von Aschmedai seines zauberrings beraubt (vermöge dessen er die dämonen beherrscht) und muss unkenntlich als bettler wandern, während Aschmedai in Salomons gestalt herrscht und seinen weibern naht. Durch seine eigene niedrigkeit entlarvt er sich, wird des ringes beraubt, Salomon wird zurtuckgeholt, und Aschmedai entflieht. Man sieht: die ähnlichkeit ist uberraschend, zug fur zug.

Da erscheinen Benfey und Varnhagen: afflant, et omnia dissipantur. Eine märchenfamilie wird vorgefuhrt: einfachstes beispiel: ein greiser könig făhrt in eines jünglings körper, flugs fährt ein zauberer in den seinen, tōtet den jüngling und ist nun seinerseits könig. Fortgeschrittnere form: ein könig făhrt in einen bettler- oder tierkörper, flugs făhrt ein anderer in den seinen, und der könig muss wandern, wăhrend der andere könig ist; der falsche könig sucht aber der königin zu nahen, diese schöpft verdacht, der echte wird entdeckt, der falsche bewogen, zum beweis seiner kunst in einen papagei oder esel zu schlupfen, worauf der echte könig seine alte hulle wider in besitz nimmt: und der betriger ist betrogen.

An stelle des tberschlupfens aus einem körper in den anderen soll nun der gestaltenwechsel getreten sein. Salomonsag ${ }^{2}$ ): in talmudischen therlieferungen (also in den ersten sechs jahrhunderten n. Chr.). 1. Die nach Varnhagen ursprlinglichste form: jerusal. Tal. (c. $350 \mathrm{n}$. Chr.): gott heisst Salomon seinen thron verlassen, ein engel nimmt diesen ein in des königs gestalt, Salomon wandert von schule zu schule: ich,

1) Ein indisches märchen (auch E. H. Meyer, Gandharven und Kentauren 151 ist von ihm überzeugt).

2) An Salomon angewachsen in folge einer stelle des psendosalomonischen, c. 500/400 v. Chr. fallenden predigers Salomon: ich, prediger, war kornig in Israel! 
prediger, war könig in Israel. Die leute glauben ihm nicht und schlagen ihn. 2. (Die quelle ist leider nicht năher angegeben): Salomon verstundigt sich; gott heisst den dămonenfürsten Aschmedai den könig des ringes berauben und in seiner gestalt herrschen. Salomon, durch einen sturmwind vom thron geschleudert, irrt umher: ich, predigør u. s. w. Wăhrend dessen macht Aschmedai die reihe von Salomons frauen durch; bei der letzten, der er zur zeit ihrer unreinlichkeit naht, wird seine niedrigkeit entdeckt, Salomon wird zurtackgeholt, Aschmedai des rings beraubt, Salomon erhält seine alte gestalt wider und herrscht füder. 3. Babil. Talm. (mitte des sechsten jahrhunderts n. Chr.): Salomon spricht $2 u$ dem gefesselten Aschmedai verăchtliche worte; dieser erbietet sich, seine macht zu erweisen, wenn ihm Salomon die kette abnehme und seinen ring tubergebe. Sobald dies geschehen, verschlingt und speit er den Salomon weit in die ferne und herrscht in des königs gestalt; Salomon wandert und spricht die tblichen worte. Hierdurch und durch Aschmedais niedrigkeit kommt der betrug an den tag; man gibt Salomon einen (!) ring (mit beiligen zeichen) und eine kette, und wie ihn Aschmedai kommen sieht, entläuft er. 4. Eine weitere fassung aus der Kabbala ist verschoben; wichtig nur, dass in ihr widerum Salomon um seiner stinden willen leidet. 5. Verwant: Buch Daniel (c. 167 v. Chr.): Nebukadnezar beruhmt sich seiner macht vor gott; zur strafe wird ihm sein reich genommen, er von den menschen ausgestossen, und muss sieben jabre bei dem wilde des feldes hausen und gras fressen, in entstellter, verwilderter gestalt. Nach sieben jahren suchen den gedemutigten seine răte und setzen ihn wider ein in seine herrlichkeit.

Diese belegkette klingt äusserst uberzeugend. Ich war nach der ersten lecture ganz niedergeschlagen und bereit mich zu ergeben. Aber nach und nach stiegen mir einige zweifel auf, und sie gestatte ich mich hier zunăchst niederzulegen.

Die älteste indische version, des inhalts, dass der greise könig in den jungling schlupft, der zauberer in den königsleib, den jungling erschlägt und füder selbst herrscht - wird von Vikramâditya erzählt, der im ersten jahrhundert vor Christus regierte, ein liebling nachmals der indischen sage. Da nach 
Benfey ${ }^{1)}$ von ihm nachweislich sagen auf Salomon tubertragen wurden, so soll nach Varnhagen von dieser fassung aus der ubertritt in die judische uberlieferung erfolgt sein. Dem entsprechend hält Varnhagen für die alteste judische sagenform die im vierten jahrhundert n. Chr. aufgezeichnete tberlieferung, nach welcher gatt dén Salomon um seiner stunden willen entthronte und einen engel an seiner statt und in seiner gestalt zum herrscher uber die Juden setzte, wăhrend Salomon im elend irrte und die worte des 'predigers' sprach ohne glauben zu finden. Vergleicht man die beiden erzăhlungen, so ist die discrepanz dieser fassungen offenbar so gross, dass gerade sio zu combinieren ṇiemandem beigekommen wăre. Ausserdem aber ist die judische fassung keine ursprtungliche sondern eine abgeleitete: 1. weil der engel wider einem irdischen könig platz machen musste, 2. weil eine altere, aus. dem zweiten jahrhundert v. Chr. stammende therlieferung bereits eine parallele bietet, der zu folge ein könig (Nebukadnezar), um seiner stinden willen ron gott entthront, nach busse im elend wider eingesetzt wurde. Hatte aber die ålteste Salomonversion eine derartige gestalt, so hatte sie mit der ăltesten indischen version nichts zu schaffen.

Die verschobene indische tuberlieferung wurde nicht vor dem vierten jahrhundert n. Chr. aufgezeichnet. Sie stimmt mit der spateren judischen Salomonrelation in verbluffender weise uberein; weit weniger verbluffend schon mit der des vierten jahrhunderts, in welcher keine rede von einem weibe Salomons ist. Diese tbereinstimmung durch sagenwanderung zu erklăren, existiert kein tuberzeugender historischer grund, da von Vikramaditya, der notorisch sagen an Salomon abgegeben hat, eine so geartete fabel nicht erzăhlt wird. Es bleibt nur die allgemeine motivierung, dass tatsăchlioh sagenubergănge von Indern auf Juden vorgekommen seien. Ein derartiger ubergang wåre v or dem zweiten jahrhundert v. Chr. nur dergestalt anzunehmen, dass die nachmals an Vikramaditya gekntipfte einfache tberlieferung das kind einer älteren, complicierteren sagenform darstelle, bezliglich: dass bereits vor der Vikramadityaversion eine compliciertere behandlung des

1) Pantschatantra 1, 129. 
nämlichen stoffes bestanden hătte. Eine derartige in der luft stehende combination ist von vornherein als unwissenscliaftlich zu verwerfen. Folglich mulsste die sage n. Chr. ubergewandert und wol auch entstanden sein. Nun tritt zwar die entsprechende judische Salomonsage erst in aufzeichnungen n. Chr. auf, aber ihre abstammung von der indischen wäre orst alsdann anzunehmen, wenn sie innerhalb der judischen sagentradition isoliert dastände, ohne einen fubler jenseits des beginnes unserer zeitrechnung zu strecken. Dies ist nicht der fall. Das charakteristische der talmudischen Salomonsage (mit ausnahme einer tberlieferung des sechston jahrhunderts) ist, dass Salomon zur strafe fur seine sunden gestlirtzt und nach seiner demutigung wider erhöht wird. In dieser fassung aber ist eine judisohe kōnigslegende an den könig Nebukadnezar gekntpft, und die wichtigen ztige dieser, in dem zweiten jahrhundert v. Chr. aufgezeichneten sage lauten, dass Nebukadnezar 1. wegen seiner stinden von gott entthront wurde, 2. sieben jahre entstellt im elend weilen musste, 3. nach ablaufe dieser bussezeit und seiner demutigung wider eingesetzt wurde. Die anknupfung einer derartigen erzählung an Salomon lag nahe in folge der, wie es scheint, populär gewordenen worte des pseudosalomonischen 'predigers': ich, prediger, war könig in Israel; aus denen leicht gefolgert werden konnte, dass Salomon wirklich einmal nicht mehr könig war; zumal der zorn gottes uber Salomons sunden und die drohung seiner entthronung der biblischen uberlieferung entsprach.1) So erklärt sich auch, dass der bussende Salomon wandern muss und immer jene worte spricht; es bedarf dazu gar nicht erst einer indischen uberlieferung. Endlich erklärt sich vielleicht aus der biblischen luberlieferung, nach der gott dem Salomon einen widersacher erweckte ${ }^{1}$ ), die ausfullung des interregnums während der busse durch einen engel in Salomons gestalt wenn nicht ein derartiger remplaçant schon der ursprtinglichen fabel eigen war und nur im Buch Daniel verschwiegen blieb. Erst an seine stelle trat dann (auch nach Varnhagens ansicht) der faunische2) Aschmedai, der aus einem ganz unabhăngig

1) Vgl. Vogt, Salman IL.

1) Ueber den durchaus faunischen charakter des jüdiscben Aschmedai vgl. Grinbaum i. d. Zeitschr. d. d. morgl. gesellsch. XXXI, 222. 
um Salomon entwickelten sagencomplex entnommen wurde, um der erzählung noch den letzten stempel aufzudrtlcken: denn die faunische brunst nach der menstruierenden frau und die begierde nach Salomons mutter hat keine ãhnlichkeit mit dem begehren des indischen usurpators nach der gattin des entthronten königs. Das wesentliche ist gerade die in Aschmedais brunst verrăterisch hervorbrechende unreinliche natur des faunischen dămons; dass in der indischen legende wie der judischen sage der usurpator die hand nach der konnigin streckt, ist ebenso zu erklăren wie die einfuhrung von Indras gattin in die sage von Nahusha: das weib darf dem roman nicht fehlen. In der talmudischen, von Varnhagen als ursprunglichste angenommenen uberlieferung ist, wie bemerkt, von einer königin noch keine rede.

Somit ergibt sich: 1. eine alte, judische tradition, schon im zweiten jahrhundert v. Chr. nachweislich, der zu folge ein könig wegen seines hochmuts von gott entthront im elend leben muss (nach der ältest erhaltenen tiberlieferung die althieratische zahl von sieben jahren), bis er, gedemtitigt, wider zu der alten herrlichkeit erhoben wird. 2. Diese sage wird an Salomon geknupft: vielleicht in anschluss an die citierten worte des pseudosalomonischen 'predigers'; die zeit des interregnums wird jetzt (oder war von vorn herein) mit einem, in des königs gestalt regierenden engel ausgefullt. 3. An dessen stelle tritt der aus den dämonenkămpfen Salomons ubernommene Aschmedai, 4. dessen (schon in jenen kămpfen zu tage tretende) faunische natur die gestaltung der lösung beherrscht.

Mit Vogt (a. a. 0.) anzunehmen, dass die ganze legende aus den worten des 'predigers' und einigen bibelstellen herausgewachsen sei, hindert der umstand, dass sie in ältester, einfachster gestalt nicht an die person Salomons geknupft ist. Die uberlieferung in der unter 1. mitgeteilten fassung als eine legende, eine priestererfindung anzunehmen, hindert der umstand, dass sie in zug um zug entsprechender, und zwar vielfach in die heldensage ubergetretener form indisch (Nahusha), griechisch (Apoll bei Admet), deutsch (Mitoðinn) und, in anderweitiger, aber ganz entsprechender verschiebung, phönizisch, also semitisch erhalten ist: ein gott oder halbgott muss wegen 
einer verschuldung (semitisch: periodisch in folge seines schicksals) verschwinden, darf aber nach seiner entsuhnung (semitisch: seiner zeit, nämlich im lenze) widerkehren. Verschuldung und suhne sind ubereinstimmend als motiv zugewachsen. Da man nun darauf aufmerksam geworden ist, dass in dem judischen glauben und cult altheidnische elemente mittberkommen sind, so scheint auch hier als eine königssage erzählt zu werden, was einst von einer gottheit berichtet wurde. Naturlich braucht diese keine judische, wol aber eine semitische gewesan zu sein. ${ }^{1}$ )

\section{Facit.}

Hiermit ist der in betracht kommende stoff, soweit er fruchtbar ist, erledigt, und das facit der untersuchung kann gezogen werden. Die hypothese des letzten paragraphen soll dabei ausser acht gelassen werden.

Wir haben herangezogen: 1. eine gruppe von deutschen und romanischen erzăhlungen, denen zu folge ein mann von rang eine wallfahrt in den orient, oder eine wallfahrt, oder einen zug gegen die heiden, oder endlich eine reise um oder bis an das ende der welt unternimmt, lange ausbleibt (in den meisten fällen uber eine verabredete zeit hinaus, die widerholt auf sieben jahre bemessen ist), im falle der weltreise a uf einer wusten insel scbeitert, von einem dămon oder engel oder heiligen erfährt, dass sein weib im begriff stehe eine neue ehe zu schliessen, durch die lufte zurtackgefuhrt just bei der hochzeit entstellt, meist bettelhaft, stets unkenntlich erscheint, sich (durch einen ring) zu erkennen gibt und in seine alten rechte eintritt. In einem auslăndischen gedicht (wol spielmannslied) scheint er schlechtweg marinaro, der seefahrer, geheissen $\mathrm{zu}$ haben. In einem mårchen vollbringt er die zeit in des teufels dienst. In einer sage ist er (der graf von Calw) nicht ther meer sondern in die berge gezogen, wo er beerden geweidet hat, zu denen or, nachdem er sein weib in der weise der schablone an der eingehung einer

1) Vielleicht klingt eine ähnliche erinnerung in der rabbinischen tradition nach, dass Elias dereinst widerkehren und den bösen Samuel töten werde (Eisenmenger II, 696. 851, vgl. Grimm, Mythol. 145). 
neuen ehe verhinderte, zurtickkehrt. Auch hier fehlt die entstellte kleidung nicht, steht aber am unrechten ort.

2. Ein held (Halfdan) hört in der ferne, dass seine (gegenwărtige oder nachmalige) braut im begriff steht eines anderen (in charakteristischen fallen eines riesen) weib zu werden, erscheint in niederer tracht (meist im momente der hochzeit) und erschlägt ibn. Die jungfrau heisst in charakteristischen fallen Gro oder Guritha, was wesensidentisch erscheint und eine beziehung zur chthonischen fruchtbarkeit offenbart. Die persönlichkeit des helden ist eine derartige, dass Thorsagen entweder an ihn angewachsen oder auf ihn thertragen erscheinen.

3. Thor, in niederer tracht aus dem osten kommend, findet bei seinem weib einen buhlen.

4. Thor, aus dem osten, dem winterland, mit winters ende zurlickkehrend (in der Haldantberlieferung bei Saxo in niederer, unkenntlich machender tracht) erschlägt einen riesen, der anspruch auf eine gōttliche, für die befruchtung der erde belangreiche jungfrau erhebt.

5. Ozinn, aus der ferne in niederer tracht im lenze zuruckkebrend, treibt einen nebenbuhler aus der herrschaft und von seinem weibe.

6. Baldur, von Höður vertrieben und seiner gattin beraubt, verjagt heimkehrend den usurpator und tritt in seine alten rechte.

7. Svipdagr kehrt im lenz aus der ferne in niedrer, unkenntlich machender tracht zu der seiner harrenden geliebten.

8. Der schwanenritter kommt aus fremdem land, von einem schwan gezogen, befreit eine jungfrau von ihren bedrängern und kehrt zuruck (vgl. die rlickkehr des grafen von Calw unter 1.).

9. Skeaf und Skyld erscheinen aus fernem land und entschwinden in dasselbe.

10. Njörðr weilt periodisch neun wintermonde bei Skadi in den bergen (vgl. den grafen von Calw) im winterland und drei sommermonde ther der erde.

11. 12. Ing zieht gen osten uber die flut. Tyr kehrt von langer wanderung heim in das winterland, in die berge ( $\mathrm{vgl}$. 
Njörr und den grafen von Calw). Vielleicht auch: während Tys abwesenheit ist die erde, seine gattin, umbuhlt.

13. Skeaf, Skyld, Vali erscheinen als kinder.

14. Skioldus erschlägt den Skatus im kampf um eine jungfrau.

Dazu an ausserdeatschen parallelen:

A. Indisch: wăhrend der abwesenheit des sommergottes herrscht ein dörrender dämon; jener kehrt zurttck und erschlägt ihn.

B. Griechisch: 1. Apoll kommt und scheidet, von schwanen gezogen, in sein heimatliches wunderland.

2. Apoll weidet in der ferne eine frist die stutenheerden des Admet.

3. Odysseus (urspringlich ein andersnamiger gott), aus der ferne, einem nebelland, nach langer abwesenheit (hieratisch sieben jahren) unkenntlich in bettlertracht heimkehrend, erlöst sein land und sein weib von vergewaltigern.

C. Semitisch: Adon (Adonis) weilt im winter fern (als mensch: in der unterwelt), im sommer bei Aphrodite, die von belang fur die (irdische) befruchtung erscheint.

Hierzu gesellen sich drei recensionen der Orendelsage: A. Die dånische: Horrendil erschlägt kōnig Koller (den kalten) im kampf um Gerutha (der name ist wesensidentisch mit Gro und Guritha), die er nachmals heiratet. B. Die norwegische: 1. Aurvandill kehrt aus dem riesenland, dem winterland jenseits der Elivagar, zu seiner harrenden gat tin Groa zurtuck. 2. Aurvandill wird von Thor auf dem rtcken in einem korb uber die Elivâgâr gêtragen. 3. Ein gestirn heisst Aurvandils zeb. C. Die deutsche: 1. Orendel scheitert auf einer orientfahrt, tut bei einem riesischen fischer Ise auf einer, seit menschengedenken unbetretenen insel knechtesdienst und kommt von da in schlechter tracht (einem grauen rock) zu einer frau Bride, erschlăgt einen (oder mebrere) gewalttătigen freier und besteigt, von allen, sobald er sich zu erkennen gibt, anerkannt, unbestritten als Bridens gemahl den thron des reiches. 2. Orendel findet, in pilgertracht heimkebrend, sein weib Bride in den hănden eines gewalttătigen freiers und erschlägt diesen. 3. Orendel, der knechtesdienste bei Ise getan hat, ist, von ihm 
entlassen, verpflichtet zu ihm zurlickzukehren. 4. Eine vorstellung, nach welcher Ise graue rosse mit seiner ruderstange jagt.

Alle diese sagen sind heimkehrsagen. Thor, Oðinn, Tyr, Baldr, Njörorr, Ing, Svipdagr, Skeaf, Skiöld, der schwanenritter, alles götter athmosphärischer, die fruchtbarkeit fördernder vorgänge, kehren heim: Thor, Oðinn, Ing aus dem osten; Tyr, Njöror, Svipdagr aus dem winterland, dem riesenland, das als im osten gelegen aufgefasst wurde; Skeaf, Skyld und der schwanenritter aus einem ungenannten land. Thor, Oðinn, Svipdagr erscheinen in niederer, entstellter gestalt. Njörðr wird von keinem weibe im götterland erwartet; Svipdagr kehrt heim zu einer sehnend oder in schlummer harrenden geliebten; Oðinn, Baldr ('T'yr?) finden bei ihrer gemahlin einen buhlenden gewalthaber, der vor ihnen entweicht. Thor findet bei seinem weibe (wie es scheint, der erde) oder einer anderen, fur die chthonische fruchtbarkeit belangreichen gōttin einen buhlerischen riesen (wol als gewalthaber), den er erschlägt. Der schwanenritter befreit eine bedrängte jungfrau, sein nachmaliges weib, indem er den bedränger erschlägt. Die einschlägigen sagen von Ing, Tyr, Skeaf, Skyld (Skiöld) sind unvollständig tiberliefert. Doch erscheinen Skeaf und Skyld, ähnlich Vali, als kinder, und Skiöld erschlägt in einer fassung im kampf um eine geliebte den Skadi. Endlich ist bei Tyr, Njöro, Skeaf, Skyld und dem schwanenritter die (periodische) rluckkehr in das winter- oder wunderland bezeugt, bei Thor so gut wie bezeugt, und ist bei Svipdag nur von der ankunft aus, bei Ing und Tyr nur von der rluckkunft in das winterland die rede.

Aus dieser zusammenfassung der gōttersage und ihrer vergleichung mit den ausserdeutschen parallelen ist zu schliessen: 1. Es gab einen indogermanischen jahreszeitenmythus, dem zu folge eine gottheit im winter fern weilte, mit dem sommer zuruckkehrte. Diesen mythus ist die ruckkehr zu einer gattin nicht unbedingt wesenseigen (vgl. Njöro, Hyperboreermythus, Dioskuren). 2. Der mythus hat unter umständen die gestalt angenommen, dass der zuruckkehrende gott von einer gattin oder braut erharrt wurde (vgl. Svipdag, Svendal). 3. Diese mythengestaltung präzisierte sich weiter dahin, dass die gattin 
oder braut ron einem, das reich inne habenden gewalthaber buhlerisch bedrängt wurde, oder aber, dass der rtlckkehrende gott eine, von einer derartigen persönlichkeit bedrängte jungfrau befreite. Der bedränger entwich (Mitoð̌inn) oder wurde getötet. 4. Das weibliche wesen stellt sich nur in einem ${ }^{1}$ ) fall mit bestimmtheit als die erde dar; Aphrodite, die vanin Freya, Thruðr sind nur als athmosphärische spenderinnen von irdischer und anderer fruchtbarkeit zu erweisen, Frigg durch den volksglauben in ahnlicher richtung zu belegen. 5. Der bedrănger ist in den controlierbaren făllen (Ullr, Hözr, Skadi, die riesen) ein winterlicher dămon. 6. In allen deutschen göttersagen ist nur von einem nebenbuhler oder vergewaltiger die rede. 7. In deutschen wie griechischen und semitischen sagen wurde das kommen und scheiden des sommergottes periodisch aufgefasst, und erklărt: bei Thor durch widerholte abenteuerzttge gegen die winterdåmonen, bei Njörð durch vermăhlung mit einer, im winterland wohnenden göttin, bei Tyr, Skeaf, Skyld und dem schwanenritter wie bei Apoll als die heimkehr in ein heimatland. In den anderen fallen ist die motivierung verwischt. 8. Ueber das land selbst scheint nirgends volle klarheit oder tubereinstimmung geherrscht zu haben; man wusste nur, dass der sommer entschwand, aber nicht, wohin er entschwand. Die Inder liessen, wio es scheint, den feuergott in die sphăre seines ursprungs, das wasser, zurtickkehren. Die Griechen malten sich ein wunderland oder auch ein fernes nebelland aus oder liessen, scheint es, den gott in die unterwelt hinabsteigen. Die Deutschen stellten sich im eisigen norden oder osten ein winterland vor, von wo der gott erschien, und in das êr kéhrên musste. 9. Aus diesem letzten grund erscheint der deutsche gott bei seiner rtuckkehr in ubler tracht. Die natur ist im winter bettelarm; greis, entstellt; die naive gedankenassociation betrachtete den jahreszeitengott den winter uber in gleicher gestalt. Eine derartige anschaung ist fur den Marsglauben und in weiterem umfange ther deutsches und slawisches gebiet von Usener ${ }^{2}$ ) und Mannhardt ${ }^{3}$ ) dargetan

1) Wenn man von 'Tyr absieht.

2) Rheinisches museum XXX, $182 \mathrm{ff}$.

3) In den Korndämonen und beiden bänden der Wald-feldkulte an verschiedenen stellen. 
Indem aber beide solch eine anschaungsweise unabhăngig von den vorbesprochnen mythenreihen nachgewiesen baben, ergibt sich die berechtigung anzunehmen, dass die auffassung des jahreszeitengottes im winter als eines bettelhaften, entstellten greises ${ }^{1}$ ) ursprunglich absolut nichts zu tun hatte mit dem mythus von dem zurlickkehrenden gott, und dass somit auch hier wider disparate, den verschiedensten erfahrungen entsprungene anschaungen aneinander gewachsen sind.

Wenn somit für Orendel bezeugt wird, dass er in unscheinbarem grauem rock unkenntlich zurtickkehrte, so lăsst diese sagengestaltung fur Oervandil und Horvendil, von denen solches nicht bezeugt ist, keine schlusse zu. Wenn Groa als die frau des Oervandil bezeugt wird, so folgt darans nicht, dass die nachricht Saxos von der vermăhlung des Horvendil mit Gerutha nach dem sieg ther Koller eine verschiebung sei ${ }^{2}$ ), whrde auch nicht daraus folgen, dass frau Bride die gemahlin des Orendel gewesen sei, wenn sich nicht 1. in der katastrophe vor den toren von Jerusalem Orendel selbst als den einbeimischen kōnig zu erkennen gäbe und anerkannt wtirde, und 2. die accessorische fortsetzung der legendenfassung augenscheinlich ein unabhangiges gedicht auf die rlickkehr Orendels zu seiner gattin gekannt und benutzt hătte. Wenn endlich Horrendil mit Koller und Orendel mit dem vergewaltiger oder umwerber seines weibes zu ksmpfen hat, so folgt daraus nicht, dass auch Oervandill bei Groa einen nebenbuhler gefunden hătte; im gegenteil wird eine derartige folgerung durch die therkommene norwegische fassung auf das bundigste widerlegt.

1) Vielleicht heranzuziehen ist Saxo 248: Orins erscheinen hispido amicalo, worn sich manches andere zu stellen scheint: vgl. Grimm, Mythol. 121, III, 56. Vgl. anch Preller I, 107: argivisch ein kahlkopfiger Zeus.

2) Nicht allein sichert das analogon des kampfes des Skioldus wider Skatus die berechtigung der dänischen wendung: auch in der gesamten Halfdangruppe und in den meisten Thorsagen ist die rede von einer vereitelten hochzeit, nicht dem buhlen um ein vermähltes weib. Die stellung des weiblichen wesens $2 \mathrm{a}$ dem befreier ist zudem in der Thorsage eine derartig wechselnde, dass eine abweichende tiberlieferung innerhalb des nämlichen sagenkreises gar nicht auffallen kann. 
Demselben princip entsprechend, darf keine willkur die tatsache aus der welt schaffen, dass der norwegischen Groa, deren chthonische natur etymologische wahrscheinlichkeit bat, in der deutsoben uberlieferung eine Bride gegentubersteht, welche eine derartige ausdentung nicht zulässt. Nachdem die erörterung der Halfdansage ergeben hat, dass analoge erzählungen von der befreiung einer Gro (oder gleichbedeutenden Guritha) an einen anderweitigen helden geknthpt worden sind, ist umgekehrt unerlaubt von vorn herein $z u$ urteilen, dass der name Bride lediglich durch verdrängung einer, deutsch zudem wol kaum erweislichen Gro in die deutsche Orendelasage eingang gefunden habe. Der name Bride, das ist die glänzende, ist ein durchaus fur die gattin des glanzwandlers geeigneter; zudem haben sich fast sămtliche jungfrauen der göttersage nicht als chthonische sondern als athmosphårische wesen, wenn auch von sommerlicher bedentung, erwiesen; so dass kein grund vorhanden ist, dem Oervandil ein fur alle mal und fur alle versionen eine chthonische gemahlin aufzubtirden. Endlich aber hat sich ergeben, dass der name der gattin in dem heim. kehrmythus durchaus in zweiter linie steht.

Dass die beispiele der Halfdangruppe und 1 ) der MullerUhlandschen sammlungen eine teils spielmannische teils traditionelle fortentwickelung des alten gōttermythus zur heldensage und abenteuererzăhlung bieten, wird niemand verkennen. Der absohied des belden in der Halfdansage wird deren charakter gemåss mit einem kriegszug motiviert; weit eigentumlicher ist die begrundung der sammlungen. Der held ist entweder in den orient gezogen, das ist: er hat eine wallfahrt in das heidenland gemacht; oder er ist auf einer wallfahrt oder gegen die heiden aus; oder endlich er ist einfach uber meer gezogen, ein marinaro, ein landfahrer. Die letztere begrthdung ist eine abgeblasste allgemeinheit, die zweite und dritte differenzierungen der ersten. Ist aber eine orient fahrt das charakteristische motiv der helden und könige, das sie so lange fern hält und erst in entstellter tracht, man weiss nicht wie; just zur hochzeit ihrer gattin mit einem nebenbuhler heimkehren lässt, so stellt sich diese motivierung zu uberraschend mit der

1) Weniggtens teilweise. 
ostfahrt der deutschen götter in das winterland, besonders Oðins orientfahrt, und ihrer heimkehr in entstellter tracht zusammen, um eine combinierung beider momente allzukthn erscheinen zu lassen. Ist aber eine derartige combination gestattet, so ist es auch die annahme, dass Orendel tatsåchlich von einer ostfahrt zu seinem weibe entstellt zurtuckkehrt, ăhnlich dem Oervandil der norwegischen tuberlieferung, und dass sich so die zur brautfahrt gestempelte orientfahrt des helden erklärt; so dass an die ostfahrt Orendels die orientfahrt, an die widerkehr nach langer abwesenheit und den kampf mit dem nebenbuhler die brautfahrt und an die schlechte tracht des widerkehrenden der graue rock sich anschloss.

Wenn diese auffassung richtig ist, so ist Orendel ursprtinglich gegen osten in das eisland gezogen, was mit der norwegischen tberlieferung ubereinstimmen wurde. Aus dieser mythischen entwickelungsphase stammt der name İe; schwerlich aber seine eigenschaft als fischer. Nur in der Hymirsage ist ein des fischens gewohnter riese uberliefert, und zwar, auf dass sein fischfang die situation fur Thors kampf mit der Mitgardschlange abgåbe. Desgleichen bedarf der legendenschreiber eines fischers um, jedenfalls in nachahmung beliebter muster, die aufindung von Christi rook in einem fischbauche zu ermōglichen. Die ursprtungliche natur Ises, der als eisriese für einen fischer so ungeeignet wie möglich erscheint, ist in jener von Mullenhoffs scharfsinn entdeckten episode des spielmannsgedichtes enthalten, in welcher Ise graue rosse jagend dargestellt wird. Mullenhoff hat seiner schiffersage zu liebe die rosse als meereswogen aufgefasst. In dieser bedeutung sind sie deutsch nicht zu belegen; selbst die albstiere, von Grimm und anderen als wasserwesen gefasst, lassen sich, im zusammenhang mit der gesamten deutschen volksanschauung von gespenstischen rossen und rindern, durchweg als nebel- oder wolkenerscheinungen ${ }^{1}$ ) dartuen. Man darf eine volksanschauung nie vereinzeln; die geheimnisse der volkskunde sind nur durch sammlung aller erreichbaren analogien zu lösen. In der ge-

1) Nebel und wolke sind für die volksphantasie nichts verschiedenartiges. 
stalt der vom winde gejagten wolke erscheinen die rosse der wilden .jagd, erscheinen sie eddisch als die rosse des Thrym; die eddisch mehrfach belegten rinderheerden der riesen sind regelmässig als wolken, und besonders sturmwolken, aufzuweisen, und der riese als viehhirt ist eine eddisch mehrfach auftretende mythengestalt.

Aus diesen grunden folgere ich, dass der graugewandige Ise graue rosse jagend eine wolkenvorstellung ist; und wenn er sie mit der ruderstange jagt, so ist nicht allein der fährmann, der ein viehhirt ist, im Harbaroslied belegt und der riesische fäbrmann in der Edda häufig $\mathrm{zu}$ finden, sondern auch der fährmannglauben mit um so mehr recht auf eine wolkenvorstellung ausgedeutet worden, als fur den vanenglauben die wolke als fahrzeug durch Alvismal str. 19 direct belegt ist. An den fährmann Ise mag sich dann der fischer leicht angeschlossen haben.

Ist es solcher gestalt wahrscheinlich, dass die grauen rosse dem graugewandigen riesen als wolkenheerde zugestanden haben, so wird, wenn Orendel in der tat von uranfang als dem Ise dienstbar gegolten haben sollte, seine dienstbarkeit die eines hirten gewesen sein; ähnlich wio in dem schlagendsten analogon zu der deutschen Orendeluberlieferung der sogenannte graf von Calw in die berge (das ist das winterland: zu vergleichen Njöror und Tyr) zieht um hirtendienste zu ubernehmen; wozu der hirtendienst des Apoll eine eigentlumliche parallele bilden würde. Dass Ises graurosse die wogen bedeutet hătten, ist schon deshalb sehr unwahrscheinlich, weil in diesem falle Ise nicht der riese der winterregion gewesen wäre, bei dem Orendel zu weilen hatte, sondern der winterliche beherrscher des meeres und der welt uberhaupt: folglich nach analogie der gesamten göttergruppe der nebenbuhler, nicht der brodherr des Orendel.

Denn in der gesamten heimkehrgruppe durch alle göttlichen und menschlichen gestaltungen hindurch ist nur von e in em nebenbuhler die rede.1) Der parallelismus der Odyssee

1) Wenn Berger, wie er mir sagt, an allen drei riesenkämpfen der Orendelibberlieferung festhält und für sie ursprüngliche zïge beizubringen weiss, so gesteht er mir doch zu, dass sie augenscheinlich die dich-

Beiträge zur geschichte der deutschen oprache. XIII. 
hat Mullenhoff bewogen, seiner kritik von Orendels rückkehr die turniersituation zu grunde zu legen, die sich als eine durchaus spielmännisch schablonenhafte offenbarte, und eine andere, in drei fassungen aneinander gereihte situation von Orendels kampf mit dem riesischen freier seines weibes für unursprünglich zu erklären, die in ihrer dritten fassung nicht allein als charakteristisch und original, sondern auch als ein schlagender beweis fur Mullenhoffs hypothese dargetan wurde, dass Orendel als der rechtmăssige herrscher und gatte Bridens unerkannt heimgekehrt ist und sich nur zu nennen braucht, um unbestritten in seine rechte einzutreten. Eine situation, die um so gewisser echt ist, als sie mit dem, von dem weiterdichter der legende zweifelsohne benutzten, schönen spielmannslied zwei wesentliche zuge gemein hat: einmal den zug, dass Orendel seinen mächtigen feind mit Bridens bulfe überwältigt, sodann aber gerade, dass dieser feind als alleiniger nebenbuhler, wenn auch mit heeresmacht, dem beimkehrenden könig gegenubersteht. So darf mit bestimmtheit gesagt werden, dass auch fur die Orendeluberlieferung von einer mehrheit von freiern keine rede ist; und es muss sehr dahingestellt bleiben, ob die mehrheit der freier der Odyssee ein mythisch wesentlicher zug, nicht eine ausgeburt sagengeschichtlicher, bezuglich dichterischer entwickelung ist.

Die hiermit gewonnene auffassung, dass der held der deutschen Orendelsage einerseits aus dem winterland heimkehre, andrerseits einen winterlichen nebenbuhler bei seinem weibe finde, scheint auf zwei schwierigkeiten zu stossen. Die erste ist, dass der winterdămon gleichsam eine doppelrolle zu spielen scheint: hier als beherrscher des winterlandes und verknechter Orendels, dort als vergewaltiger seines reiches und nebenbubler bei seiner gattin. Aber wenn es nicht gestattet ist, aus der einen uberlieferung zthe in die andere bintiberzunehmen, welche in dieser nicht zu verspuren sind: so ist es umgekehrt methodisch zulässig, einen zwei uberlieferungen gemeinsamen zug nach der charakteristischeren version zu be-

terisclie verdreifachung des ursprïnglich einmaligen ksmpfes aus grïnden künstlerischer steigerung darstellen. Die turniersituation hält auch er flir einem vorbild nachgebildet, wenn auch bereits der vorlage angehürig. 
urteilen; wenn es sich also als wahrscheinlich ergab, dass auch dem deutschen Orendel ein einziger nebenbuhler entgegentrat, so ist es um so berechtigter den dänischen namen dieses nebenbuhlers Koller, den kalten, fur die deutsche uberlieferung fruchtbar zu machen, als die gesamte göttergruppe den winterlichen charakter des unliebsamen bewerbers unverkennbar zu tage treten liess. Und ferner ergibt eine kritik der nordischen versionen den bemerkenswerten umstand, dass die norwegische uberlieferung uberhaupt nur von dem winterland weiss und die dänische widerum nur den nebenbuhler erwähnt: das bedeutet: nur in der deutschen uberlieferung beide ztige vereinigt erscheinen. ${ }^{1}$ )

Die zweite schwierigkeit, Ises land als eine eisregion und den helden der sage als einen sommerlichen glanzwandler aufzufassen, besteht in der ausdrlicklichen tberlieferung des deutschen liedes, dass Orendel durch einen schiffbruch in Ises knechtschaft geraten sei. Auch dieser einwurf ist durch frubere erörterungen ${ }^{2}$ ) vorweggenommen worden: der name des glanzwandlers musste sich in folge des aussterbens einer deutschen wurzel aur $=$ glänzen mit einer gewissen notwendigkeit in den flutenwandler verschieben; und diesen lange in der ferne festgehaltenen und in bettelhaftem aufzug widerkehrenden flutenwandler in einen schiffbruchig verschlagenen seehelden sich wandeln zu sehn, kann in jenen zeiten nicht verwundern, welche, dem abenteuer zugeneigt, den orient bereits lebhaft im auge hatten, als er noch nicht das heilige grab bedeutete, sondern das byzantinische reich. Aus letzterem umstand erklärt sich wol, dass die Orendelsage, abweichend von anderen deutschen tuberlieferungen analogen inhalts, ihren belden nicht

1) Diese beobachtung erhält willkommene bestätigung durch den volksglauben. Die forschungen Grimms (M) und Mannhardts (Bk) haben klar gelegt, dass der volksbrauch des sommer-winterkampfes und der des sommereinznges (letzterer bemerkenswerter weise gern verknüpft mit dem winteraustragen) im wesentlichen geschieden auf verschiedenen gebieten auftreten. - $\mathrm{Zu}$ der jahreszeitlichen auffassung des aus- und einzuges vgl. das dichterwort der carm. bur.: redit ab exilio ver coma rutilante, und: aestas in exilium iam peregrinatur; zu der jabreszeitlichen kampfauffassung die nordischen opfer til sigrs (Grimm, Myth. 35 , III, 75).

2) S. 23 . 
durch eine wallfahrt in das beilige land seinem weibe entfuhrte: so nämlich, dass die spielleute der kreuzzugsepoche bereits den im osten gescheiterten helden vorfanden und, ob sie schon den osten in das beilige land verschoben, des schiffbruchs furder nicht zu entraten wagten.

Hiermit ist die kritik der deutschen uberlieferung geschlossen. Sie liess einen schicksalsvollen lebenslauf erkennen: der mythus von dem im winterlichen osten weilenden lichtgott und seiner bettelhaften rlickkehr im fruhling zu seinem, von einem winterlichen dämon umbuhlten weibe gestaltete sich im munde abenteuerlustiger sänger $\mathrm{zu}$ dem roman eines im fernen osten schiffbruchigen, nach langer knechtschaft in armseligstem zustand widerkehrenden seehelden; spielleute der kreuzzugsepoche stempelten das scheitern im osten, das auch für fruhere zeiten einen geographischen inhalt hatte, zu einem scheitern auf der fahrt in das gelobte land, und ein kecker reimschmied stellte die uberlieferung auf den kopf und machte aus der ruckkehr von der orientfahrt die typische brautfahrt in den orient und aus den kämpfen des heimkehrenden königs mit dem bublerischen usurpator seines thrones und weibes die bei seinen hörern beliebte abenteuerreise eines heiratslustigen fürstensobnes.

Die norwegische und die dänische uberlieferung der Orendelsage haben miteinander äusserlich nichts gemeinsam als den namen des belden und einen wenigstens ubereinstimmenden namen seiner geliebten; so dass erst durch das mittelglied des deutschen gedichtes ihre innere zusammengehörigkeit klar gelegt wird. Die dänische uberlieferung enthält nur den kampf mit dem nebenbuhler, die norwegische nur die ríckkehr aus dem winterland; jene hat sich in einen holmgang aus eifersucht verwandelt, diese trägt ein durchaus mythisches gewand. Um den zusammenhang noch mehr zu verdunkeln, hat sich in die norwegische uberlieferung eine andere Aurvandilsage eingeschlichen, die mit der typischen heimkehrsage der nordischen mythik nichts gemein hat als die anschauung, dass der jahreszeitengott im lenze seinen einzug in die welt hält.

Man betrachte die uberlieferung: Thor hat soeben im osten, im riesenland, einen grossen holmgang mit Hrungnir bestanden. Heimgekehrt berichtet er der Groa, dass er ibren 
gatten Oervandil aus dem riesenland uber die Elivagar getragen habe, und dass derselbe demnächst zuruckkehren werde. Man fragt sich: wann hat Thor den Oervandil uber die Elivagar getragen? nach dem kampfe mit Hrungnir? aber warum ist dann Oervandill noch nicht erschienen? oder vor dem kampfe? aber dann fragt man mit um so mehr recht, wie es kommt, dass Thor seine ruckkehr zu dem götterheim vollzogen hat und Oervandill, der sich doch schon diesseits des trennenden stroms befinden soll, noch nicht zu seiner gattin heimgelangt ist? Schon dieser innere widerspruch beleuchtet die unzuverlässigkeit der mitteilung. Thor hat Oervandil uber die Elivagar getragen; das ist durch sie bezeugt; Oervandill kehrt heim als der gatte der Groa; daran ist nicht mehr zu zweifeln. Aber dass diese tatsachen einander unentbehrlich seien oder uberhaupt nur zusammengehörten - das ist keineswegs bewiesen.

Und nun betrachte man die art, wie Thor den Oervandil uber die Elivagar trägt. In einem korb (mais), der unabhängig von unserer sage im Harbaroslied als requisit Thois erscheint, soll Oervandill so gelegen haben, dass der taschenmesserartig zusammengeklappte körper ganz in ihm verschwand; nur den fuss schiebt er einmal eine zehe breit heraus: und sofort erfriert die zehe. Diese vorstellung ist ist fur den Oervandil als den aus dem winterland zurlickkehrenden gatten der Groa durchaus ungeheuerlich: 1 . weil es in der gesamten mythik wol aller völker ein unicum wăre, dass ein in mannesgestalt gedachter gott eines anderen bedurfte um aus dem dămonengebiet in das götterreich zu gelangen; 2. weil in sămtlichen, deutschen wie ausserdeutschen, parallelen göttersagen der jahreszeitengott die wanderung in und aus dem winterland ohne fremde hulfe bewerkstelligt; 3 . weil man sich unwillkurlich fragt, wie wol der gott in das riesenland hinubergelangt sei, da er, um wider heriber zu kommen, der schultern Thors bedurfte; 4 . weil sich die ganze anschauung dieser schnürbundel-beförderung nur mit einer gewaltanstrengung in die auffassung einränken lässt, dass der vollausgestaltete, an körpergrösse Thor ebenbutrtige gott auf dem rucken des donnerers in einem korb zusammengekauert den weg liber die Elivagar gemacht bätte. Aus allen diesen erwägungen schliesse 
ich, dass mit der anschauung von Oervandils, des gatten der Groa, rtuckkehr aus dem riesenlande zu seinem harrenden weib, der grünenden erde, eine weitere anschauung verwachsen ist, der zu folge der im winterlande geborene frubling in der befruchtenden gewitterwolke auf den schultern des Thor seine einkehr in die welt hält, und berufe mich darauf, dass diese anschauung des im lenze neugeborenen jahreszeitengottes nicht allein deutsch zu belegen ist, sondern in der griechischen Apollonsage gleichfalls sich neben dem heimkehrmythus unabhängig entwickelt hat. Die episode von dem erfrorenen zeh bin ich dann geneigt fur eine hubsche erfindung zu halten, um eine dritte anschauung: die benennung eines, vielleicht im lenze erscheinenden sternes mit Oervandils namen, zu der anderweitigen liberlieferung in beziehung zu setzen; aus einer derartigen, anklang findenden episode wturde sich dann leicht die wunderliche, als ursprtinglich kaum denkbare benennung eines sternes nach der zehe eines gottes erklăren.

Es ist noch eine andere lösung möglich. Oervandill trägt in seinem namen eine beziehung $\mathrm{zu}$ dem himmlischen feuer. Nun lehrt eine eingehende untersuchung der deutschen wie, es scheint, der vedischen und, vielleicht, auch der griechischen mythik, dass in der volksanschauung sonnenfeuer und blitzfeuer unzertrennlich sind, fortwährend vermischt, nahezu als das nämliche betrachtet werden. Es ist dies ja im grunde gar nicht anders zu erwarten, da die naive naturanschaung die stets verketteten und auseinander scheinbar entspringenden wechsel von wetternacht und sonnengefunkel als eine einheit, als das wirken der nămlichen gottheit empfinden musste. Da es sich nun nachweisen lässt, dass Loki und Thor in ihrer festgeprägten zweieinigkeit die einheit von donner und blitz bedeuten ${ }^{1}$ ), so ist die möglichkeit vorhanden, dass eine ăhnliche

1) Genau wie Thor und Thialfi ebenso ist die blutsfreundschaft von Oðin und Loki zu erklären: die verknlupfung von sturm- und gewittererscheinungen; ebenso auch die vielbesprochenen eddischen dreieinigkeiten, welche man ganz richtig auf wasser, luft und feuer ausdeutete, aber abstract naturphilosophisch als verkörperung der drei elemente anffasste, statt concret als die schöpferische dreiheit von blitz, sturm und regen in der befruchtenden gewitterwolke. 
vorstellung den Thor in seinem wolkenkorb die himmelsfeuergottheit, in der wolke den blitz tragen liess. ${ }^{1}$ )

Mit dieser controverse ist die sagengeschichtliche kritik sämtlicher uberlieferungen und im wesentlichen unsere untersuchung beendet. Der verlauf derselben war, dass in dem ersten paragraphen die charakteristik der uberlieferungen erfolgte, in dem zweiten die widergabe und controlierung der Mullenhoffschen kritik, in dem dritten bis funften die anbahnung einer selbständigen sagengeschichtlichen erörterung vermittelst der sammlung, anordnung und vergleichnng eines reichhaltigen deutschen und ausserdeutschen analogienmaterials, auf dessen grundlage in dem letzten paragraphen die endgultige kritik der Orendelsage und ihrer verschiedenen versionen vorgenommen werden durfte. Indem wir das ergebnis unserer untersuchung zusammenfassen, beantworten wir zugleich die vier vorfragen der einleitung, wenn auch in umgekehrter reihenfolge:

Dem indogermanischen urvolke war gleich semitischen stämmen eine naturanschauung eigentumlich, der zu folge der sommergott im winter als abwesend und im frubling als zuruckkehrend gedacht wurde. Dieser primitive mythus hat griechisch eine mehrfache, deutsch eine vielfache ausprägung erhalten und ist in beiden völkern als eine heimkehrsage in die heldensage, deutsch auch in das märchen ubergetreten. Eine sondergestaltung hat der deutsche mythus in der sage von Aurvandil, das ist: dem glanzwandler, erfahren. Dieselbe

1) Zu der ganzen vorstellang des 'Thor, der den Oervandil auf den schultern über die Elivagar trägt, kann ich mich nicht enthalten zwei unaufgeklärte paralleliuberlieferungen wenigstens anzuführen: die deutsche der Wielandsage, derzufolge Wate seinen sohn Wieland anf den schultern durch den sund trägt (merkwürdig besonders durch die, wie es scheint, sturmriesenartige natur des vaters und die alfenhafte schmiedefertigkeit des sohnes); und die griechische der Orionsage, welche man allzuschnell mit der ausdeutung auf vorgänge des sternenhimmels abzutun gedachte: Orion, riesisch vorgestellt, ein ungestüm stlirmender jäger, wolken und wogen türmend und wirbelnd, wird auch vorgestellt den schmiedegenossen des Hephäst Kedalion (das ist feuerbrand) auf den schultern (gen sonnenaufgang) tragend. Der vollständigkeit halber sei auch die Christophoroslegende erwähnt, obwol aus ihr für unseren fall nichts zu lernen ist. 
ist in drei, getrennt und unabhăngig von einander entstandenen und entwickelten fassungen tberliefert. Die norwegische fassung gibt dem mythus von dem heimkehrenden lenzesgott die wendung, dass er aus dem winterland zu der ergrthenden erde als seiner gattin kommt (was in der tberlieferung nit einer disparaten anderweitigen naturanschauung zusammengeriet); die dånische fassung gibt dem mythus die wendung, dass der heimkehrende lenzesgott den winterdämon erschlägt und die von ihm umbuhlte jungfrau (ein chthonisches wesen) sich vermählt; die deutsche fassung vereinigt beide, im grunde unvereinbaren wendungen, indem sie den lenzesgott aus der gefangenschaft des winterdămons zurttckkehrend den seine gattin (kein chthonisches wesen) umbuhlenden winterdämon erschlagen lăsst, und fugt noch zwei weitere anschauungen hinzu: 1. dass der lenzesgott verhaftet ist, sich dereinst widerum in die gefangenschaft des winters zu begeben; 2. dass der jahreszeitengott im winter ein bettelhaftes gewand genommen hat, so dass der heimkehrende lenzesgott seinem weibe unkenntlich vor die augen tritt. Das verhältnis der drei uberlieferungen ist mithin dahin zu bestimmen, dass alle drei, auf liedern beruhend, den nämlichen mythus in auseinandergehenden entwickelungen darstellen, das ist: drei selbständige abartungen des nämlichen mythus bieten, die dånische und die norwegische abartung sich am weitesten von einander entfernen, die deutsche zwischen beiden in der mitte steht, die dånische verhältnismässig einfach uberliefert, die norwegische mit anderweitigen uberlieferungen versetzt ist, die deutsche eine reibe von entwickelungen bis zur spielmånnischen brautfahrts-, kreuzzugs- und reliquienlegende durchlaufen hat; mit einem worte: dass die drei uberlieferungen drei abarten des nämlichen mythus auf verschiedenen entwickelungsstufen und mehr oder minder in verquickung mit fremden elementen darstellen.

LEIPZIG.

L. BEER. 